Southern Methodist University

SMU Scholar

Spring 5-20-2017

\title{
Supplementing Maize Agriculture in Basketmaker II Subsistence: Dietary Analysis of Human Paleofeces from Turkey Pen Ruin (42SA3714)
}

Jenna M. Battillo

Southern Methodist University, jmarie.battillo@gmail.com

Follow this and additional works at: https://scholar.smu.edu/hum_sci_anthropology_etds

Part of the Archaeological Anthropology Commons

\section{Recommended Citation}

Battillo, Jenna M., "Supplementing Maize Agriculture in Basketmaker II Subsistence: Dietary Analysis of Human Paleofeces from Turkey Pen Ruin (42SA3714)" (2017). Anthropology Theses and Dissertations. DOI: https://doi.org/10.25172/td/10164149

https://scholar.smu.edu/hum_sci_anthropology_etds/1 
SUPPLEMENTING MAIZE AGRICULTURE IN BASKETMAKER II SUBSISTENCE:

DIETARY ANALYSIS OF HUMAN PALEOFECES FROM TURKEY PEN RUIN

(42SA3714)

Approved by:

Prof. Karen Lupo

Professor of Anthropology

Prof. Sunday Eiselt

Associate Professor of Anthropology

Prof. Bonnie Jacobs

Professor of Earth Sciences

Prof. William D. Lipe

Professor Emeritus of Anthropology

Washington State University 
SUPPLEMENTING MAIZE AGRICULTURE IN BASKETMAKER II SUBSISTENCE:

DIETARY ANALYSIS OF HUMAN PALEOFECES FROM TURKEY PEN RUIN

(42SA3714)

A Dissertation Presented to the Graduate Faculty of

Dedman College

Southern Methodist University

in

Partial Fulfillment of the Requirements

for the degree of

Doctor of Philosophy

with a

Major in Anthropology

by

Jenna Battillo

B.A., Anthropology and Classical Studies, University of Florida

M.A., Human Skeletal Biology, New York University

May 20, 2017 
Copyright (2017)

Jenna Battillo

All Rights Reserved 


\section{ACKNOWLEDGEMENTS}

This work is the culmination of years of research, laboratory work, self-doubt, and writing. Throughout the highs and lows of writing this dissertation I have had much help along the way. These acknowledgements are not only for my committee who helped me to piece together this research into a coherent narrative, but for everyone who ever listened to me whine, poured me a cup of coffee (or something a little stronger), and helped me get through the enormity of this process. First and foremost I must thank Dr. Karen Lupo, who never seemed to lose faith in me, and who patiently waded through the disorganized stream-of-thought I presented to her as chapters. I must also thank Dr. Bonnie Jacobs, who has been a friend as much as an adviser and helped keep me sane during hours of lab work and microscopy. I could not have identified all of those pesky grains without you, Bonnie. Dr. Sunday Eiselt taught me a new way to look at the history of anthropology in the Southwest during an independent study that ultimately resulted in an appendix to this dissertation. Her thoughts on niche construction helped me to tell a more interesting story and approach this research with greater curiosity and insight. Finally, Dr. Bill Lipe has been an inspiration and fount of knowledge regarding Cedar Mesa and Basketmaker archaeology, and always a pleasure to talk with.

I would also like to thank Dr. Deborah Bolnick and her graduate students Jaime MataMiguez and Rick W.A. Smith who conducted the targeted PCR analysis for this project. Their contributions made this a more interesting and complete investigation into ancient diet. For 
funding the DNA analysis and other aspects of this project I owe the Institute for the Study of Earth and Man (ISEM) and the SMU Office of Research and Graduate Studies a debt of gratitude, as well.

To my friends and fellow graduate students who commiserated and shared drinks with me, you cannot know how important you all have been, but I must especially thank Abby Fisher, Ashvina Patel, Michael Aiuvalasit, Sarah DuBois, Maia Clay, Stephanie Schwob, Pamela Hogan, and Amber Parrish all of whom have been vital sources of encouragement, inspiration, and relief in ways big and small. Lastly, I must thank my parents, for years of encouragement, unwavering support, and kindly putting up with me moving all over the country. You have been my anchors and the only constants during my tenure as a graduate student. There are many more names that belong on this list, but I had to start and end somewhere. To everyone who helped me to get here, thank you. 
Battillo, Jenna $\quad$ B.A., Anthropology and Classical Studies, University of Florida, 2007

M.A., Human Skeletal Biology, New York University, 2009

Supplementing Maize Agriculture in Basketmaker II Subsistence:

Dietary Analysis of Human Paleofeces from Turkey Pen Ruin

$\underline{(42 S A 3714)}$

Adviser: Professor Karen Lupo

Doctor of Philosophy conferred May 20, 2017

Dissertation completed May 15, 2017

This research explores the factors that motivated increasing reliance on maize during the Basketmaker II period in the North American Southwest. Through the analysis of 44 human paleofeces from Turkey Pen Ruin, Utah, I investigate resource choice and nutritional supplementation of maize before the advent of bean horticulture. In order to discern what resources provided caloric and nutritional supplementation to maize, all paleofecal specimens were analyzed for pollen and macrofossil content, and 20 were further sampled for PCR analysis targeted at several select animal and plant species. Eight paleofecal specimens from various stratigraphic layers were directly AMS dated in order to better assess the chronology of the midden from which they were excavated, and to determine their cultural phase association. The resulting data allowed for the testing of three hypotheses based in human behavioral ecology, specifically applying diet-breadth and patch-choice models.

The results of this project demonstrate that the diet of these early maize farmers was relatively broad, and included a high proportion of resources with lower caloric returns than maize. Furthermore, plants associated with field and disturbance settings, such as goosefoot (Chenopodium spp.) and purslane (Portulaca spp.), which provide excellent nutritional complements to maize, made large contributions to the diet. Overall, these findings indicate that 
people were pushed to increase their reliance on farming due to resource depression, and that the anthropogenic niche created by farming activities encouraged greater focus on the field as a patch of multiple types of resources, and not only as a location for growing maize. The discovery of corn smut (Ustilago maydis) spores in all but one of the specimens studied suggest that this parasitic fungus may also have made a noteworthy contribution to the diet, further supporting the emphasis on the field as a patch. In combination, these data and theoretical analyses help to explain the subsistence choices made by Basketmaker II people. In particular, these results clarify what motivated people to increasingly focus on farming, and highlight the wild resources used to augment maize-based nutrition prior to the incorporation of beans, which provided essential nutrients during later periods. 


\section{TABLE OF CONTENTS}

LIST OF FIGURES $\quad$ xii

LIST OF TABLES $\quad$ xiii

LIST AND DESCRIPTIONS OF APPENDICES $\quad$ xv

CHAPTER 1

$\begin{array}{ll}\text { Data and Context } & 2\end{array}$

$\begin{array}{ll}\text { Approach } & 3\end{array}$

$\begin{array}{ll}\text { CHAPTER } 2 & 5\end{array}$

Theoretical Contexts: Conventional and Recent Explanations for the Advent of Food

Production 6

$\begin{array}{ll}\text { Conventional Ideas } & 6\end{array}$

A Different Approach to Agricultural Theory 11

Human Behavioral Ecology and the Adoption of Food Production 19

Human Behavioral Ecology 20

Optimal Foraging Theory: Diet-Breadth and Patch-Choice Models 21

Evolutionary Development and Niche Construction Theory 28

Domestication as a Secondary Event $\quad 30$

$\begin{array}{ll}\text { Conclusion } & 33\end{array}$

$\begin{array}{ll}\text { CHAPTER } 3 & 34\end{array}$

A Brief Culture History of the Northern Southwest 35 
Ancestral Pueblo

Archaeological Chronologies

Basketmaker II Subsistence and Culture

The Adoption of Agriculture in the Southwest

Basketmaker II Maize Dependence

Site Description

Environmental and Ecological Context

Geography and Climate

Ecology

Conclusion

Botanical Analyses

Sample Selection and Preparation

Pollen Processing and Analysis

68

Ustilago maydis

Caveats Regarding Dietary Pollen and Spores

Macrobotanical Analysis

Other Analyses

DNA Analysis 
Statistical Analyses

Conclusion

Faunal Resources

Conclusion

CHAPTER 6

Palynological Results

Analysis 
DNA Results

Analysis

Synthesis of the Data

122

Ecological Patch Association

124

AMS Dating Results

Analysis

128

Conclusion

129

CHAPTER 7

131

Hypothesis Testing

Hypothesis 1

Hypothesis 2

135

Hypothesis 3

140

Discussion and Conclusions 


\section{LIST OF FIGURES}

Figure 3.1. Map of Cedar Mesa and Cedar Mesa Project area with color coding for elevation. 49

Figure 3.2. Map showing location of Turkey Pen Ruin within upper Grand Gulch. $\quad 50$

$\begin{array}{ll}\text { Figure 3.3a. The rockshelter overhang. } & 51\end{array}$

Figure 3.3b. Puebloan house structures with soot stains and BMII period rock art. $\quad 51$

Figure 3.3c. View from within Turkey Pen Ruin. 51

$\begin{array}{ll}\text { Figure 3.4a. Rock art. } & 52\end{array}$

Figure 3.4b. Axe grinding slicks from Turkey Pen Ruin. 52

Figure 3.5. Partially isolated midden column. 54

$\begin{array}{ll}\text { Figure 3.6. Turkey Pen Ruin midden profile with associated radiocarbon dates. } & 57\end{array}$

$\begin{array}{ll}\text { Figure 3.7. Cedar Mesa Project sampling design. } & 61\end{array}$

$\begin{array}{ll}\text { Figure 6.1. Pollen percentages for major taxa by sample. } & 106\end{array}$

$\begin{array}{ll}\text { Figure 6.2. Bar chart of pollen density by sample. } & 107\end{array}$

$\begin{array}{ll}\text { Figure 6.3. Results from Aasen } 1984 . & 109\end{array}$

$\begin{array}{ll}\text { Figure 6.4. Macrofossil percentages by sample. } & 117\end{array}$

Figure 6.5. Images of the rodent humerus fragment, anterior view and posterior view. $\quad 118$

$\begin{array}{ll}\text { Figure 6.6. Midden profile with DirectAMS dates integrated. } & 128\end{array}$ 


\section{LIST OF TABLES}

Table 3.1. Modern Pueblos in the Southwest 38

Table 3.2. Chronology of the Puebloan Region of the Northern Southwest 39

Table 4.1. PCR Primers and Associated Citations 76

Table 4.2. Ecological Patches and Associated Plants $\quad 81$

Table 5.1. Selected Essential Nutrient Content for 100g Raw Corn with Corresponding EARs 85

Table 5.2. Percentage of Essential Nutrients Compared to Raw Corn 87

Table 5.3. Local Faunal Resources at Cedar Mesa and Their Caloric Return Rates 90

Table 5.4a. Comparison of Caloric Return Rates for Selected Resources on the Colorado Plateau

Table 5.4b. Caloric Return Rates for Maize Farming 93

Table 5.5. Plants Native to Cedar Mesa Commonly Associated with Field Settings 99

Table 6.1. Combined Pollen Results Divided into Standard Taxonomic Groupings 104

Table 6.2. Pollen Taxa Distributions between Samples 105

Table 6.3. Pollen Densities Ordered Lowest to Highest 108

Table 6.4. Statistics on Pollen Density by Taxa 108

Table 6.5. Calculated Corn Smut Densities for All Samples 113

Table 6.6. Macrofossil Representation for All Specimens Combined 115

Table 6.7. Statistics for Macrofossil Weight by Taxa for All Specimens 116

Table 6.8. Combined Faunal and Plant DNA Results 121 
Table 6.9. Pollen Representation by Ecological Zone 125

Table 6.10. Macrofossil Representation by Ecological Zone 125

Table 6.11. AMS Dates and Associations of Paleofecal Samples 127

Table 7.1. Resource Use and Nutritional Expectations 132

Table 7.2. High-Ranked Wild Resource Representation 133

Table 7.3. Low-Ranked Wild Resource Representation 136

Table. 7.4. Expectations of Resource Use and Nutrition for Hypothesis $3 \quad 141$

Table 7.5. Field Resource Representation 142 


\section{LIST AND DESCRIPTIONS OF APPENDICES}

APPENDIX A - General Information on the Paleofecal Specimens

Appendix A lists details about the paleofecal specimens including sample weights and solution Munsell colors, midden layer associations, and radiocarbon date associations.

\section{APPENDIX B - Pollen Data}

Appendix B shows the raw counts, densities, and percentages of pollen by taxa and sample. It also shows the results for corn smut spores.

APPENDIX C - Macrofossil Data

Appendix C shows the macrofossil weights and percentages by sample.

APPENDIX D - DNA Data

Appendix D shows the results of the targeted PCR analyses and corresponding data regarding the primers.

APPENDIX E - Use of Native Plants in the Southwest

Appendix E lists, categorizes, and details ethnographically documented uses of various plant species among indigenous Southwestern groups. 
This work is dedicated to the Puebloan peoples whose ancestors are the subject of this study. 


\section{CHAPTER 1}

\section{Project Overview}

Subsistence is widely acknowledged as an important foundation for many cultural traits; what people eat and how they obtain food influences their culture in profound ways. The development of farming during the Neolithic Revolution changed the course of human history, allowing for the rapid development of complex societies, large cities, and the accompanying technological advancements (Childe 1928; 1935). Most analysts now agree that regional and historical contingencies led to shifts in foraging productivity or population density that resulted in people choosing to produce food instead of relying exclusively on forage (Weisdorf 2005; Winterhalder and Kennett 2006).

Specifically in the Southwest there has been much debate over whether maize agriculture spread primarily through cultural diffusion to local foragers or through migration of maizedependent farmers (Roth 2017). Although the data analyzed here cannot address this issue directly, by highlighting the scenarios that encouraged increased focus on food production and considering the complementary use of local forage, this work may have implications regarding these competing models of maize proliferation. Furthermore, in recent years, researchers have begun examining the adoption of maize in the Southwest from a perspective based in human behavioral ecology and cost-benefit analysis (Kennett and Winterhalder 2006; Phillips 2009). By examining the wild foods used to supplement the diet of an increasingly maize-reliant population, I aim to reveal the salient ecological circumstances that encouraged the shift to maize 
reliance during the BMII period in the Four Corners of the Southwestern United States. The nutritional and caloric value of foraged resources relative to corn can help explain the role of farming in the overall subsistence strategy and what motivated its people to increase their reliance on maize - a pull toward raising subsistence efficiency, or a push to obtain enough calories and nutrients from a degraded environment.

\section{Data and Context}

Materials recovered from Turkey Pen Ruin, southeast Utah provide an ideal opportunity to examine questions about past human diets because it is a well-dated, dry rock shelter site with excellent organic preservation, including human paleofeces (Aasen 1984; Lipe et al. 2011; Matson 1991). This dissertation describes the pollen and macrobotanical evidence from 44 human paleofeces from a single stratified midden at Turkey Pen Ruin. Twenty of these samples were also processed for animal and plant DNA to test for meat resources and plants unlikely to be represented in the macrobotanical and pollen data. To help clarify chronology, eight specimens from six different layers of the midden were submitted for AMS assay.

The specimens analyzed in this dissertation are all ancestral Puebloan paleofeces from a stratified midden dating primarily to the late Basketmaker II period (ca. 90 BC - AD 400). The temporal context of Basketmaker II (hereafter BMII) is important because the people of this time period were the first in the northern Southwest to become reliant on maize farming (Coltrain et al. 2006; 2007; 2012; Lipe 1999b; Martin 1999; Matson 1991; 2006a, b; Matson and Chisholm 2007). They were also the first to develop many of the cultural traits that would later come to define the region including turkey husbandry (Lipe et al. 2016; Nott 2010; Speller et al. 2010) and the architectural origins of the kiva (Lekson 1985; Matson 1991, 44; Morris and Burgh 1954). 
Turkey Pen Ruin exhibits the maize-centered farming economy characteristic of BMII. However, the combined absence of bean horticulture during this period (Geib and Spurr 2000; Lipe 1999b; Matson 2006b) and an apparent lack of meat consumption at this particular site (Aasen 1984; Cooper et al. 2016), begs the question of how the inhabitants were getting sufficient amounts of essential amino acids and what motivated them to focus so much of their energy on a crop deficient in several essential nutrients (Bressani et al. 1997; Ellwood et al. 2013; Holstad 2010; Spielmann and Angstadt-Leto 1996). For these and other reasons Turkey Pen Ruin is an ideal site for studying the initial evolution of the Southwestern agricultural economy and the motivation to adopt maize horticulture in the larger culture area.

\section{Approach}

Using paleofecal analysis I hope to gain a better understanding of the dietary decisions prehistoric people made to meet their basic energetic and nutritional needs from farming and supplemental foraging. Through the application of models based in human behavioral ecology (HBE), one of the major questions I address is the underlying motivation of these choices. Specifically, if agriculture was a highly productive endeavor adopted and intensified out of preference, then foraged resources chosen to complement maize farming should be calorically superior to maize (Childe 1951; Meggers 1954; Pryor 1986). Alternatively, if people were pressured to increase their reliance on cultigens due to a reduction in foraging productivity (Barlow 2002; Lee and DeVore 1968), then they would need to supplement agriculture with inefficient resources that were calorically inferior to maize. I use the diet-breadth model and caloric returns on local resources (calories gained per time spent obtaining and processing a resource) to evaluate resource choice and to understand what motivated BMII peoples to focus their subsistence strategy on farming. 
I also use the patch choice model to evaluate the patches that farmers might have exploited. Because farming creates an artificial patch that can support certain wild plants alongside cultigens, patch choice can be applied to food production by looking at the field itself as a patch. The field patch is not only where crops are grown, but where weedy plants that thrive in disturbed contexts provide an additional benefit. The use of weedy disturbance plants as a resource has been investigated in similar contexts elsewhere (Bye 1981; Ford 1984; Kahl 1987; Stiger 1979). In this context they could provide an added incentive to expand farming pursuits.

By comparing data from this project against pollen and macrobotanical data from Kate Aasen's (1984) analysis of 28 separate paleofeces from this same site and temporal context, I hope to paint a more detailed picture of subsistence at Turkey Pen Ruin. By incorporating HBEbased interpretations of paleodietary data, this dissertation will endeavor to explain what motivated some of the first farmers of the ancient Southwest to center their economy on maize (Zea mays). 


\section{CHAPTER 2}

\section{Theoretical Background}

"Why should I farm when there are so many Mongongo nuts?" - Bushman of The Kalahari as quoted in Lee and DeVore (1968)

This chapter provides a larger historical context and a theoretical framework for my hypotheses regarding food production during the Basketmaker II period in the northern Southwest. This discussion is centered against a backdrop of conflicting classical and modern assumptions about the relative efficiency of foraging and farming. Beginning with Childe's Oasis Theory, I will map out the major transitions in theoretical understandings of the agricultural revolution through the $20^{\text {th }}$ Century, and end with an explanation of modern ideas such as niche construction and other models based in evolutionary theory. A major portion of this chapter reviews the application of human behavioral ecology to studies of food production, with particular focus on diet-breadth and patch-choice models - the theoretical models used in this dissertation. Finally, since Basketmaker II peoples were maize farmers who adopted their staple crop after it was domesticated in Mesoamerica, this chapter also includes a discussion on the spread of farming from primary to secondary centers. 


\section{Theoretical Contexts: Conventional and Recent Explanations for the Advent of Food Production}

Conventional Ideas

Conventional models, especially those developed prior to the late 1960s, have often portrayed the adoption of food production as part of humankind's natural progression, limited only by the environmental, technological, and demographic potential for agricultural development (Childe 1951; Flannery 1969; 1973; 1976; Meggers 1954; White 1949; 1959). Agriculture was viewed as the high point in human civilization and as naturally superior to foraging. Conventional approaches often operated under the assumption that high agricultural returns juxtaposed against less productive and undependable foraged resources led to the adoption of domesticated foods_-basically a pull toward increased bounty and stability (Meggers 1954; Pryor 1986). For some of these researchers, the central question was not what caused societies to adopt agriculture, but rather what factor or factors prevented other societies from embracing food production (Meggers 1954; Pryor 1986).

One of the first theoretical attempts to tackle the advent of agriculture was the Oasis Theory proposed by V. Gordon Childe $(1928 ; 1934 ; 1951)$. Childe believed (correctly) that the Near East was where the first experiments in food production took place. By compiling and chronologically sorting archaeological data from that region, he created a theoretical framework that included several technological stages of resource acquisition and settlement that evolved from a foraging economy, into the Neolithic, and eventually to urbanized civilization (Childe 1928; 1951; Flannery 1994). Childe's explanations for the adoption of agriculture were not universal, nor did he intend them to be (Flannery 1994). His Oasis Theory was based on the particular ecology and environment of the region; Childe argued that shifting rain patterns during 
the terminal Pleistocene had a destabilizing effect on the Near East. Although the larger environmental shifts were gradual, they rapidly changed the Near East from a productive region of more or less continuous grasslands, to a harsh desert with shrinking, scattered oases (Childe $1928 ; 1934 ; 1951)$. Childe proposed that warm, arid conditions in the terminal Pleistocene forced people and animals to gather in the limited places where water and plants were plentiful. This unavoidable congregation led to a shift in the way that people foraged; instead of simply searching out favored foods, they began to selectively breed and manage first plants, then animals. He further argued that the process of food production motivated cultivators to accumulate a surplus of stored food and seeds to replant. Sedentism and social stratification evolved out of this shift to economic dependence on food stores and thus began the Neolithic Revolution (Childe 1928; 1934; 1951).

Childe and his contemporaries viewed this shift as a swift and unambiguous leap forward. Like previous ideas about agriculture (e.g., Hobbes 1651) and like many of the theoretical models to follow (Braidwood 1963; Braidwood and Howe 1960; Flannery 1969; 1973; 1976; Meggers 1954), Childe's theory was couched in the assumption that people adopted agriculture because it was superior to foraging in terms of efficiency and as an overall lifestyle choice. Characteristic of his Marxist theoretical bent, Childe considered hunter-gatherers to be savages, living difficult, brutish lives, dependent on their environment instead of conquering and manipulating it (Childe 1951; Flannery 1994). Sedentism was clearly superior to mobility, and farming was considered more stable and productive than foraging, so farming was motivated by a desire to increase the food supply with less relative effort. The invention of food production was therefore unquestioned progress toward humankind's greater dominion over nature (Childe 1951; Flannery 1994). 
Paradoxically, Oasis Theory was considered too environmentally determinist by later scholars, since it was rooted in rapid climatic change. This consideration led many researchers to deemphasize the importance of climate change as a possible catalyst for food production for decades following (Braidwood and Howe 1960; Weisdorf 2005; Winterhalder and Kennett 2006). Furthermore, by the 1940s and 50s, geological and paleobotanical analyses, in conjunction with radiocarbon dating, demonstrated a gradual, less-encompassing climatic shift at the end of the Pleistocene that could not have led to the sudden desiccation essential to Childe's Oasis Theory (Braidwood 1963; Braidwood and Howe 1960; Helbaek 1960; Weisdorf 2005; Wright 1960).

Although they intended to find supporting evidence for Childe's model, much of the work that undermined Oasis Theory was conducted by Robert Braidwood and colleagues as part of the Iraq-Jarmo Project (Braidwood 1963; Braidwood and Howe 1960). Built upon years of multidisciplinary research in the Levant, Braidwood et al. developed the Hilly Flanks Theory, which soon gained prominence as a model for domestication (Braidwood 1963; Braidwood and Howe 1960). Braidwood agreed with Childe that the Near East was the region where agriculture originated and that it was economically superior to hunting and gathering, but disagreed on how and why this shift in subsistence practices took place. While Braidwood and his colleagues developed their model using culture history like Childe, Hilly Flanks Theory was also firmly grounded in paleobotanical, geological, and ecological data on the natural borders of vegetation zones.

As in the American Southwest, vegetation regimes, soil types, and precipitation in the Near East are strongly segregated along elevational lines (Braidwood and Howe 1960). Braidwood and colleagues determined that grasslands in the foothills and intermontane valleys of 
the Fertile Crescent, between approximately 455 and 915 meters above sea level, were an ideal setting for prehistoric experiments in cultivation (Braidwood 1963; Braidwood and Howe 1960). According to Hilly Flanks Theory, the domestication of wheat and barley evolved from intensification of foraging practices and technology in areas that were rich in wild grasses. The first cultivators likely started with wheat and then moved on to cultivate barley; other cultigens and animal husbandry soon followed (Braidwood 1963; Braidwood and Howe 1960; Helbaek 1960). Eventually, people began replanting crops in river valleys where village-farming communities could practice irrigation and more intensive forms of agriculture that were not possible with incipient horticulture where these early cultigens naturally grew (Braidwood and Howe 1960). Braidwood's theory was also region specific, largely centered on the Fertile Crescent's natural abundances of plants and animals amenable to domestication, but it placed a greater focus on human ingenuity than Childe's Oasis Theory.

Subsequent ideas such as Lewis Binford's Equilibrium Model (1968) and Kent Flannery's Broad Spectrum Revolution (1969) focused on explaining the Neolithic Revolution in terms of population pressure in marginal landscapes. Binford (1968) argued that Braidwood's Hilly Flanks Theory lacked explanatory power and offered no justification for why people with a successful economy would intensify foraging efforts and experiment with cultivation in a highly productive environment. Binford proposed that rising sea levels encroached on occupied territories and forced foraging populations into smaller, more marginal areas with shifting seasonal productivity (Binford 1968). This climate-driven circumscription increased sedentism and population packing in places where the precursors to modern cultigens naturally thrived. Increases in sedentism fueled population growth through shortened interbirth intervals because mothers' burdens were decreased when dependent children did not have to be transported. Once 
population density grew to levels out of equilibrium with the surrounding resources, technological shifts toward food production provided a means to correct that disequilibrium. However, there is no archaeological evidence that supports the rising sea level that led to this population packing, as envisioned by Binford (Cohen 1977).

Flannery's (1969) Broad Spectrum Revolution, on the other hand, relied completely on population pressure as a catalyst for food production. Flannery argued that Late Paleolithic population growth in areas with abundant resources pushed daughter populations into more marginal areas. While earlier Paleolithic peoples focused their foraging efforts on a small selection of highly productive resources, populations in marginal areas were forced to increase their diet breadth and adapt their subsistence technology to include resources such as invertebrates, fish, waterfowl, and seed-based plant resources (Flannery 1969). As with Binford, Flannery thought the balance between environmental productivity and population size was key to explaining the expansion of diet and the advent of new subsistence technologies. People residing in areas with lower natural productivity had to find a way to increase food acquisition. Based on the observation that a focus on small-package resources and the associated tool kits often appear in the record just before food production, Flannery argued that this increase in resource acquisition was initially accomplished through exploiting a wider range of wild resources.

A central idea behind the Broad Spectrum Revolution is that people increased their diet breadth to include smaller resource packages, such as invertebrates and grass seeds, when more preferred resource availability decreased. Eventually, these adaptations paved the way for food production, which became the favored method of increasing territorial carrying capacity (Flannery 1969). Since the majority of protein still came from ungulates, presumably hunted by men, he argued that cultivation fell under the purview of women so it would not interfere with 
game acquisition. This new economic system centered on cultivated resources was more successful than economies based solely on foraging, so it soon spread from the marginal environments where it originated to areas with greater resource availability (Flannery 1969).

However, more recent work by Stiner and colleagues (2000) found that zooarchaeological data in the Near East and Mediterranean do not necessarily support a straightforward transition to increased use of small prey in the Late Paleolithic, rather they show a transition in the variety and types of small prey captured. Specifically, the major shift noted was from exclusive use of sessile, littoral prey such as mollusks and limpets, to a greater incorporation of birds and lagomorphs (taxa that are more difficult to catch, but replenish quickly). This is a departure from the traditional foraging theory models (MacArthur and Pianka 1966; Odum and Odum 1959) and instead shows that resource diversification associated with the broad spectrum revolution may have meant greater inclusion of small animal resources that are less likely to become depressed by overexploitation. These findings do not conflict with Binford and Flannery's ideas about resource diversification prior to the adoption of agriculture, but show that expansion of resource use may have been more skewed toward employing new methods and including more sustainable faunal resources to support densely packed, less-mobile populations (Stiner et al. 2000).

\section{A Different Approach to Agricultural Theory}

For many years assumptions about the superiority of agriculture went largely unchallenged (Cohen 1977; Harlan 1995; Weisdorf 2005). Then, in the 1960s and 70s, theoretical work by Ester Boserup (1965) and Marshall Sahlins (1972), ethnographic descriptions by Richard B. Lee and Irven DeVore (1968), and experimental work by agronomist and plant 
biologist Jack Harlan $(1976,1992)$ and others sparked a multidisciplinary debate regarding the economic lives of hunter-gatherers.

Ester Boserup (1965) approached the issue of food production from an economic perspective, but one that challenged the Malthusian views of resource-limited population growth established in the late 1700s. She stated that population growth (particularly increasing density) was the trigger for both food production and intensification of agriculture. According to Boserup, people adopted agriculture and increased production to meet the rising demands of populations growing beyond their natural environmental carrying capacity, turning Malthus' model on its head. However, she also asserted that rates of return (energy per unit time) diminished with increasing energy expenditures, so that farming — particularly intensified agriculture — was less efficient than simple foraging (Boserup 1965). Jack Harlan also argued that farming was harder work and that it produced a less nutritious and less stable food supply, a contention he supported through ethnographic evidence and experimentation (Harlan 1976; 1992; 1995). He stated that agricultural economies were more prone to famine and less equipped to deal with food shortages. Conversely, through harvesting experiments, Harlan $(1976 ; 1992 ; 1995)$ found that it was possible to harvest enough wild seed crops in a very short period of time to sustain a family for an entire year. Under such circumstances agriculture should only be adopted out of necessity—a push toward food production.

A pivotal point in this debate was the 1966 "Man the Hunter" symposium, from which the 1968 edited volume of the same name was derived. In particular, ethnographic analysis of the !Kung San, presented at this symposium by Richard B. Lee, challenged traditional ideas about the hardships faced by hunter-gatherers and showed that people could get all that they needed from relatively little foraging effort. Even in an environment as harsh as the Kalahari Desert, Lee 
found that foragers could collect enough mongongo nuts in 15 to 19 hours per week to meet their subsistence needs (Lee and DeVore 1968). Based on findings by Lee and others, Marshall Sahlins (1972) argued that the hunter-gatherer lifestyle was one of relative affluence. He stated that foraging societies desired fewer material goods, were able to maintain egalitarian relations, and by virtue of not wanting for much were the "original affluent society." In Sahlins view, foraging populations did not have to hoard goods or strive for material possessions, and could get all they needed from their environment with less effort than a sedentary food producer who required more advanced tools and wealth accumulation (Sahlins 1972). Although later researchers demonstrated that the !Kung and other foragers worked longer hours than Lee and DeVore initially calculated (Hawkes and O'Connell 1981; Kaplan 2000). Cumulatively, these studies led to a paradigmatic change that viewed agriculture as an expensive strategy in comparison to hunting and gathering (Barlow 2002; 2006; Kaplan 2000; Phillips 2009; Weisdorf 2004; 2005).

In this view, farming is time-consuming and difficult, and dependency on domesticated foods has extended consequences for human demography, health, the division of labor and sociocultural organization (Harlan 1976; 1992; 1995; Lee and DeVore 1968; Sahlins 1972; Weisdorf 2005). More intensive food production strategies that implement water control devices, terraced fields, and other high-cost technologies are even more inefficient in comparison to simpler forms of food production (Barlow 2002; 2006; Boserup 1965; Phillips 2009). Under these circumstances, food production should only be adopted under environmental or historical circumstances that shift the equilibrium between the population and their resources. Such a push can result from long-term resource depression (reduced resource encounter rates) from climatic 
shifts or increased population density (Barlow 2002; 2006; Boserup 1965; Cohen 1977; Phillips 2009; Wills 1988).

Mark Cohen was among the first archaeologists to take the position that foraging was superior to agriculture. Cohen asked why anyone would choose food production over foraging, if the latter required much less effort than agriculture (Harlan 1995; Weisdorf 2005). Inspired by Ester Boserup's (1965) argument, Cohen (1977) argued that population growth was the driving force behind the adoption of food production. At a time when an estimated one third of the world suffered from hunger, the claim that intensified agriculture was the most efficient economic system seemed flawed to Cohen. Informed by ethnographic accounts of the !Kung from Lee and DeVore (1968) and the economic ideas of Boserup (1965) and Sahlins (1972), Cohen claimed that the lives of hunter-gatherers were not as difficult as they had been portrayed, and that their diet and lifestyles were in many ways superior to that of agricultural populations. He argued that agriculture and food production were high-cost activities that resulted in a loss of nutritional diversity, so hunter-gatherers should only attempt food production if the needs of their population had exceeded environmental carrying capacity (Cohen 1977).

Unlike the archaeological theories described above, Cohen's theory was not regionspecific, but was intended to explain a global subsistence transition. His overarching goal was to answer why such a large percentage of the world's people transitioned to agricultural economies in a relatively short amount of time (a few thousand years). He proposed that a major switch from a subsistence strategy that was successful for tens of thousands of years must have arisen from a shift in selective pressures. Cohen's research at archaeological sites in coastal Peru showed a decrease in preferred resources over time, and eventual replacement of those foods by suboptimal resources collected from more distant locations leading up to the agricultural period 
(Cohen 1977). According to Cohen, human populations had grown steadily for thousands of years until favorable regions became overcrowded, pushing people to occupy less favorable areas with lower carrying capacities requiring the adoption of farming. Furthermore, denselypopulated, sedentary occupations have a greater environmental impact and require more resources per unit of land than small settlements, leading people to intensify production via advanced irrigation and larger scale farming than possible for small populations (Cohen 1977).

Cohen was not the first to consider the influence of human populations on the terminal Pleistocene environment and its importance to the eventual adoption of agriculture. Paul Martin's ideas about the megafaunal extinction of the late Pleistocene also hinged on population growth. If the megafauna were rapidly hunted to extinction as proposed by Martin's (1973) blitzkrieg model, then people experienced population expansion that simultaneously caused the loss of a valuable food source. Thus, the megafaunal extinction resulting from demographic pressure may have ultimately been a causal factor in the adoption of agriculture (Martin 1967; Roberts 1989; Smith 1975).

Building on the work of Paul Martin $(1967 ; 1973)$, Vernon Smith (1975) noted that the megafaunal extinction coincided with the adoption of small-sized animal and plant resources that were precursors to cultivation. However, regardless of whether humans, climate, or some combination thereof caused megafaunal extinctions (Grayson 1984a, b; Grayson and Meltzer 2003; Smith 1975), the rise and spread of food production often does not spatially or temporally align with these events (Weisdorf 2005). For example, in North America megafaunal extinctions took place thousands of years prior to the advent and adoption of food production and extinctions in Australia never resulted in the adoption of food production. 
During the 1980s models based on population pressure were more critically examined. Kent Flannery’s (1986) work at Guilá Naquitz Cave in Oaxaca helped to disprove population pressure as a universal cause in sparking the advent of farming. Although this site boasts the earliest domesticated maize macrofossils yet discovered, Flannery's data showed that populations did not significantly increase prior to the advent of food production in Mesoamerica. Other attempts to support population pressure as the driving force for the advent of domestication also returned little supporting evidence. For instance, Cohen and Armelagos (1984) organized a large-scale study of skeletal remains from late Paleolithic and early Neolithic sites from around the world to test the idea that nutritional stress among foraging populations catalyzed the advent of agriculture. They hypothesized that skeletal markers of malnutrition combined with changes in isotopic dietary signals in foraging populations prior to the Neolithic would provide support for an imbalance between population and environmental carrying capacity. However, the Late Paleolithic (Epipaleolithic) skeletal remains in their sample did not exhibit signs of regular food stress. Contrary to expectations, Neolithic peoples were much less healthy than their Late Paleolithic counterparts. Neolithic skeletons commonly exhibited signs of anemia (i.e., cribra orbitalia and porotic hyperostosis), as well as enamel hypoplasia and Harris lines, indicating stress-related pauses in tooth and bone growth, and signs of infectious disease proliferated by increasing sedentism (Cohen and Armelagos 1984; Harlan 1995). These data offer support for Cohen's stance regarding agricultural inefficiency, but do not support resource stress from population pressure as an a priori condition to its adoption. Although, the archaeological record often shows increasing population densities associated with the emergence of farming, food production could be the cause instead of the result of this population increase, 
so the issue of which came first - population growth or food production - remains unresolved (Weisdorf 2005).

Eventually, researchers began to move away from population pressure and other singlecausal models to explain the advent and adoption of food production (Weisdorf 2005). Instead of dichotomizing foraging and farming, theorists began to consider common threads that might link both modes of subsistence and explain how cultivation evolved out of foraging (e.g., Harris 1989; Rindos 1984). David Rindos (1980; 1984) argued that coevolution between plants and humans resulted in a symbiosis by which plants were propagated and protected from competitors while people secured a preferred food supply. Prior to the advent of agriculture, intensive foraging altered plant genetics and distribution, which in turn influenced foraging strategies. The changes caused to plants by intensified foraging eventually resulted in complete domestication, so that domestication itself triggered the adoption of farming when the symbiotic relationship between people and certain plants became so strong that some species could no longer propagate without human assistance (Rindos 1980; 1984). Rindos $(1980 ; 1984)$ ignored questions of motivation as "unnecessary to the model" in favor of a more parsimonious, coevolutionary approach to food production research.

David Harris' (1989) model is similar, but he posits domestication evolved out of the landscape-management activities of foragers such as land clearance and burning regimes. In Harris' explanation intensification of foraging efforts and horticulture arose through natural selection due to a positive correlation between labor input per unit of land and the caloric output received (Harris 1989). In other words, when people intensified their foraging efforts and eventually began cultivating, their evolutionary fitness increased with the greater availability of food, and with each shift toward greater intensification evolutionary fitness benefited, which is in 
some ways counter to Boserup and other modern ideas regarding subsistence economics. What differentiated these ideas from earlier theoretical concepts, however, was the lack of attention paid to intentionality and the emphasis on symbiosis between plants (and animals) and the people domesticating them.

In the early 1990s, Brian Hayden (1990; 1992) adopted a more anthropocentric perspective on the adoption of agriculture. He proposed that ambitious individuals within complex hunter-gatherer groups chose food production as a means of displaying wealth and power through extravagant feasting. Competitive feasting is ethnographically documented among complex hunter-gatherers (e.g., the Tlingit and Coast Salish) and horticultural groups (e.g. the Kawelka), as a means of displaying power (Hayden and Villeneuve 2011). Hayden argued that competition for status in the Mesolithic Near East within Natufian society inspired ambitious individuals to begin producing a surplus, rather than collecting food to meet their subsistence needs, sensu stricto (Hayden 1990; 1992). This type of competition is impossible among simple foragers who would have to transport extra food over great distances, and who often rely on resources like large game that do not quickly replenish, so that taking a surplus could cause resource depression. After Archaic and Mesolithic populations developed the technology to exploit smaller, rapidly reproducing animals, as well as common grasses and seedproducing annuals, competition and wealth accumulation became tenable. According to Hayden's competitive-status-based hypothesis, aspects of Natufian social complexity combined with the ecological productivity of the Levant provided all of the necessary prerequisites for food production to emerge. Ofer Bar-Yosef (1998) also remarked that the particularities of Natufian culture such as the focus on cereals, grinding tools, and the variety of mobility patterns were paramount to the development of food production, but tempered his interpretations with 
emphasis on ecological and climatic contexts. Among these he identified the reduction in rainfall associated with the Younger Dryas (ca. 11-10kya) as a catalyst for the first experiments in cultivation among the Natufian who became sedentary in response to this shift. Such explanations harken back to Binford (1968), but with improved understanding of the paleoclimatic data and a greater focus on the cultural peculiarities of the region.

\section{Human Behavioral Ecology and the Adoption of Food Production}

Recent investigations into food production have increasingly borrowed from efficiencybased foraging models. The suite of models and theories known collectively as human behavioral ecology (HBE) are central to many investigations into both the initial adoption and eventual spread of agriculture (Barlow 2002; 2006; Diehl 1997; Gremillion 2004; Gremillion and Piperno 2009; Kennett and Winterhalder 2006; Philips 2009; Piperno 2006; Winterhalder and Goland 1997; Zeder 2006). Since HBE is not couched in an assumption of inherent superiority of either food production or foraging, proximate explanations for the advent of food production are contextually-specific (e.g., climatic shifts, increased population packing, or resource depression), but do not preclude potential ultimate causes (such as a need to increase environmental carrying capacity) that may be more universal. For instance, in one region farming may be adopted following a decrease in local environmental production due to temperature decrease, whereas in another, an increase in population density may force groups into smaller territories; both of these proximate cause scenarios ultimately mean that people need to increase their territorial carrying capacity. Another major advantage is that some of the models, such as optimality models, can explain the adoption of different types of food production in various environmental and historical contexts by modeling local resource return rates and considering marginal returns (long-term payoffs) on agricultural investments relative to immediate returns from resources specific to that 
region and time period. Furthermore, HBE offers a theoretical framework that can incorporate environmental factors without ignoring human ingenuity or choice in subsistence practices (Gremillion and Piperno 2009; Kennett and Winterhalder 2006).

\section{Human Behavioral Ecology}

Human behavioral ecology (HBE) is the study of behavioral and cultural diversity from a neo-Darwinian perspective. As such, HBE fosters interpretations of various human behaviors without precluding environmental, demographic, or social triggers and explanations, since social factors can exert selective pressures that are just as influential as those derived strictly from the physical environment (Bird and O'Connell 2006; Galef and Giraldeau 2001; Sterck et al. 1997). Although HBE encompasses a variety of models with differing degrees of complexity, at their core, all of these models rely on several underlying assumptions derived from evolutionary theory. HBE models are couched in the Darwinian principle that traits that increase fitness accumulate in populations and those that negatively impact fitness are selected against (Broughton and O'Connell 1999; Krebs and Davies 1987; West and Burton-Chellew 2013). Within any population, limited access to resources such as food and mates creates competition, and individuals who possess traits that render them more successful in that competition will be more likely to pass on their genes (and therefore those advantageous genetic traits) to the next generation (Darwin 1859; Pianka 2011). HBE specifically analyzes behavior, and so inherently operates under the assumption that behavioral traits, particularly via social learning mechanisms, can be influenced by genetics and are therefore subject to natural selective processes (Boyd and Richerson 1985).

According to HBE, individuals are strategists who attempt to maximize their own returns of a given payoff for time and effort, and when these attempts are effective they can positively 
impact evolutionary fitness (Broughton and O'Connell 1999; Charnov and Orians 1973; Emlen 1966; Krebs and Davies 1987; Lupo 2007; Stephens and Krebs 1986; Winterhalder and Smith 2000). Here, evolutionary fitness refers to overall mating success in conjunction with long-term offspring survival and offspring mating success. It should be noted that the effects of advantageous traits can manifest in a number of ways, such as an influence on the likelihood of mating, offspring survival, personal survival, and increased health, all of which can ultimately impact evolutionary fitness. In light of this, HBE attempts to explain various behavioral strategies by applying predictive mathematical models to test the fitness-related benefits of a behavior within a given set of ecological and/or sociobiological parameters (Broughton and O’Connell 1999; Krebs and Davies 1987; Lupo 2007; Stephens and Krebs 1986; Winterhalder and Smith 2000).

\section{Optimal Foraging Theory: Diet-Breadth and Patch-Choice Models}

HBE encompasses many diverse models. Here I focus on the two applied in this dissertation: diet-breadth and patch-choice models. Principles from both of these models have already been effectively applied to answering questions about maize agriculture (Barlow 2002; 2006; Diehl 1997; Gremillion and Piperno 2009; Phillips 2009) in different contexts. Dietbreadth and patch-choice are both considered optimality models - part of a larger group of quantitative models known as optimal foraging theory (OFT). OFT is specifically focused on addressing resource selection, time and spatial allocation, and other aspects of foraging strategies (Smith 1983; Winterhalder and Smith 2000, 54). Importantly, optimality does not necessarily include the most optimal behavior imaginable, but refers instead to the most relatively optimal strategy or behavior under a particular set of environmental parameters (Broughton and O’Connell 1999, 154). In light of this, hypothesis testing in OFT generally includes an 
assessment of the alternative choices or strategies possible within the relevant constraints (Broughton and O'Connell 1999; Charnov and Orians 1973; Lupo 2007; Smith 1983;

Winterhalder 1981; Winterhalder and Smith 2000). OFT operates under the assumptions that people make dietary choices to maximize subsistence efficiency, and that the effectiveness of these choices correlates with evolutionary fitness (Charnov and Orians 1973; Emlen 1966; Smith 1983).

OFT models, like HBE more broadly, often center on cost-benefit analyses. Within OFT, cost-benefit analysis is based on the relative ranks of different resources and it determines which resources should be pursued under different circumstances. Costs are partitioned into two categories: search and handling. Handling costs considers the time spent pursuing, harvesting or killing, transporting, and processing a resource against the value of a particular resource. Search time is generalized across all resources (Winterhalder 1981). In the diet-breadth model resources are ranked along a single continuum usually according to average caloric efficiency (energy/handling time the so-called post-encounter return rate). There are several factors that can alter a resource's ranking such as technological advancements that decrease processing times or changes in resource density (Barlow 2006; Kennett and Winterhalder 2006; Lupo 2007, 148). For instance, small invertebrates in large, easily exploitable patches that can be mass-harvested (such as a swarm of locusts), are more energetically efficient resources than larger-sized game due to density and ease of access. However, energy is not the only possible currency, sometimes other specific nutrients are more important than caloric intake alone. In these instances, costbenefit analysis may still consider the need to obtain enough calories, but will center on another factor such as balancing protein and carbohydrate intake or obtaining an adequate amount of calcium (Jensen et al. 2012; Kay 2002; Simpson et al. 2004; Winterhalder 1981). 
According to diet-breadth model, availability of high-ranked, productive resources influences whether or not lower ranked resources enter the diet (MacArthur and Pianka 1966; Charnov and Orians 1973; Hames and Vickers 1982; Stephens and Krebs 1986; Hawkes and O’Connell 1992; Kaplan and Hill 1992; Nagaoka 2002a, b; Lupo 2007; Gremillion and Piperno 2009). If high ranking resources are readily available, the diet will be narrow as low ranking resources that would diminish the average rate of returns will not be pursued. In this case it is more efficient to ignore certain resources if the forager is likely to encounter an item with a higher post-encounter return rate (Stephens and Krebs 1986). In this case, the mean postencounter return rate (including unsuccessful pursuits) of the specific resource encountered is weighed against the average expected return rate of continued search for a higher ranking prey item (Stephens and Krebs 1986). When the average rate of returns diminishes due to a decrease in access to high-ranked resources (regardless of the reason) lower ranked resources will enter the diet, increasing diet breadth. Resources are added to and dropped from the diet in rank order, so that the lowest ranked resources will be dropped from the diet first and relatively higher ranked resources will be the first to enter back into the diet. In theory, foragers add resources into the diet until the average return rate (the average rate of energetic returns per time spent foraging) begins to diminish (MacArthur and Pianka 1966; Stephens and Krebs 1986; Charnov and Orians 1973; Hames and Vickers 1982; Hawkes and O'Connell 1992; Kaplan and Hill 1992; Lupo 2007; Gremillion and Piperno 2009).

One weaknesses of this model is that variation in long-term return rates and marginal values on investments such as technology are ignored because explicit assumptions center on immediate average return rates (Gremillion and Piperno 2009). This can diminish its capacity to predict the adoption of economic strategies such as food production and those that focus on 
sustainable resources that can quickly replenish weighted against resources that are more readily depleted (Gremillion and Piperno 2009). In spite of these predictive weaknesses, this model can still be effectively applied toward food production and farming economies (Hawkes and O’Connell 1992, 63). If agriculture is a highly productive endeavor (Childe 1951; Meggers 1954; Flannery 1969), then the diet breadth of a farming population should be narrowly focused on high-ranked domesticated food products with little need to add wild resources. If, on the other hand, food production is costly and inefficient as proposed by Boserup (1965) and others then the diet of farming populations should be broad and include wild low-ranking resources to help supplement the farming-based food supply.

Patch-choice is a more spatially focused model, based on the idea that environments are rarely homogenous and resources are not randomly encountered. Certain resources often occur in specific patches so that once an animal or plant is encountered there's an increased the likelihood of encountering that resource again (Charnov 1976). Patches can be coarsely defined as entire habitats (e.g., terrestrial vs. marine), as environments within larger settings (grassland, lacustrine, etc.), or as a specific resource or even the means used to obtain that resource (e.g., net or spear hunting) (Smith 1991; Nagaoka 2002a, b; Burger et al. 2005; Lupo 2007, 149-150). For example, economically important wild plant species often grow in particular settings, allowing for more fine-grained patch designations such as field or disturbed settings and pinyon-juniper woodlands.

Patch-choice model, in conjunction with marginal value theorem, predicts when foragers will abandon one patch and move to another. If foraging depletes the patch, foragers will move to a new patch after the net return rate of the patch they currently occupy falls below the average for all other patches in the environment, taking into account travel time (Charnov and Orians 
1973; Charnov 1976; Charnov et al. 1976). Reduction in overall foraging efficiency leads either to more intensive use of a single patch, an increase in the number of patches used, or both.

Any explanatory power gained from the use of these models should be understood within the regional and historical context of specific cases. In the case discussed here, maize arrived in the Southwest as a fully domesticated crop imported from Mesoamerica (da Fonseca et al. 2015; Merrill et al. 2009). The adoption of domesticated maize by indigenous hunter-gatherers in the American southwest required less experimentation than the earliest cultivation of this plant from wild progenitors; but as maize moved north to the Colorado Plateau, experiments with cultivation in cooler climates required the development of new strains adapted to more temperate, high desert climates (Adams 2004; Huckell 2006; Benson 2011, 5; da Fonseca et al. 2015).

Barlow $(2002 ; 2006)$ applied concepts from diet-breadth model to explore the circumstances of maize farming among the Fremont. Although researchers debate the nature of Fremont cultural identities and adaptations, they agree that this archaeological complex extends from the southeastern portion of the Great Basin to northern Southwest from ca. AD 700-1200. Fremont economies were based on a mixture of farming and foraging, with highly varied emphasis on maize farming relative to foraging (Barlow 2002: 65-70). Similar adaptations characterize earlier BMII populations in the northern Southwest. Using experimental data, Barlow $(2002 ; 2006)$ modeled the efficiency of different farming methods (simple horticulture and intensive agriculture) relative to foraging for wild prey and plant resources on the Colorado Plateau. Barlow wanted to explore the productivity of hunting and gathering relative to farming in order to explain the mix of farming and foraging economies that characterized the Fremont. She found that simple horticulture based on dry farming with slash-and-burn and digging stick 
technology was calorically comparable to foraging for high-ranked wild plant resources such as pinyon (Pinus edulis, P. monophylla) and cattail (Typha latifolia) pollen. But intensive agriculture involving water control features was comparatively more expensive yielding much lower net return rates than foraging or simple farming. Barlow predicted that increases in agricultural investments should coincide with decreasing opportunities to collect high-ranked resources. Conversely, she argued that people would decrease time spent in agricultural pursuits when there was a rise in productive foraging opportunities (Barlow 2002; 2006). In fact, deintensification of prehistoric agriculture, similar to that predicted by Barlow is evidenced apparent in some areas of the American Southwest (Phillips 2009).

Barlow (2002) proposed that the Fremont were pushed into adopting agriculture by low foraging productivity due to decreased prey encounter rates and eventually intensified production following increased resource depression (defined as decreased resource abundance or lower encounter rates). Although she noted the importance of resource storability, her analysis placed emphasis on the immediate returns and resource rankings sensu stricto. In 2006 Barlow emphasized greater understanding of long-term investments, stating that expected marginal returns for time spent cultivating should be considered against expected immediate returns from foraging. Basically a forager may decide to spend an hour tilling soil if they think the increased crop yield (marginal value) from that effort will be greater than the immediate return they could get from hunting or foraging (Barlow 2006). David Phillips (2009) made a similar argument based on the importance of marginal values for understanding agricultural intensification and deintensification in the Southwest. When crops are productive, the extra hours that go into irrigation, field preparation, and tending increases the final payoff significantly enough to warrant the time spent. However, if the chance of crop failure is high, the time spent in pre- 
harvest agricultural pursuits may be more efficiently applied toward hunting or foraging, so that the perception of crop failure and stress can lead to a reduction in intensive farming practices (Phillips 2009).

Barlow $(2002 ; 2006)$ argued that explanations for the inclusion of maize and different levels of agricultural investment should not rest solely on the productivity of corn and highranked wild resources, but should also consider the availability of lower-ranked wild seeds that are storable. The latter have similar benefits to maize and can potentially provide security during periods of scarcity. However, if farming and agriculture are truly more efficient and stable than foraging, archaeologists should see use of wild storable seeds diminish, and eventually all but vanish, with each technological development aimed at improving food production and storage.

Both Barlow's and Phillip's models assume that processing costs of seeds are equal across time. But as Gremillion (2004) observed, the effort invested in processing low-ranked wild seeds during harvest season when other resources are abundant may incur high opportunity costs. However, since these seeds are storable and can be processed at a later date (or season) when pursuit of higher ranked resources is impossible, the time spent harvesting may be considered a more efficient investment if processing can be delayed (Gremillion 2004; Gremillion and Piperno 2009). Furthermore, storable wild resources that are available prior to the harvest could provide a safety net in case of future crop failure. For example, many of the wild seeds available on the Colorado Plateau such as Indian Ricegrass (Achnatherum/Oryzopsis hymenoides) and goosefoot (Chenopodium spp.) are relatively low-ranked due to lengthy processing times (Barlow 2002; 2006; Ferguson 2007, 65-69; Simms 1985, 124). Although these characteristics, alone do not increase the rank of these seeds relative to other storable resources such as beans and corn, it may help to explain their inclusion in the diet. 


\section{Evolutionary Development and Niche Construction Theory}

Other recent hypotheses on the advent of cultivation and domestication are outgrowths of nuanced understandings of genetic variation and gene expression in domesticated plants and animals. Although the importance of new mutations in encouraging plant and animal domestication is still recognized (Braidwood and Howe 1960; Zeder et al. 2006), ideas from evolutionary developmental biology based on phenotypic plasticity offer a more elegant solution (Gremillion and Piperno 2009). Furthermore, genetic evidence regarding the phenotypic changes in domesticates, can enhance estimates of the potential resource return rates from early experimentation in cultivation. Gremillion and Piperno (2009) propose that regulatory genes, which control the timing, location and expression of other genes, may be responsible for the expression certain phenotypic traits associated with domestication. So instead of selecting for a rare or novel mutation, selective pressure might instead impact the expression of genes already present in a population. If cryptic genetic variation was artificially or naturally selected, the average phenotype of a plant species could be changed within a few generations without the need for intensively breeding specimens that exhibit a singular new mutation (Gremillion and Piperno 2009). Although not necessarily applicable to every cultigen, one possible example of this scenario is maize since studies have shown that certain maize-like characteristics such as branching and flower arrangement (inflorescence) can be induced in Teosinte (the putative wild precursor) by environmental stress (Doebley 2004; Gremillion and Piperno 2009; West-Eberhard 2003). Gremillion and Piperno (2009) argue that this process in conjunction with niche construction theory could explain the process of domestication through human-based selective pressures altering gene expression. 
Niche construction theory falls within the larger theoretical framework of Human Behavioral Ecology (HBE). It states that organisms intentionally and unintentionally modify their environment in ways that change selective pressures for their own species and sometimes other species as well (Kendal et al. 2011; Odling-Smee et al. 1996; 2003; Zeder 2012). For example, earthworm burrowing mixes and aerates sediments creating an environment that alters selective pressure for plants by influencing root system growth and nutrient uptake patterns. This also potentially influences the selective pressures on future earthworms, positively impacting their ability to burrow through the soil. Niche construction can also act as a conduit for coevolutionary processes when one species becomes dependent on the environmental alterations made by another (Odling-Smee et al. 1996), such as corals and the fish that inhabit coral reefs. Changes caused by niche construction are not always beneficial to the species creating them, yet can still alter selective pressures acting on phenotypic traits characteristic of a population (Odling-Smee et al. 1996; 2003). For instance, human agricultural activities often create areas of standing water where mosquitoes that spread infectious disease thrive (Diamond and Bellwood 2003; Harlan 1995). When applied to humans, niche construction coalesces with socio-cultural behaviors so that changes can evolve and spread quite rapidly. As with Rindos and Harris's hypotheses, evolutionary devolopment and niche construction models are not focused on motivation, but focus on revealing how domestication might occur (Gremillion and Piperno 2009; Zeder 2012; Zeder et al. 2006),

In the studies described above, neither Barlow (2002; 2006) nor Philips (2009) considered how niche construction resulting from farming might impact wild resource productivity. A post-hoc factor to consider are the indirect benefits of farming, and how these might impact resource procurement strategies once food production has already begun. Farming 
activity creates disturbed soil that fosters the growth of pioneer plants and crops attract pests such as cottontail (Sylvilagus auduboni) and deer (Odocoileus spp.) that can be desirable prey (Adams 2004, 175-176; Ford 1984; 2000; Szuter 1984). Horticulture and agriculture can thereby generate new opportunities to forage for weedy plants and invading fauna, and further enhance the value of fields as a resource patch for both food procurement and production (Adams 2004, 175-176; Fish 2004, 127; Ford 1984; 2000; Hill 1997; Stiger 1979). Normally when calculating energetic return rates of foraging and farming the two strategies are considered to be mutually exclusive - time spent farming cannot also go toward foraging (Barlow 2006). But if the field is considered more holistically, as a patch containing both cultivated and uncultivated plants, that division is less strict. If forage is part of the same resource patch as cultigens, then weeding can be considered foraging and people can harvest wild plants at the same time as they are caring for or harvesting their cultivated crops (Adams 2004, 175-176; Ford 1984; 2000). The immediate returns of farming efforts encompass the harvest of weedy annuals and garden pests that offer a complementary immediate payoff for marginal agricultural labor investments.

\section{Domestication as a Secondary Event}

Although the earliest known experiments with cultivation took place in the Near East (Bar-Yosef 1998; Braidwood and Howe 1960; Childe 1928; 1934; 1951; Diamond and Bellwood 2003), several other centers of domestication can be found in Asia, Africa, and the Americas from which agriculture spread either by cultural diffusion, migration, or both (Diamond and Bellwood 2003; Harlan 1971; 1976; 1992; Smith 1998). Many scholars recognize approximately nine primary centers where food production was independently invented, although cultural exchange between primary centers often makes it difficult to determine the actual origin for a specific crop, and there can be multiple origins for a given domesticate (Diamond and Bellwood 
2003; Harlan 1971; 1992; 1995; Piperno 2011; Smith 1998). These primary centers of domestication are where all of the world's major staple crops originated, but do not represent every independent domestication event. For instance the Southwest is a secondary agricultural center where maize farming was adopted from Mesoamerica (da Fonseca et al. 2015; MacNeish and Eubanks 2000; Matson 1991; Merrill et al. 2009; Piperno 2011; Pope et al. 2001), but recent evidence demonstrates that Basketmaker II populations independently developed turkey husbandry (Nott 2010, Speller et al. 2010). Similarly, dogs were ostensibly domesticated on multiple occasions by hunter-gatherers in Europe and Eurasia (Larson et al. 2012).

There are several different explanations regarding the spread of agriculture from its original centers, each of which apply to different geographic regions and contexts. One is based on migration and the idea that agricultural peoples marginalized and/or replaced hunter-gatherer populations (Diamond and Bellwood 2003). Because agricultural populations often exhibit a much higher population growth rate than foraging groups, their expansion from initial domestication centers seems to be a plausible explanation. This can take place as a violent confrontation, through deforestation and destruction of territory, or simply through indirect impacts on natural resources by the farming communities, that force hunter gatherers to assimilate (and intermarry) or move. Although this explanation is not universal, there are numerous recent and historical examples of expanding farmers forcefully and violently replacing foraging populations. The colonization of Tasmania and Australia, as well as the European colonization of the Americas and the corresponding genocides provide stark examples of the violence that can accompany such expansions when state systems are involved (Diamond 1997).

The opposing scenario is one of cultural diffusion, where hunter-gatherer groups in territories adjacent to farming communities adopt agricultural lifeways or at least adopt some 
form of food production without the necessity of migration or genetic intermingling (Diamond and Bellwood 2003). Evidence from recent genetic and linguistic studies (Kemp et al. 2010, Malhi et al. 2003, Merrill et al. 2009) suggests this may be how the spread of agriculture into the American Southwest took place, where Southwestern Archaic populations adopted maize.

More commonly, food production spread through some combination of population expansion and cultural diffusion, involving the spread of genes, language, and culture. When the spread of farming involved the movement of people it usually, but not always, resulted in clinal genetic admixture as a result of intermarriage between immigrant farmers and indigenous foragers (Ammerman and Cavalli-Sforza 1984; Diamond and Bellwood 2003). For example, the early spread of agriculture from the Mediterranean northward into Europe resulted in higher levels of genetic admixture with early farming populations closer to the Mediterranean in comparison to European hunter-gatherers further north in places such as Ireland. According to Ammerman and Cavalli-Sforza (1984), even though language, culture, religion, and subsistence practices in northern Europe area were heavily influenced by the farming cultures of the eastern Mediterranean, the clinal genetic admixture resulted from a relatively low amount of genetic influx (Ammerman and Cavalli-Sforza 1984). Although other scenarios are possible (Fu et al. 2012; Sampietro et al. 2007), the evidence shows that the spread of agriculture often involves a complex combination of migration, intermarriage, and cultural diffusion (Ammerman and Cavalli-Sforza 1984; Diamond and Bellwood 2003).

Models in human behavioral ecology may be less reliable for explaining agricultural adoption in peripheral areas where it was spread through population migration and/or replacement. Subsistence migrant farmers in an unfamiliar area would be unlikely to abandon the means of subsistence to which they were accustomed in order to take up foraging for resources 
that may not be entirely familiar to them (but see Barlow 2002; Diamond and Bellwood 2003, 599; Phillips 2009). However, it is unlikely that this was the case with the development of farming in the Southwest (Merrill et al. 2009), so a human behavioral ecology-based theoretical approach to explaining the adoption of food production is logical in this context.

\section{Conclusion}

Although numerous factors have been proposed as catalysts for the adoption of agriculture, my focus is on testing whether the inhabitants of Turkey Pen Ruin chose to farm maize because it was profitable, or they were forced to farm due to resource depression and unprofitable foraging returns. I do not seek to test any of the specific theories described here regarding the advent of agriculture. Instead I test the conflicting assumptions about the relative efficiency of agriculture that are imbedded within these theories from the perspective of optimal foraging theory. An important element underlying both the push and pull ideas discussed in this chapter is that understanding wild resource productivity is central to understanding the implementation of agriculture. The pull model is centered on a strong preference for agriculture, since environmental productivity is expected to be generally low with diminishing returns and agriculture is considered highly efficient (Meggers 1954; Pryor 1986; Flannery 1969; 1976). The push model, on the other hand, emphasizes horticulture and agriculture as a supplement to decreases in good environmental productivity that may be temporary (Barlow 2002; 2006; Phillips 2009); this model correspondingly predicts that increased prey/resource availability can lead to a reduction in agricultural efforts. By applying HBE-based models to data from paleofecal analysis, I aim to inform on the circumstances that led the Basketmakers of Cedar Mesa to adopt maize as the central staple of their diet. 


\section{CHAPTER 3}

\section{Archaeological and Environmental Context}

This chapter contextualizes the Basketmaker II period and Turk Pen Ruin within the geography and culture history of the greater Southwest. The specific site history of Turkey Pen Ruin and the occupation history of Cedar Mesa are also detailed here. Following that, I describe the relevant environmental and geographic attributes of Cedar Mesa, in particular those that relate to plant community arrangement, available resources, and subsistence strategies at Turkey Pen Ruin. Although the American Southwest is home to numerous cultural groups including Navajo, Apache, and Hispanic populations, among others, for the purposes of this chapter, I will focus on aboriginal farming groups whose cultural heritage and genetic descent are most obviously related to the occupants of Turkey Pen Ruin - the Puebloan groups from the northern Southwest.

The American Southwest was famously defined by Erik Reed in 1964 as stretching from Las Vegas, Nevada to Las Vegas, New Mexico and Durango, Mexico to Durango, Colorado. But this brief description of a land bordered by four places with two names belies a vast region with much geological, ecological, and cultural diversity (and leaves out Utah). Although there is still some debate depending on the factors one uses to define it, the American Southwest includes Arizona and New Mexico, encompasses swaths of Utah, Colorado, and Mexico, and is sometimes considered to include parts of Texas, Nevada, and southern California (Cordell and Gumerman 2006; Cordell and McBrinn 2012; Kantner 2004, 4-7). There are few regions in the 
world that have received as much archaeological attention as the Southwest. Sparked by popular interest in "mysterious" cliff dwellings and vast, multi-storied pueblos, and spurred by spectacular preservation and the remarkable precision of tree-ring dating, there is little wonder that so many archaeologists have turned their attentions toward this region (Fowler 2000). Furthermore, the accounts and ethnographies of descendant populations offer valuable insights into their ancestral history, cultural exchange, and continuity, as well as change and adaptation during more difficult times (Colwell-Chanthaphonh 2010; Cordell and Gumerman 2006; Dozier 1964; Fowler 2000; Ortiz 1979; Ortman 2012).

\section{A Brief Culture History of the Northern Southwest}

Ethnographers and archaeologists divide the Southwest can into several culture areas based in part on material culture and language distributions. The three major culture areas associated with native farming groups are the Hohokam in the Sonoran Desert, the Mogollon extending across eastern Arizona, southern New Mexico, and into Sonora and Chihuahua, and the Ancestral Puebloan region, which covers the northern portion of the Southwest centered on the southern Colorado Plateau (Kantner 2004, 9-10). The Hohokam and Mogollon subregions shared many similarities with the Puebloan cultures to the north arising from similar adaptations for farming in arid climates and millennia of cultural exchange (Cordell and Gumerman 2006; Kantner 2004). Populations in all three areas share corn, bean, and squash agriculture adopted from Mexico, certain architectural similarities (though the Hohokam never developed multi-story pueblos), traditions of turkey husbandry, long distance trade networks and a long history of ceramic production. Cultural differentiation both within and between these subregions generally increased through time with some exceptions. From approximately $500 \mathrm{BC}$ to $\mathrm{AD} 800$ (Basketmaker II through Pueblo I in the northern Southwest), these regions all displayed very 
similar material culture and architectural styles, but around AD 800 greater regionalization of ceramic styles, architecture, and settlement layouts began to emerge (Cordell and Gumerman 2006, 7-9).

\section{Ancestral Pueblo}

The Ancestral Pueblo region (formerly called Anasazi) is the homeland of the Puebloan groups descended from Basketmaker II archaeological cultures. This region is home to many of the archaeological and cultural wonders for which the American Southwest is most famous, including Mesa Verde, Chaco Canyon, and Bandelier National Monument. Modern Pueblos are maize-reliant farming peoples who traditionally construct and inhabit multi-story adobe or stone apartments with public plazas and semi-subterranean religious structures called kivas (Cordell and Gumerman 2006; Fowler 2000; Keegan 1999). This specific pattern developed over the course of centuries. For instance, the kiva was not always a purely ritual structure (Lipe 2006, 264-268). Also, the configuration and orientation of pueblos is dependent on temporal and geographic context, and the plaza has not always been a central architectural feature (Lipe 2006). Nonetheless, this general description is broadly applicable among modern Pueblo groups after Pueblo III.

Although many common threads run through the modern Pueblo cultures, this region exhibits a great deal of linguistic and cultural diversity across time and space (Dozier 1964; Fowler 2000; Keegan 1999; Ortman 2012). Modern Pueblos speak languages from six different families or sub-families (Hopi, Keres, Tewa, Tiwa, Towa, and Zuni), as well as English and Spanish. Villages generally house mission churches established by the Spanish, and communities practice a mix of Christian and native religion (Keegan 1999; Parsons 1939). Religious practices include traditional plaza dances, the use of prayer sticks, kiva ceremonies, and clown and 
Kachina performances and rituals. The Eastern Pueblos maintain a ritual calendar marked by public dancing and feasts; major feast days are often associated with a patron saint and is generally accompanied by a special Catholic mass (Keegan 1999, 11; Parsons 1939).

Geography is central to the histories of Puebloan peoples, although tied to their native lands and places, the strings are long. Even after the advent of year-round occupations in the Basketmaker II period, regional abandonment, migration, and cultural reconfiguration were and continue to be central themes in Pueblo society (Cordell and Gumerman 2006; Kohler et al. 2010; Ortman 2012). Although many aspects of Pueblo culture such as farming, the kiva ritual, and patterns of inheritance have remained relatively consistent, change through movement and migration is a hallmark of Pueblo history. This was accompanied by high levels of interaction between different Pueblo communities as well as between the Pueblos and their Hohokam, Mogollon, and Athapaskan neighbors. Furthermore, depopulation of one region and movement into another was often gradual and involved resettlement into multiple areas. Consequently, direct connections between specific archaeological sites and contemporary Pueblo communities can be difficult to trace, and often a single site is tied to multiple descendant groups (Cordell and Gumerman 2006; Kohler et al. 2010; Reid 2006). Modern Puebloan groups exhibit a variety of religious customs and marriage and inheritance patterns linked to linguistic differences (Dozier 1964; Eggan 1950; Kirchhoff 1954; Ortman 2012; Parsons 1939). Paul Kirchhoff (1954) divided historic Pueblos into two larger groups based on a series of linguistic, religious, and kinship traits. The first of these groups-Hopi, Zuni, Keres, and Jemez-includes exogamous, matrilineal clans. These pueblos are organized into multiple kiva groups. Their origin stories center on human emergence from underground, they use four or six cardinal directions beginning in the north, and all maintain important ritual associations with the numbers four and seven 
(Kirchhoff 1954, 549). The second group includes Tiwa- and Tewa-speaking Pueblos composed of endogamous patrilineal clans. These Pueblos have dualistic political and ceremonial organizations involving paired kivas or kiva groups. They believe that humans emerged from underwater, instead of underground. Tiwa and Tewa religion uses five cardinal directions that begin in the east, and emphasizes multiples of three as ritually important numbers (Kirchhoff 1954, 549).

Table 3.1. Modern Pueblos in the Southwest

\begin{tabular}{|c|c|c|}
\hline Pueblo & Linguistic Association & Current Location (State) \\
\hline Hopi 3 groups/mesas & \multirow{4}{*}{ Hopi/Uto-Aztecan } & \multirow{4}{*}{ Arizona } \\
\hline $\begin{array}{l}\text { First Mesa-Walpi, } \\
\text { Sichomovi, Polacca }\end{array}$ & & \\
\hline $\begin{array}{l}\text { Second Mesa- } \\
\text { Michongnovi, Shipaulovi, } \\
\text { Toreva }\end{array}$ & & \\
\hline $\begin{array}{l}\text { Third Mesa - Oraibi, } \\
\text { Kyakotsmovi, Hotevilla, } \\
\text { Bacabi }\end{array}$ & & \\
\hline First Mesa - Hano & Tewa & Arizona \\
\hline Acoma & Keres & \multirow{19}{*}{ New Mexico } \\
\hline Cochiti & Keres & \\
\hline Isleta & Tiwa & \\
\hline Jemez & Towa & \\
\hline Kewa/Santo Domingo & Keres & \\
\hline Laguna & Keres & \\
\hline Nambe & Tewa & \\
\hline Ohkay Owingeh/San Juan & Tewa & \\
\hline Picuris & Tiwa & \\
\hline Pojoaque & Tewa & \\
\hline Sandia & Tiwa & \\
\hline San Felipe & Keres & \\
\hline San Ildefonso & Tewa & \\
\hline Santa Ana & Keres & \\
\hline Santa Clara & Tewa & \\
\hline Taos & Tiwa & \\
\hline Tesuque & Tewa & \\
\hline Zia & Keres & \\
\hline Zuni & Zuni & \\
\hline
\end{tabular}

List from Underhill 1991, page 9. 
Archaeological Chronologies

At the first Pecos Conference in 1927 A.V. Kidder presented what would later be known as the Pecos Classification (Guernsey and Kidder 1921; Kidder and Guernsey 1919). This chronology of the northern Southwest, developed by Kidder and Samuel Guernsey, began with a postulated, pre-agricultural Basketmaker I stage and extended through the Pueblo V historic period ca. AD 1600. The Pecos system been amended over the years, particularly through the application of absolute dating techniques, most notably dendrochronology (Douglass 1929). For the most part, however, Kidder's chronology defining Basketmaker periods followed by several Puebloan periods remains intact (Lipe 1999a; Table 3.2). One problem with this classification system was the implicit assumption of gradualist change that accompanied it, particularly as regards the adoption of agriculture (Lipe 1999a). This assumption does not match the current evidence of cultural change and transition in the Southwest.

Table 3.2. Chronology of the Puebloan Region of the Northern Southwest

\begin{tabular}{|c|c|c|}
\hline Paleoindian & $\begin{array}{c}>10,000-6000 \\
B C\end{array}$ & $\begin{array}{l}\text { Mobile hunter-gatherer populations, characterized } \\
\text { by small bands, atlatl technology, a large focus on } \\
\text { big game, particularly megafauna. Clovis and } \\
\text { Folsom type-sites in New Mexico. }\end{array}$ \\
\hline Archaic & $6000-2000 \mathrm{BC}$ & $\begin{array}{l}\text { Mobile hunter-gatherer populations still using } \\
\text { atlatl and dart technology, but no longer hunting } \\
\text { megafauna. Heavier reliance on ground stone } \\
\text { technology and smaller seeds. Open and rock } \\
\text { shelter settlements. }\end{array}$ \\
\hline $\begin{array}{c}\text { Early Agricultural } \\
\text { Period/Early } \\
\text { BMII }\end{array}$ & $2000-500$ BC & $\begin{array}{l}\text { Adoption of corn and squash horticulture, but } \\
\text { largely a continuation of the Archaic lifestyle. } \\
\text { Long-term seasonal cave habitation. }\end{array}$ \\
\hline Basketmaker II & $\begin{array}{c}500 \mathrm{BC}-\mathrm{AD} \\
500\end{array}$ & $\begin{array}{l}\text { Shallow pit house architecture, plus storage pits or } \\
\text { cists indicate increasing sedentism; hamlet-sized } \\
\text { settlements. Corn and squash farming dominate } \\
\text { the subsistence strategy and turkey husbandry } \\
\text { developed for feather blankets and ritual uses. }\end{array}$ \\
\hline
\end{tabular}




\begin{tabular}{|c|c|c|}
\hline Basketmaker III & AD $500-750$ & $\begin{array}{l}\text { First use of ceramics (at least for Western } \\
\text { Basketmakers), plain gray wares with some black- } \\
\text { on-white; advent of bean horticulture; bow and } \\
\text { arrow technology; deep pit house architecture. } \\
\text { Settlement size increased. First Great Kiva in } \\
\text { Chaco Canyon. }\end{array}$ \\
\hline Pueblo I & AD $750-900$ & $\begin{array}{l}\text { Unit pueblos made from jacal with some masonry. } \\
\text { Great Kivas become more common. Village-sized } \\
\text { settlements. Plain and neckbanded gray pottery. } \\
\text { Introduction of cotton (from trade) and } \\
\text { development of loom weaving. }\end{array}$ \\
\hline Pueblo II & AD $900-1150$ & $\begin{array}{l}\text { Chacoan influence - multi-story Great Houses, } \\
\text { Kivas, Chacoan "roads." Corrugated gray and } \\
\text { elaborate black-on-white pottery. Large } \\
\text { settlements. Trade with Mexico for luxury items. }\end{array}$ \\
\hline Pueblo III & AD $1150-1290$ & $\begin{array}{l}\text { Large pueblos and cliff dwellings; towers; } \\
\text { corrugated gray and elaborate black-on-white } \\
\text { pottery. Mesa Verde rises to prominence. } \\
\text { Depopulation of the Four Corners by AD } 1290 .\end{array}$ \\
\hline Pueblo IV & AD 1290 - 1539 & $\begin{array}{l}\text { Migration and integration in Rio Grande and to the } \\
\text { south. Large, plaza-oriented pueblos with a lower } \\
\text { ratio of kivas; kachina culture becomes } \\
\text { widespread. Ute and Navajo sites are present. }\end{array}$ \\
\hline Historic Period & 1539 - present & $\begin{array}{l}\text { Marked by the Spanish arrival. Population decline } \\
\text { due to the introduction of European diseases and } \\
\text { violent conflict. Sheep husbandry and horses } \\
\text { adopted by some groups. Mormons arrive at Cedar } \\
\text { Mesa in } 1880 \text {. Establishment of reservations. }\end{array}$ \\
\hline
\end{tabular}

Sources: Cordell and Gumerman 2006, Kantner 2004; Kidder 1927; Lipe 2015; Matson 1991

The chronological history of the American Southwest is well-established due in large part to three factors: excellent preservation of wood for tree-ring dating, excellent organic preservation for radiocarbon dating, and readily distinguishable ceramic traditions (Fowler 2000; Lipe 1999a). However, multiple chronologies and cultural phases are necessary to describe intraregional complexity and to explain the differing rates of change and cultural adaptations that occurred throughout the various sub-regions described above, which is beyond the scope of this 
dissertation. The timeline specific to the northern Southwest (Ancient Puebloan) subregion is shown in Table 3.2.

\section{Basketmaker II Subsistence and Culture}

The Adoption of Agriculture in the Southwest

By 2,500 BC Southwestern peoples had begun to incorporate maize-based horticulture into their diet (Drake et al. 2012; Hall 2010; Matson 1991; Smiley 1994; 1998). Archaeologists have long debated the nature of maize's movement into the Southwest, whether it occurred via population migration, cultural diffusion, or some combination thereof (Roth 2017). The migration model states that farmers migrated into the Sonoran Desert and Tucson Basin from Mexico settling along arable alluvial plains. These migrants brought maize, language, and a suite of cultural traits with them as they advanced from southern Arizona to the Colorado Plateau (Berry and Berry 1986; Hill 2001; 2002; Huckell 1995; Matson 2002; Roth 2017). The linguistic argument for this model is based on purported the movement of Proto-Uto-Aztecan from Mexico northward to the Great Basin (Bellwood 2001; Hill 2001; 2002). Although initially these linguistic data were more strongly supported by corresponding genetic evidence (Hill 2002), more current mitochondrial DNA data do not support migration of women from Mexico into the Sonoran Desert or further north (Kemp et al. 2010; Malhi et al. 2003; Merrill et al. 2009). This does not preclude the possibility of male-driven migration, but given the patterns of other documented migrations in the Southwest, and the centrality of women's work to an agricultural economy, it seems unlikely that men would be the exclusive drivers bringing maize into the Southwest (Merrill et al. 2009; Roth 2017). 
Proponents of the migration model postulate that Western Basketmakers are a far northern expansion of this migration. Specifically, R.G. Matson $(1999 ; 2002)$ has argued that the BMII populations of Cedar Mesa were migrants from the southern Southwest who were heavily dependent on agriculture prior to their arrival. This claim is supported by differences in material culture (especially stone tools and house structures) between Eastern and Western Basketmakers, and shared traits between Western BMII peoples and San Pedro Cochise farmers from further south (Matson 1999; 2002). However, other researchers have questioned Matson's conclusions based on the wide distribution of these material traits, potentially rendering them undiagnostic in this regard (Roth 2017, 29). Isotopic evidence clearly demonstrates that earliest BMII inhabitants of Cedar Mesa were fully reliant on maize (Coltrain et al. 2007; 2012; Coltrain and Janetski 2013), but this is not conclusive evidence that Western Basketmakers were part of a larger migration of farming communities into the Southwest. These populations could have derived from indigenous Archaic foragers who adopted maize farming before arriving at Cedar Mesa.

The opposing indigenous adoption model states that maize horticulture was adopted by Archaic foraging populations and incorporated into their subsistence exiting subsistence strategy (Irwin-Williams 1973; Roth 2017; Wills 1988, 36). According to this model, the adoption of food production and degree of reliance on maize was contingent upon local population density and environmental circumstances. Maize adoption was largely motivated by predictability and storability under this model; these two traits made maize a suitable supplement to foraged foods as a risk-management strategy (Irwin-Williams 1973; Roth 2017). Although proponents of the migration model have pointed to evidence of sudden demographic shifts in the south, Bradley Vierra (2008) observed that shifting patterns of landscape use by local Archaic peoples in response to changing subsistence adaptations would mirror the effect of immigrating farming 
populations in the archaeological record. The linguistic evidence for the migration model has also been questioned. Merrill et al. (2009) proposed that the Proto-Uto-Aztecan language family originated in the Great Basin and moved southward. They argue that the absence of linguistic cognates for maize-related terms between the Southern Uto-Aztecan (e.g., Mesoamerican, Tarahumaran, O’odham) and Northern Uto-Aztecan languages (e.g., Hopi and Numic languages) strongly suggests an earlier linguistic expansion, unrelated to the diffusion of agriculture (Merrill et al. 2009). Other lines of evidence including genetics and archaeological evidence indicate this initial expansion took place during the mid-Holocene (Merrill et al. 2009).

If the indigenous adoption model is supported, then there should be a period of supplemental use of maize prior to reliance on it as a dietary staple (Irwin-Williams 1973; Roth 2017). In the northern Southwest this is consistent with the Early Agricultural Period, during which maize served a supplemental role than in BMII. However, this period is not evident at Cedar Mesa, potentially supporting Matson's (1999, 2002) assertions.

\section{Basketmaker II Maize Dependence}

As stated above, at the outset of its adoption, maize was supplemental to a diet more dependent on gathered plants and hunted animals (Haury 1962; Minnis 1985; 1989; Reed 1974; Wills 1988; Woodbury and Zubrow 1979), but at some point during BMII, foraging became secondary to agricultural pursuits (Geib and Spurr 2002; Huckell et al. 2002; Lipe 1999b; Matson 1991). BMII diets varied based on the specific degree of reliance on horticulture versus foraging, as well as differences in the local ecology and types of forage targeted (Androy 2003; Matson 1991; 2006a, b). Isotopic analyses of bone collagen from late BMII human remains in the Four Corners show that the level of maize consumed from ca. $400 \mathrm{BC}$ to AD 400 was on par with that of subsequent cultural periods and was significantly greater than that eaten by earlier 
populations (Chisholm and Matson 1994; Coltrain and Janetski 2013; Coltrain et al. 2006; 2007; 2012; Hurst et al. 2011; Martin 1999; Matson and Chisholm 1991; 2007). Other C4 plants (pigweed/amaranth (Amaranthus spp.), dropseed (Sporobolus spp.), and saltbush (Atriplex canescens)) and CAM plants (cacti and yucca) (Coltrain et al. 2007, 308) can contribute to this signal, as can C3-dependent meat resources, so the incorporation of macrobotanical studies is also important for establishing the level of maize inclusion in the diet.

Studies based on paleobotanical evidence corroborate conclusions based on the isotopic data, and further support maize reliance during BMII (Aasen 1984; Androy 2003; Cordas 2000; Hard et al. 1996; Lepofsky 1986; Radomski 1999). Furthermore, Reinhard et al. (1987) found that inhabitants of Cedar Mesa had a pinworm (Enterobius vermicularis) infection rate of approximately $30 \%$, which is consistent with a sedentary agricultural lifestyle (Bryant and Reinhard 2012; Reinhard et al. 1987). However, since these samples were excavated as part of the salvage project conducted by Margaret Powers (1984), their temporal attribution is uncertain and potentially included specimens from the Pueblo II-III occupation, as well as BMII paleofeces.

BMII was the principal formative period in the history of the American Southwest; the development of farming-based economies during this period gave rise to advances in food production still used by Puebloan peoples today (Ford 1984; Lipe 1999b; Matson 1991; 2006b, Reed 1954). Although the Basketmaker III period exhibited more rapid technological development, including bow-and-arrow technology, bean horticulture, and widespread use of ceramic storage and cooking containers, BMII encompasses the cultural and economic transition from foraging to farming society. Turkey husbandry (Lipe et al. 2016; Nott 2010; Speller et al. 2010), permanent settlements and the origins of the pit house (Lekson 1985; Matson 1991, 44; 
Morris and Burgh 1954), clustered mesa-top settlements (Dohm 1994), the first ceramics in the Southwest (Eddy 1961; 1966; Sesler and Hovezak 2011; Skibo and Blinman 1999), and heavy reliance on agriculture can all be traced to BMII times (Charles and Cole 2006; Chisholm and Matson 1994; Coltrain et al. 2006; 2007; 2012; Lipe 1999b; Martin 1999; Matson 1991; 2006b; Matson and Chisholm 1991; 2007). Since this period was central to the development of agricultural reliance, information on diet and nutritional supplementation of maize during BMII can lead to a better understanding of how the Southwest economic complex based on corn, bean, and squash farming ultimately evolved.

BMII is a temporally broad and geographically widespread archaeological culture. It spanned 1000 years across hundreds of square miles of the Colorado Plateau. BMII populations can be spatially categorized into at least two probable ethnic groups (Eastern and Western Basketmaker), and these can be further differentiated by several spatio-temporally distinct cultural phases (Haase 2006; Lipe 1999a, b; Matson 1991; 2006b, Morris and Burgh 1954; Smiley 2002). The designation of BMII is largely based on general mode of subsistence and its resulting cultural traits. BMII peoples were pre-ceramic, semi-sedentary maize horticulturalists who lived in permanent household or hamlet-level settlements (Matson 2006b). Like their Archaic predecessors, they relied on one-hand manos and metates to grind their food, and they excavated various types of cists, often into the floors of pit houses, as storage facilities. They hunted with atlatls but generally did not eat much meat (Matson 2006b). Farming methods and occupational settings varied temporally and by region, as did some architectural details.

Although maize dependence in these populations has been established, a maize-based diet does not offer complete nutrition. Several essential vitamins and nutrients are insufficiently supplied by maize, including lysine, vitamin A, vitamin C, B-complex vitamins, and iron, as 
discussed in further detail in Chapter 5 (Bressani et al. 1997; Spielmann and Angstadt-Leto 1996; USDA 2012). Before the advent of bean horticulture ca. AD 500 (Geib and Spurr 2000; Wormington 1961), it is unclear how these populations adequately supplemented their maizebased diet and obtained these and other essential nutrients in the absence of substantial amounts of meat. There is evidence that nixtamalization (alkali cooking) by limestone boiling enhances the accessibility of some nutrients present in maize (Ellwood et al. 2013), but additional supplements would still be required in circumstances of heavy reliance on corn. Specifically, nixtamalization prevents pellagra — a disease caused by nutritional deficiency that affects the skin, digestive, and nervous systems — by increasing the digestibility of niacin. Further, nixtamalization provides better access to some essential amino acids present in maize such as methionine, tryptophan, and lysine (Bressani et al. 1997; Ellwood et al. 2013). Nevertheless, even nixtamalized maize does not contain sufficient quantities of amino acids to meet human nutritional needs (Bressani et al. 1997; Matson 2016; Spielmann and Angstadt-Leto 1996).

Meat, including turkey (Meleagris spp.), offers one possible nutritional supplement to complement maize (Spielmann and Angstadt-Leto 1996). However, current evidence does not indicate the inclusion of much animal protein in BMII diet at Turkey Pen Ruin (Cooper et al. 2016). Some have even suggested that the BMII diet at Turkey Pen Ruin was very nearly vegetarian (Matson and Chisholm 1991); although given what we now know, this assessment is appears to overestimate the degree of plant dependence at the site. Turkey husbandry during BMII is apparent (Lipe et al. 2011; 2016; Nott 2010; Speller et al. 2010), but there is no evidence supporting regular use of turkey meat at Turkey Pen Ruin based on isotopic or coprolite studies (Aasen 1984; Cooper et al. 2013; 2016; Lipe et al. 2016). In light of the above, questions about 
subsistence and nutrition from this period should center on supplemental plant foraging habits and possible supplemental meat consumption.

With no bean horticulture and without evidence supporting significant inclusion of meat in their diet, foraged plants offer an alternative primary supplement for incomplete maize nutrition during BMII at Turkey Pen Ruin. Uncultivated plant resources such as amaranth, chenopodium, purslane (Portulaca spp.), pine nuts (Pinus edulis), and Indian ricegrass offer excellent supplements to maize (Bressani et al. 1987; 1997; Gebhardt and Thomas 2007; Matuz et al. 2000; Pal and Prakash 1998; Simopoulos 2004; Thomas and Gebhardt 2006). Some of these plants such as chenopodium and amaranth also yield edible greens that provide easily accessible nutrients, but their protein-rich seeds are relatively low ranked due to high collection and processing costs (see Chapter 5 for nutrition information and caloric return rates). Inclusion of these low ranked items could indicate of a lack of access to higher ranked resources such as pine nuts that provide more calories and nutrients for less effort. Alternatively, some of these plants are drawn to areas disturbed by humans and tend to grow at higher rates in shade-free environments such as agricultural fields. Consequently, these weedy annuals could have provided a convenient and nutritious supplements to corn, despite their presumed low rank in the diet.

The use of weedy annuals as a supplement to maize agriculture is ethnographically documented among the Tarahumara of northern Mexico (Bye 1981; Kahl 1987), who also rely heavily on plant resources with little supplemental animal protein (Cerquiera et al. 1979). Furthermore, several of the plants that would have grown in and around agricultural fields also have medicinal qualities: amaranth and purslane can help alleviate diarrhea and other ailments (Simopoulos 2004; Kalinova and Dadakova 2009) and chenopodium has anti-parasitic properties 
(Kliks 1985). These properties would have been advantageous in an increasingly sedentary population experiencing high rates of infection. In short, information on specific plants and how they contributed to the diet at Turkey Pen Ruin enables us to build on current understandings of resource availability, diet breadth, and subsistence choices during this crucial time in Pueblo prehistory.

\section{Site Description}

The paleofeces incorporated into this study were all excavated from Turkey Pen Ruin, a dry rock shelter site nestled deep within upper Grand Gulch in the northwest portion of Cedar Mesa (Figures 3.1 and 3.2). Turkey Pen Ruin is one of the longest-occupied sites on Cedar Mesa, inhabited intermittently for hundreds of years during the BMII, BMIII, and Pueblo II-III periods (Aasen 1984; Bedell 2000; Lipe et al. 2011; Powers 1984). The site is composed of two levels with several rooms for occupation and storage as well as one subterranean kiva dating to PII or III, and one above-ground kiva dating to PIII (Bedell 2000; Powers 1984); the larger, lower level is easily accessible on foot, while the higher level can only be accessed by ladders or climbing and appears to house only storage rooms and the above-ground kiva (Figures 3.3a, b, and c). Rock art is abundant including handprints, simple geometric shapes, and anthropomorphic and animal images, and axe grinding slicks occur in clusters, primarily in southwestern portion of the lower level (Figures 3.4a and b). Smoke stains on the roof of the rock shelter delineate the locations of house walls (both currently standing and no longer present). The cliff overhang provides a pleasant view to the southeast into Grand Gulch and serves as an effective shelter from the heat of the afternoon sun in summer (Powers 1984). Evidence for BMII occupation (other than the associated dates and paleofeces) includes jar-shaped cists excavated into the floor of the shelter as well as some of the rock art at the site (Bedell 2000, Powers 1984). 


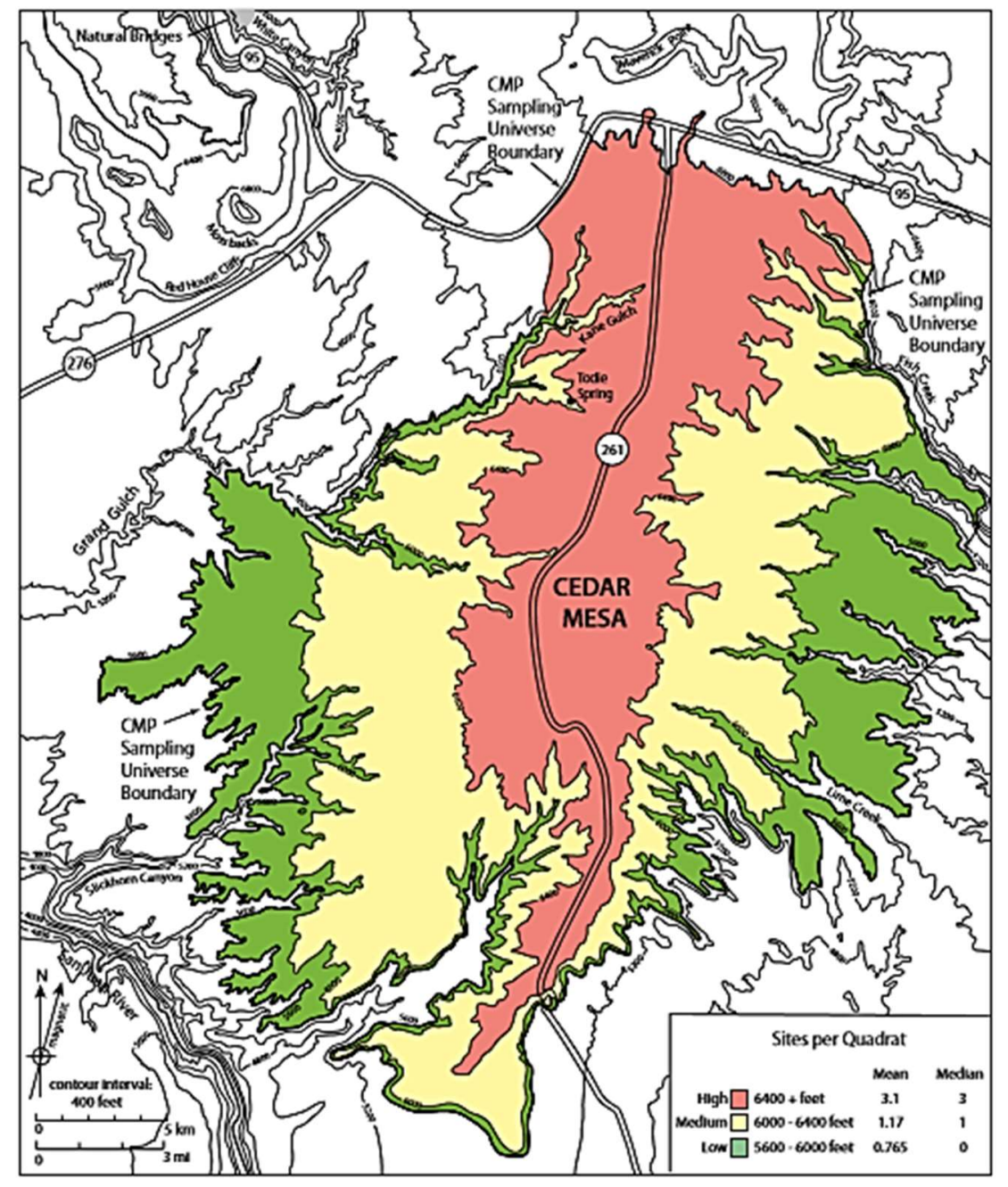

Figure 3.1. Map of Cedar Mesa and Cedar Mesa Project area with color coding for elevation. Map by Sue Matson, provided courtesy of William D. Lipe. 

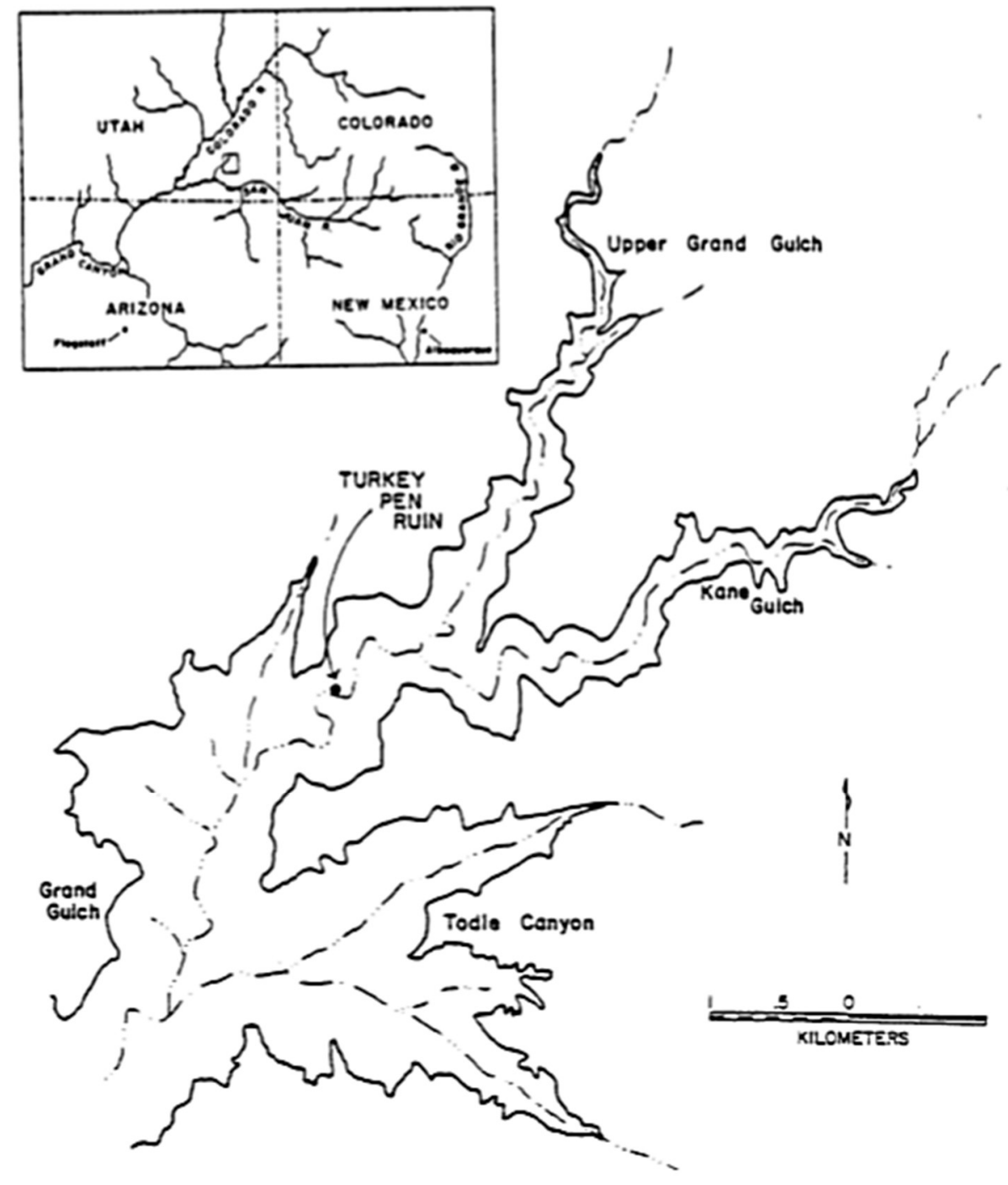

Figure 3.2. Map showing location of Turkey Pen Ruin within upper Grand Gulch. Figure from Aasen 1984, 15: Figure 1. 

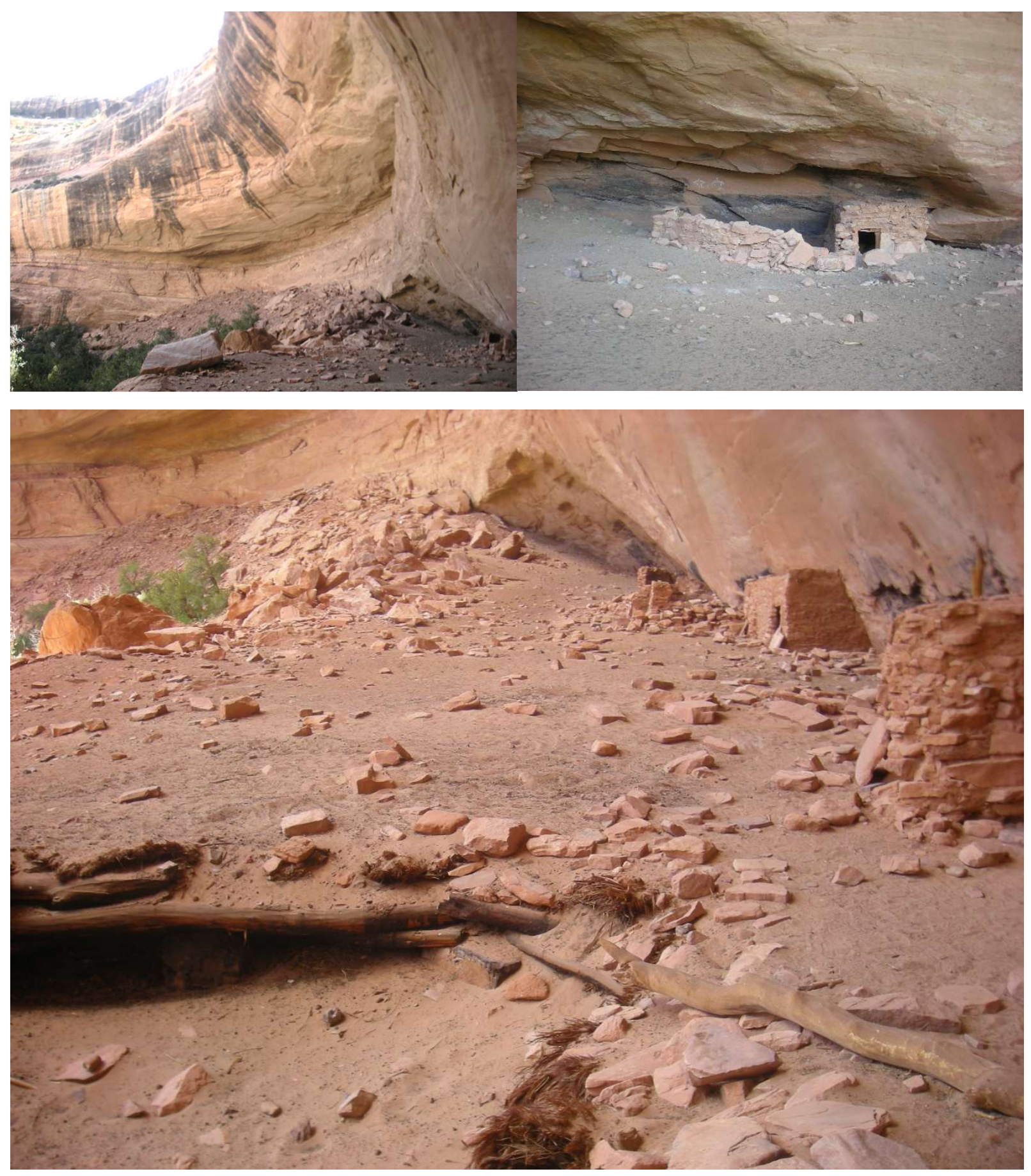

Figure 3.3a. The rockshelter overhang. (top left)

Figure 3.3b. Puebloan house structures with soot stains and BMII period rock art. (top right)

Figure 3.3c. View from within Turkey Pen Ruin. (bottom) This figure shows a portion of the subterranean kiva, the remains of some of the Puebloan structures. Remnant masonry is visible on the upper shelf of the rockshelter in the top left portion of the image. 
Precipitation in this area is unpredictable, however, water can be accessed from springs at the canyon heads, canyon stream beds, and mesa-top potholes (tinajas) (Matson et al. 1990, I-9; West 1978). Abundant, diverse local plant life would have provided inhabitants with construction materials, materials for basketry and other crafts, medicinal resources, and of course forage. The sandstone all around the site can be used to make grinding implements and Cedar Mesa's high quality limestone is ideal for stone boiling (Ellwood et al. 2013; Holstad 2010; Matson 2016,28). Animal resources, particularly big game, are not thought to have been very abundant in this area during BMII times (Matson 1991). However, Turkey Pen Ruin has some of the earliest evidence for turkey domestication in the Southwestern United States (Lipe et al. 2016; Nott 2010; Speller et al. 2010). Strong evidence supporting turkey husbandry at Cedar Mesa and Turkey Pen Ruin has been dated to the BMII period (Lipe et al. 2016; Nott 2010; Speller et al. 2010), and the site itself is named for a turkey pen associated with the later Puebloan occupation (Lipe et al. 2016; Matson 1991).

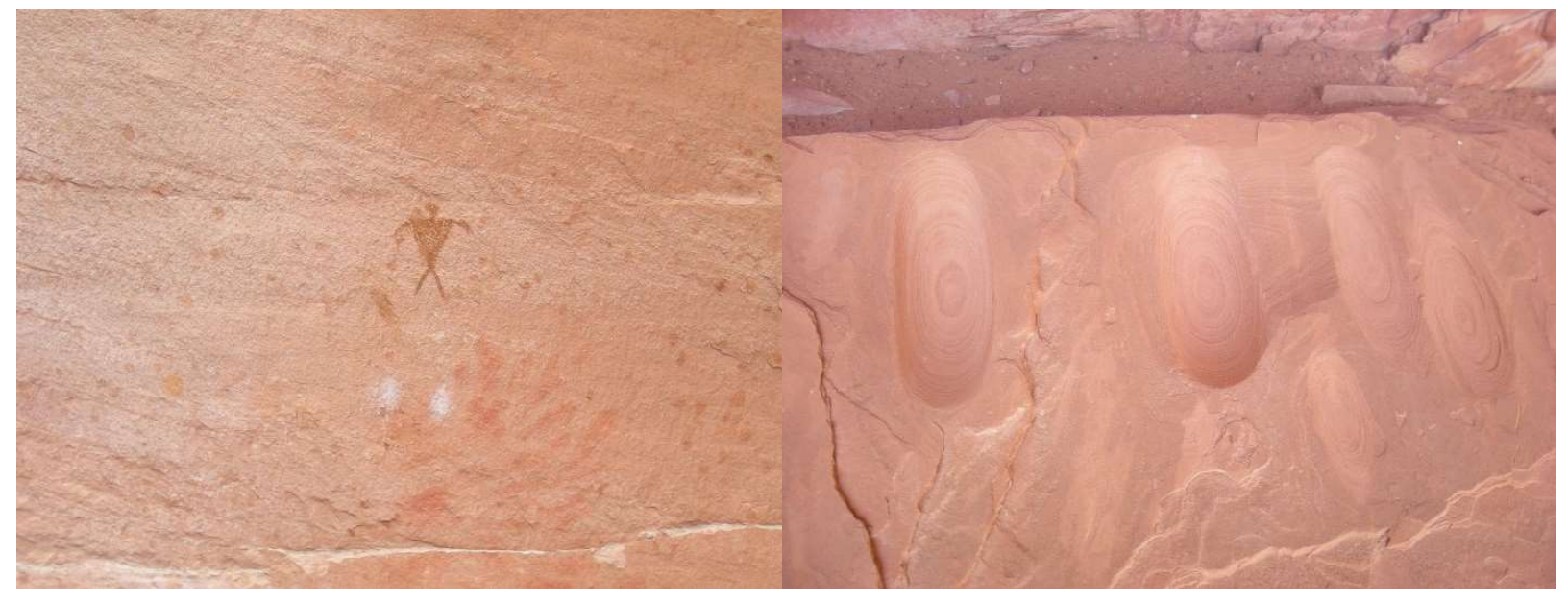

Figure 3.4a. Rock art.

Figure 3.4b. Axe grinding slicks from Turkey Pen Ruin. 
Although not grandiose, Turkey Pen Ruin is an archaeologically interesting and beautifully situated site. However, much of the published data and information derived from the site has come not from the architecture and rock art, but from a 50 x $50 \mathrm{~cm}$ stratified midden column and the associated side clearing excavated by R.G. Matson and a team of archaeologists in 1972 as part of the Cedar Mesa Project (Figure 3.5). This column was excavated using a "Junius Bird" method of exposing and isolating a single stratified segment in order to ultimately transport a portion of intact sediment and sediment layers to the laboratory for future research (Matson 2015). All but the topmost layer of this midden appears to have been deposited during the BMII occupation and has yielded numerous, well-preserved organic remains, including an abundance of human and animal paleofeces (Aasen 1984; Kemp et al. 2009; Lipe et al. 2011; Matson 1991; Nott 2010). The excavated portion of the midden also contained numerous corn cobs, quids, feathers, human hair, egg shells, and other plant and animal remains (Cordas 2000; Lepofsky 1986; Lipe et al. 2011; Radomski 1999). Multiple MA theses (Aasen 1984; Cordas 2000; Nott 2010), conference presentations (Battillo et al. 2014; 2016; Cooper et al. 2013; Kemp et al. 2009; Nott et al. 2009; Wyatt et al. 2009), and publications (Cooper et al. 2016; Lipe et al. 2011; 2016; Speller et al. 2010) have been either partially or wholly written on the contents of this midden. Studies on the Turkey Pen Ruin midden have provided invaluable data on Basketmaker II diet, turkey domestication, and ancient human genetics. Since previous research has demonstrated a high degree of spatial variation in supplemental dietary plant use in the Southwest (Androy 2003; Minnis 1989), a large amount of data from a single site allows the study of resource choice, without space as a confounding factor.

Given the quantity and quality of the information that has been gleaned from this single midden column, it is especially unfortunate that only a few years after its excavation, a large 
portion of Turkey Pen midden was pillaged by looters in 1979 (Matson 2015; Powers 1984).

This destruction spurred a salvage excavation, led by Margaret Powers (1984), which resulted in further coprolite analysis (Reinhard 1987) and the recovery of more Basketmaker material (sandals, Z-type twisted cordage, and chapalote maize) as well as Puebloan materials (Powers 1984). The two looters responsible for the 1979 vandalism were prosecuted under ARPA and convicted of damage to government property, but this is cold comfort in light of the damage incurred from multiple episodes of looting (Green and Hanks 1985; Lipe et al. 2016; Powers 1984).

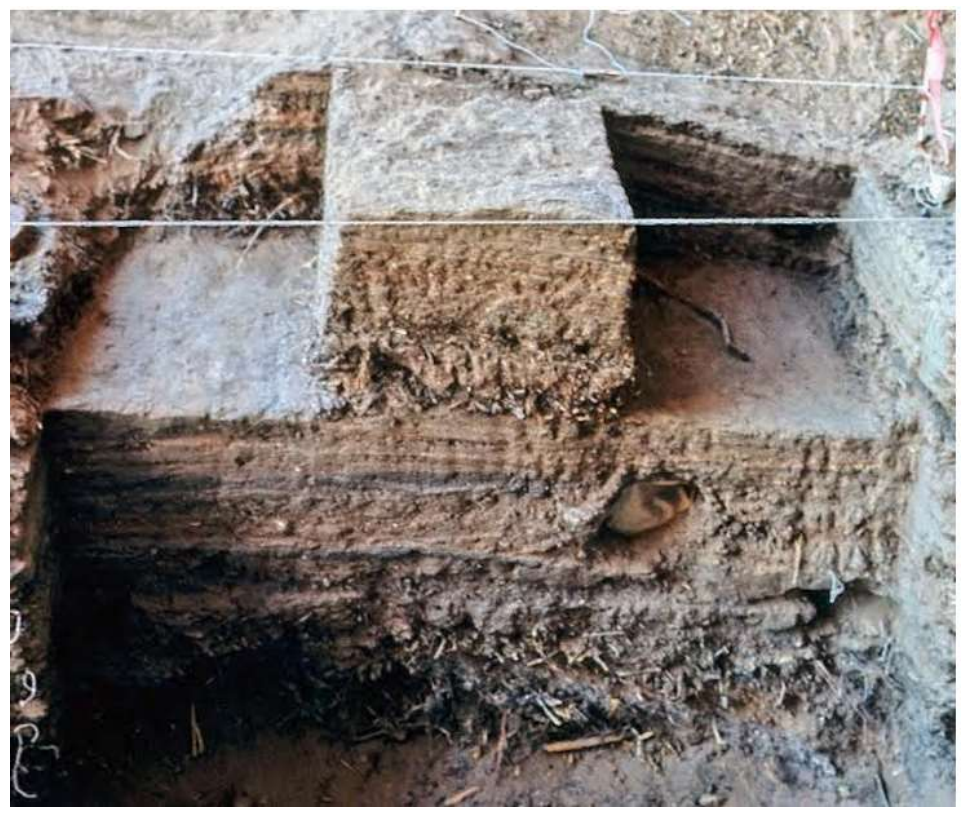

Figure 3.5. Partially isolated midden column. Photograph courtesy of R.G. and Susan Matson.

Calibrated radiocarbon dates from the Turkey Pen midden column span from approximately $90 \mathrm{BC}$ to $\mathrm{AD} 540$ (Figure 3.6), incorporating the latest portion of the White Dog cultural phase (500 BC - ca. $1 \mathrm{AD})$ and extending through the terminal Grand Gulch phase (AD 200 - 400) (Aasen 1984; Lipe et al. 2011; Matson et al. 1990). The Grand Gulch Phase, established by Matson and colleagues during the Cedar Mesa Project, is a bit of a misnomer 
given its association with dry, mesa-top farming and movement away from canyon-based floodwater farming (Matson 1991; Matson et al. 1990). Clovis and Archaic use of Cedar Mesa is evident (Cole 1993; Coltrain et al. 2007; Davis and Till 2014; Geib and Davidson 1994), but the vast majority of the occupation is from BMII and later periods. The preponderance of BMII occupations fall within the Grand Gulch phase (Matson et al. 1990).

The midden dates from Turkey Pen Ruin also encompass an unnamed time period between AD 1 and 200 that has sometimes been grouped with the White Dog or Lolomai phases (Matson 1991). The White Dog phase is so named for the mummified dog burials found in White Dog Cave, Arizona and is generally attributed to rock shelter sites older than 2000 years, although some later BMII occupations have also been tied to this phase (Geib and Spurr 2000; 2002; Matson 2006). This phase is also characterized by floodwater farming, one-hand manos, two-rod-and-bundle basketry, and less dependence on corn than subsequent phases (Matson 1991). The later Lolomai phase dating approximately AD 50 to 250 (Matson 1991; Smiley 1985) is commonly associated with open-air pithouse occupations in areas suitable for floodwater farming on Black Mesa. However, this difference may be an artifact of geography rather than a cultural variation, since Black Mesa can be distinguished from Cedar Mesa by its many broad washes and poor-quality upland soil. These combined factors would have encouraged the Lolomai Basketmakers to pursue floodwater rather than mesa-top farming and occupations (Matson 1991).

Although there is a later date of around $\mathrm{AD} 1045$ from the uppermost portion of the column, all samples in this study come from levels dating approximately $100 \mathrm{BC}$ to $\mathrm{AD} 500$ (Aasen 1984; Kemp et al. 2009; Lipe et al. 2011; Matson 1991; 2015). Turkey Pen Ruin lacks some of the defining traits of the Grand Gulch phase. For instance, this phase is characterized by 
an occupational shift to new areas with an increasing use of mesa tops rather than rock shelters (Dohm 1994; Matson 1991; 1994; 2006a, b; Matson et al. 1990). Prior to this phase, Western BMII peoples are thought to have used floodwater farming techniques, with fields in broad washes and other low lying areas. This type of farming was likely facilitated by ease of access since prior to the Grand Gulch Phase BMII peoples generally lived in rock shelters (Lipe 1966; Matson 1991; 2006a, b; Smiley 1994; 1998; Smiley and Gumerman 1986). During the Grand Gulch Phase, dry farming on mesa tops led to occupations in dispersed hamlet clusters at higher elevations and a movement away from canyons and rock shelters (Coltrain et al. 2012; Dohm 1994; Hurst et al. 2011; Matson 1991; 1994; 2006a, b; Matson et al. 1990). Mesa-top Grand Gulch Phase inhabitants of Cedar Mesa had settlement patterns remarkably similar to BMIII and Puebloan peoples, likely indicative a similar approach to subsistence farming (Dohm 1994). Settlements during this period were often built in areas with dense pinyon-juniper woodlands, which grow in the deepest and most productive mesa-top soils - a good gauge of higher precipitation (Haase 1983; Matson 1991, 83-92). Since Turkey Pen Ruin is a rock shelter habitation falling into this time period, dietary research could inform on a wider range of adaptive strategies and help to explain what motivated people to move to the mesa tops. Furthermore, radiocarbon dating conducted on eight of the paleofecal samples, in conjunction with the midden stratigraphy and associated dates, can potentially help to illuminate dietary shifts associated with the Grand Gulch phase. 


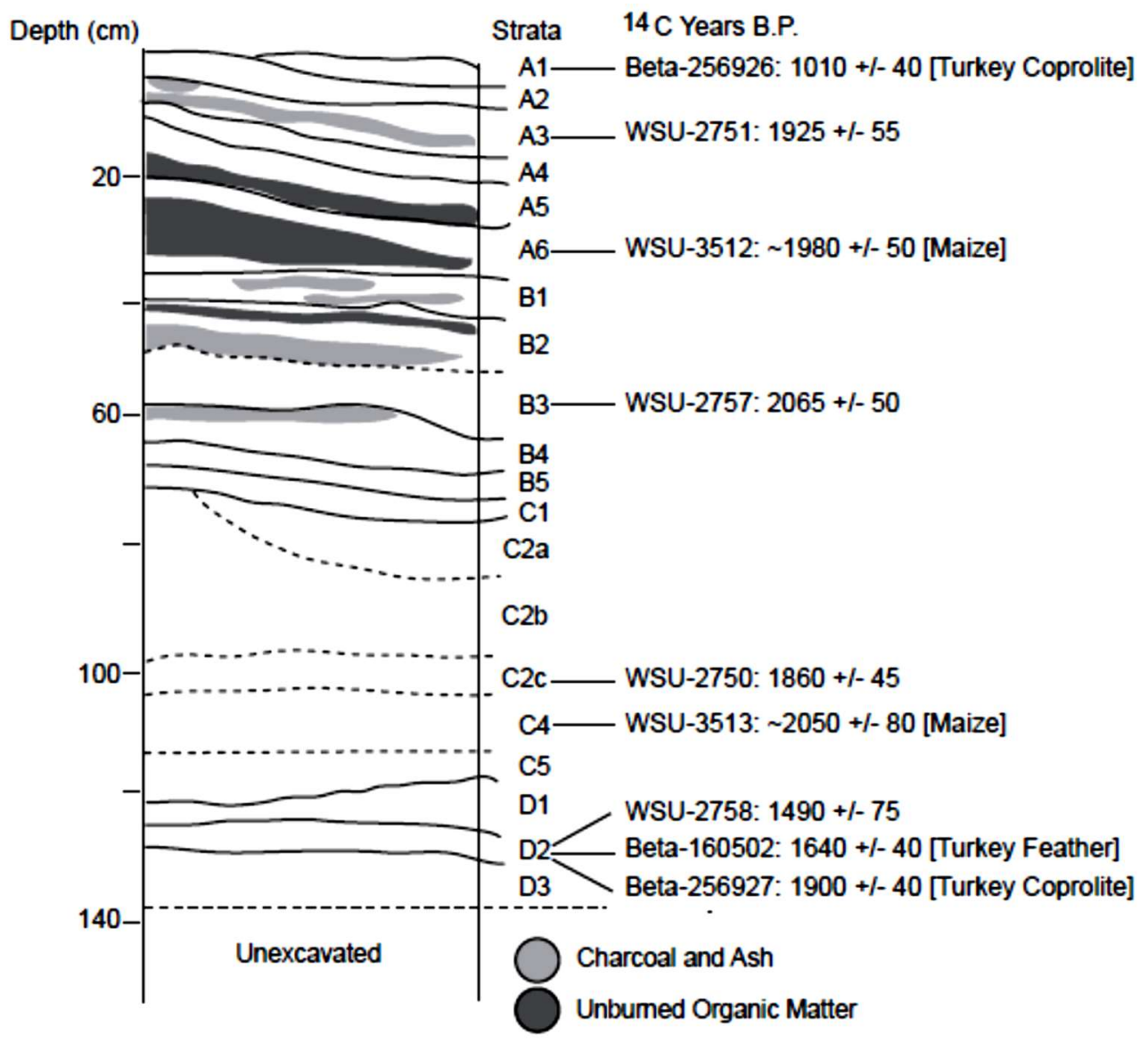

Figure 3.6. Turkey Pen Ruin midden profile with associated radiocarbon dates. Figure from Lipe et al. 2011.

Previous analyses of the macrobotanicals and paleofeces from the midden indicate mixed consumption of maize, wild plants, and weedy annuals (Aasen 1984; Lepofsky 1986; Reinhard 1992). Analyses of macrobotanical remains, paleofeces, and midden flotation samples identified corn, squash (Cucurbita spp.), amaranth, ragweed (Ambrosia spp.), banana yucca (Yucca baccata), pine nuts (Pinus edulis), and an abundance of quids (Cordas 2000; Lepofsky 1986; Powers 1984; Radomski 1999; Reinhard 1992). Aasen (1984) analyzed 28 human paleofeces (and two turkey droppings) from Turkey Pen Ruin and found that maize, pine nuts, and Indian ricegrass were the three most common food items. Based on the additional presence of beeweed (Cleome spp.) pollen, and other seasonal plant remains, Aasen (1984: 63-64) concluded that most 
of the plants eaten by inhabitants were harvestable from early summer to fall, although she did not rule out the possibility that some specimens with low pollen concentration values were attributable to a winter occupation. In a later study incorporating Aasen's data, Jerry Androy (2003) concurred that Turkey Pen Ruin was likely a late spring through fall occupation, as did Dana Lepofsky (1986) in her study of the macrobotanical remains from the midden matrix (see Matson 1991, 94-97). However, not all of the data are in accord with this inference, especially since many of these summer/fall plants are storable and because Indian ricegrass (found by Aasen) and stickyweed (Mentzelia spp.) (found by Lepofsky) commonly peak in spring. Further testing on a larger sample could help to support Aasen's conclusion or could support a yearround occupation. Although conventional wisdom holds that Basketmaker II peoples were seasonally mobile, their heavy dependence on maize indicates that these groups were more sedentary than previously thought (Matson 1991). Nelson (1994) also shows that sources for lithic tools were predominantly local and thus indicated raw material procurement patterns similar to those of later occupations on Cedar Mesa. Furthermore, Reinhard and Jones (1987) discovered evidence of spring occupation during their analysis of 25 unprovenienced coprolites from the Turkey Pen "cleanup" project, but due to the lack of specific context and the presence of beans in two of these samples, the temporal association is less certain (Androy 2003; Matson 1991).

More recently, researchers have taken an interest in turkey husbandry at Turkey Pen Ruin. As with much modern research on domestication (Zeder et al. 2006), studies of turkey domestication in the US Southwest have benefited from aDNA evidence, some of which has come from Turkey Pen Ruin (Nott 2010; Speller et al. 2010). A large number of turkey feathers, some bones, and feces were recovered from the site, and the dietary constituents and mtDNA 
from the turkey feces associated with the midden have been analyzed to determine the origins of turkey domestication in the Four Corners region (Lipe et al. 2011; Nott 2010; Speller et al. 2010; Wyatt et al. 2009). Based on the high occurrence of corn relative to wild resources, Nott (2010) concluded that turkeys were being kept and fed. Moreover, researchers investigating mtDNA found that the birds kept at Turkey Pen Ruin originated in North America and were not from domesticated Mexican stock, as was previously thought (Speller et al. 2010, Wyatt et al. 2009). Interestingly, the advent of turkey husbandry appears to have had no measurable effect on BMII diet. Recent work using isotope analysis of a single strand of hair from Turkey Pen Ruin shows it is unlikely that people consumed turkeys (Cooper et al. 2013, 2016). Cooper and colleagues $(2013,2016)$ similarly found that nitrogen isotope levels of a human hair did not place its owner on a higher trophic level than turkeys, indicating that neither turkey meat nor eggs were a regular part of the diet. If not raised as a source of supplemental protein, turkeys likely provided feathers and bones for blankets and ritual use (Lipe et al. 2016; Speller et al. 2010), and possibly provided valuable pest control services (Stiger 1979). Furthermore, relatively few faunal remains were recovered from Turkey Pen Ruin, supporting arguments for little meat consumption (Aasen 1984; Cooper et al. 2013; Matson and Chisholm 1991) and leading some to suggest that the prehistoric occupants of Cedar Mesa had limited hunting opportunities (Androy 2003; Matson 1991; Powers 1984). Reinhard and Jones (1987) found bone in 12 out of the 25 paleofecal samples they analyzed, and animal hair and feathers in others, but Aasen (1984) found bone in only four out of 28 samples. Since Reinhard and Jones' specimens were unprovenienced and given that Aasen's data is much more in line with other findings from the BMII occupation of this site, the preponderance of evidence still indicates that meat consumption among was low. If 
this is the case, then wild plants would have been vital sources of essential amino acids, iron, and other nutrients lacking in maize prior to the advent of bean horticulture in the area.

\section{Environmental and Ecological Context}

\section{Geography and Climate}

Cedar Mesa as a physiographic landform is loosely defined as the portion of monument upwarp bordered by Comb Ridge on the east side, the Elk Ridge escarpment to the north, Redrock Cliffs to the west, and the San Juan Canyonlands to south (Figure 3.7). The topography is characterized by broad, billowing mesa-tops incised by deep, narrow canyons like Grand Gulch (Matson 1991, 102; Matson et al. 1990). The mesa itself is composed of Permian-age, calcareous Cedar Mesa sandstone, interspersed with lenses of shale and limestone (West 1978, 13). Matson and colleagues defined the Cedar Mesa Project area as the 800 sq. $\mathrm{km}$ area encompassing the mesa top and portions of the surrounding washes ranging from approximately $5600-6800$ feet $(1706-2073 \mathrm{~m})$ (the elevations most likely to have good farming and associated archaeological sites) (Matson et al. 1990; Matson 2015). The mesa-top is not truly flat, given that a central ridge runs along its north-south axis and the resulting east-west slopes divide the drainage from the mesa top into Grand Gulch and Comb Wash (Matson et al. 1990, I6); the mesa top is also higher in the northern than southern portions (West 1978, 11). The floor of Grand Gulch is approximately 6000 feet (1829 m) above sea level in the vicinity of Turkey Pen Ruin.

As part of the Colorado Plateau, Cedar Mesa is classified as having a cold/high desert climate, typified by cold winters, hot daytime summer temperatures, and little rainfall (CEC 1997). Average precipitation is approximately $10 \mathrm{in} .(254 \mathrm{~mm})$ in the southern portion of the 
mesa, and about 12-13 in. (300-330 mm) in the northern portions (Matson et al. 1990, I-26; West 1978: 17). This presents something of a catch-22, however, since the northern portion of the mesa is also more elevated and therefore has an average growing season of only 129 days, while the southern mesa growing season is approximately 144 days, well within the Hopi maize requirements of a 130-day growing season (Matson et al., 1990, I-10). Vegetation on the eastern side of the mesa indicates that that area receives more moisture than the western portions (West 1978, 18). Although summer rains are often intense, rapid runoff and evaporation render them less effective than winter precipitation for contributing to plant growth, so the shifting seasonal precipitation patterns are also important to potential crop output and wild resource abundance (Haase 1983; Matson et al., 1990 I-8; West 1978, 18).

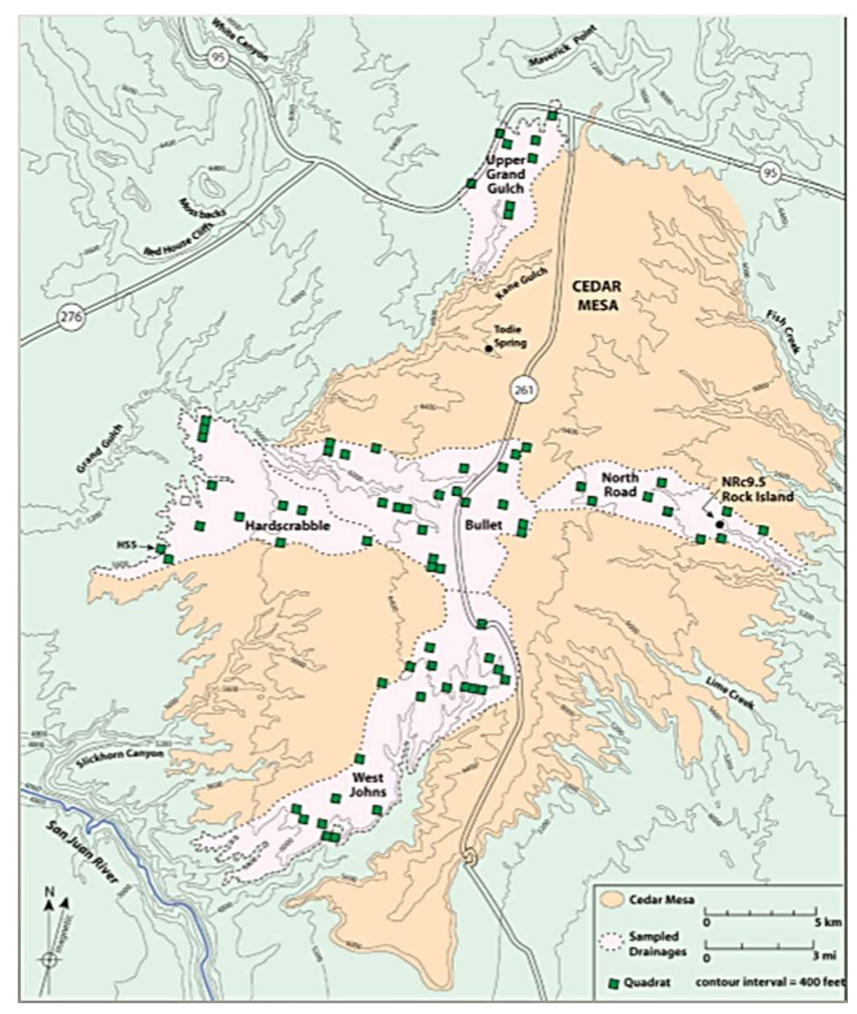

Figure 3.7. Cedar Mesa Project sampling design. Figure from Matson's 2011 presentation at the $76^{\text {th }}$ annual meeting of the Society for American Archaeology. 
Although these are modern statistics, there is little evidence for change in the environment of the Southwest since the mid-Holocene except for episodic droughts. However, these episodic shifts in climate may have contributed to the lack of high-value resources during the late Archaic and Early Agricultural Period. Evidence from palynological records, $\delta^{18} \mathrm{O}$ isotopes, tree rings, and other sources show a prolonged dry period between ca. 2800 and 1850 BP in the western and central Great Basin (Grayson 2011; Mensing et al. 2007; 2013; Tausch et al. 2004). Though these climatic studies do not include evidence from the Four Corners region, drier conditions may have prevailed in this area as part of a larger drought pattern in the Southwest associated with El Niño-Southern Oscillation conditions (Mensing et al. 2013). Rouston and colleagues (2011) used tree ring data from bristlecone pine (Pinus aristata) to reconstruct more than 2000 years of climate records in the Four Corners and found that AD 1400 (the entire late BMII period) represents an unusually arid time. In particular, during the period from AD 122-172, the tree ring data indicate that a mega-drought covered vast swaths of the Western US (Rouston et al. 2011). These data, however, are limited, so that the precise impact of this drought for local conditions on Cedar Mesa is not well understood.

\section{Ecology}

The American Southwest encompasses multiple deserts, mountain ranges, major and minor rivers, plateaus, and canyons; the variation in latitude and the diversity of landforms have formed a number of ecologically-distinct areas. However, in the Southwest, the major ecological divisions within a given area can often best be mapped according to altitudinal zonation (Daubenmire 1943; Merriam 1889; West 1978). Although there are differences in flora and fauna with respect to latitude (e.g., Saguaro cactus do not grow in the north), elevation is strongly 
correlated with precipitation and number of frost-free days, so that major vegetation regimes tend to self-segregate along topographic lines (Daubenmire 1943; Merriam 1889).

C. Hart Merriam (1889) and R.F. Daubenmire (1943) defined and delineated several vegetation zones in nearby Arizona and the Rocky Mountains, but only three of these are seen at Cedar Mesa. It should be noted that Merriam's (1889) more imprecise zones encapsulate all of the vegetation regimes on Cedar Mesa into one larger zone: the Upper Sonoran or chaparral zone, which includes sagebrush (Artemisia spp.), scrub oak (Quercus spp.), pinyon, and juniper (Juniperus spp.), so his classifications are not useful for this project. Although elevation is the primary factor affecting modern (and likely archaeological) plant distributions on Cedar Mesa, other factors include exposure, aspect, microclimate, and edaphic (soil) factors (West 1978, 31). Gerald West (1978) identified nine separate vegetation zones on and surrounding Cedar Mesa, but for the purposes of this project, I will focus on the six of these found on Cedar Mesa as defined by the Cedar Mesa Project (Matson et al. 1990).

Starting from the highest elevations, pinyon-juniper woodlands are commonly associated with elevations of approximately 1370-2290 m. At Cedar Mesa they grow primarily on the mesatop (approx. 1951-2134 m) and are clustered in areas of deeper soil (Daubenmire 1943; Gottfried et al. 1995; West 1978, 32-38). These conifers are also commonly accompanied by grasses (Poa, Stipa, and other genera), forbs (Euphorbiaceae), prickly pear (Opuntia spp.), and some sparsely distributed shrubs such as soap bush (Ceanothus) and mountain mahogany (Cercocarpus montanus) (Daubenmire 1943; Gottfried et al. 1995; West 1978). Sage parkland also occurs in patches of the mesa top within and around pinyon-juniper woodland, as it did in ancient times (West 1978, 39). These patches are dominated by a combination of sage and grasses but also includes other plants and are generally more diverse than pinyon-juniper woodlands. Though not 
generally associated with the mesa-top, West $(1978,41)$ noted dense thickets of blackbrush (Coleogyne ramosissima) in some places along the western edge of the mesa; this plant is found only in well-drained sandy areas that receive less than eight inches of annual precipitation (West 1978, 41), so blackbrush would primarily occur in the southern portions of the mesa, which receive less rain (Matson et al. 1990, Ch. 1).

The oak-mountain mahogany zone (Daubenmire 1943) is visible in the canyon areas of Cedar Mesa and encompasses West's (1978) rim-rock and cliffside and canyon bottom zones. Many of the plants that fall into this vegetation regime thrive in Grand Gulch. This zone is dominated by oak (Quercus spp.), mountain mahogany, willows (Salix spp.) and cottonwood (Populus spp.), but also includes three-leaf sumac (Rhus trilobata), antelope bitterbrush (Purshia tridentate), serviceberry (Amelanchier spp.), snowberry (Symphoricarpos spp.), and species of hackberry (Celtis spp.) and elm (Ulmus spp.) in some areas (Daubenmire 1943). At Cedar Mesa, the rim-rock and cliffside zone includes some extension of pinyon and juniper as well. Grand Gulch, itself, is divided into multiple terraces and includes a streambed and areas of standing water. While the higher terraces are somewhat similar to the mesa-top including pinyon, juniper, and sage, the lowest terrace and stream beds are distinct and dominated by other taxa such as cottonwood and willow (West 1978).

Finally, at the lowest elevations surrounding Cedar Mesa, the basal plain vegetation (Daubenmire 1943) is dominated by sagebrush, bunch grasses, cacti, and halophytes such as greasewood (Sarcobatus vermiculatis) and saltbush. This zone is also likely to include blackbrush since lower elevations receive less precipitation than the mesa.

West also found disturbance zones at most elevations around Cedar Mesa. Modern disturbance occurred as a result of grazing of sheep and cattle, oil and gas activities, and road 
construction, but some of the disturbance areas were abandoned experimental garden plots left by members of the Cedar Mesa Project (West 1978, 46). Although disturbed areas can occur at any elevation, what is relevant about these plant communities is that they are consistently and markedly different from the vegetative communities that surround them. Disturbance areas are dominated by plants from genus Amaranthus and Chenopodium, as well as asters and members of the family Brassicaceae (West 1978, 46).

\section{Conclusion}

Analysis of the Basketmaker II paleofeces from Turkey Pen Ruin affords the opportunity to examine the circumstances leading up to modern, intensified Puebloan farming practices. The temporal association of these specimens with maize-dependent farmers prior to the advent of bean horticulture allows for analyses that incorporate caloric and nutritional concerns. The geographic location of Turkey Pen Ruin within a landscape that can be divided into ecological zones provides potential for research into landscape-based foraging patterns. Aspects of the Southwestern environment such as altitudinal variation in plant communities and differentiation between the plant composition of disturbed settings and the surrounding ecological communities provide for the possibility of developing a more in-depth understanding of the subsistence strategies of the earliest farmers to occupy Cedar Mesa. Furthermore, the context of the samples in this study within the greater history of BMII agricultural development mean that research into the Basketmaker II occupation at Turkey Pen Ruin could reveal key factors that led to the subsequent Grand Gulch phase transition to mesa-top occupations and more intensive dryfarming methods still used by modern Hopi and Zuni peoples (Eggan 1950). 


\section{CHAPTER 4}

\section{Materials and Methods}

A total of 44 human paleofeces from Turkey Pen Ruin were analyzed for this dissertation. All specimens were sampled and analyzed for pollen and macroscopically identifiable plant and animal remains. Twenty of these also were tested for human, plant, and animal DNA, and eight were assayed for AMS dates. Since the analyses used here are destructive, all specimens were subsampled, leaving a portion of each for future research. The methods for sample processing and data collection are discussed below, as are the caveats regarding each type of data set.

\section{Botanical Analyses}

\section{Sample Selection and Preparation}

Paleofecal samples were chosen based on several criteria, including size (with a preference for larger samples), physical integrity, likely human affinity, and context within the midden. I included samples from all midden strata and as many of the layers as possible in order to capture any potential temporal changes or trends, however not all of the layers were equally represented since some of them contained significantly more specimens than others.

Several dozen paleofeces were recovered from the excavated portion of this midden, which also included turkey and herbivore droppings. However, based on color, physical appearance, organic contents (for example, ground corn and charcoal), DNA evidence, and to a 
lesser extent solution color and opacity in trisodium phosphate (discussed below), all paleofecal samples analyzed here appear to be attributable to humans. Although it was my original intent to include some of the samples previously analyzed by Kate Aasen in 1984 to assess inter-observer error, this was impossible since those samples could not be located. It is probable that all of the samples she analyzed were destroyed in the course of her work and any remaining fecal fragments were lost over time.

Prior to processing, each whole paleofecal specimen and the portion subsampled for botanical analysis were weighed. Specimens were sampled using disposable razor blades to prevent cross-contamination. Due to variation in shape, size, texture, and density of the paleofeces, it was impossible to subsample in uniform weights or sizes. I also attempted to cut along existing contours to prevent specimen disintegration, and when possible I used fragments from specimens that were already broken so that no cutting was required. Furthermore, initial sampling from very large specimens in the earliest stages of data collection resulted in some samples being larger than those processed later in the study from much smaller specimens. However, to limit the impacts that different sized samples had on the interpretation of results, raw pollen counts were converted to percentages and densities based on grains per gram, and macrobotanical samples were subsampled in uniform volumes for analysis.

Before sieving for macrobotanical remains and chemical processing for pollen analysis, the weighed subsamples were gently rehydrated in a trisodium phosphate $\left(\mathrm{Na}_{3} \mathrm{PO}_{4}\right)$ solution (approx. 0.5\%) for a minimum of 48 hours (after Callen and Cameron 1960). Following rehydration the color of the solution of each sample was recorded by reference to a Munsell color chart. The level of solution opacity was also noted because solution color and transparency can indicate whether paleofeces originated from a human (generally dark and opaque solution), 
carnivore, or herbivore (lighter more translucent solution) (Fry 1976; Jones 1983). However, more recent research, including work at Antelope House (Reinhard 1988) has found that this method is not always a reliable indicator of human affinity (Reinhard and Bryant 1992, 259261), and so it was not given much weight in this project.

\section{Pollen Processing and Analysis}

Palynological analysis was conducted to investigate ingested economic pollen and to gather seasonal and ecological data from pollen present as a result of local pollen rain. Determinations regarding whether a particular pollen taxon was ingested because it was part of the subsistence economy or was incidentally ingested due to environmental presence were based three criteria: 1) the mechanism of distribution (wind or insect/animal), 2) the amount/density of a particular pollen in a subsample, as discussed further below, and 3) the presence of clusters of connected pollen grains that can demonstrate direct ingestion of flowers, and are unlikely to be deposited by wind (Dean 1993; Reinhard 1993). I also took into consideration the associated macrobotanical contents in the paleofeces. For example, a large amount of grass pollen associated with a high density of Indian ricegrass seeds in the same sample suggests that pollen was ingested as part of the diet.

Processing of the first several samples was conducted at a dedicated palynological laboratory in the Anthropology Department at Washington State University, but the majority were processed in the palynology laboratory located in the Earth Sciences Department at Southern Methodist University. Palynological sample processing requires at least two laboratory working days and digestion in several different acids and oxidizing agents. The primary structural component of a pollen grain—sporopollenin—can withstand extreme conditions and very low $\mathrm{pH}$ levels in acids that will destroy other particulates in a sample (Faegri and Iverson 
1989). Palynological samples, therefore, are processed with the intent of eliminating other particles in the sample while simultaneously removing proteins and cellulose from the pollen grains that can obstruct identifying features. The pollen samples in this dissertation were processed according to a combination of standard procedures described below and as outlined in a variety of publications and studies (Bryant and Hall 1993; Faegri and Iverson 1989; and others).

After trisodium phosphate rehydration, samples were rinsed with deionized water and consolidated into $50 \mathrm{ml} \mathrm{Nalgene} \mathrm{test} \mathrm{tubes.} \mathrm{Consolidated} \mathrm{samples} \mathrm{were} \mathrm{then} \mathrm{digested} \mathrm{in} 10 \%$ hydrochloric acid $(\mathrm{HCl})$ with two tablets of 12,100 Lycopodium tracer spores (each) for approximately three to five minutes. After $\mathrm{HCl}$ digestion finished dissolving the Lycopodium tablets, disaggregating the sample, and eliminating any carbonates, each sample was wet sieved through a 150 micron mesh screen. The portion caught in the screen was set aside to dry and collected for macroscopic analysis. Particles small enough to pass through the sieve were consolidated and left in $50 \mathrm{ml}$ plastic test tubes to digest overnight in $48 \%$ hydrofluoric acid (HF) in order to eliminate any remaining silicates from the sieved sample.

Following HF digestion, samples were thoroughly rinsed, transferred to $12 \mathrm{ml}$ glass test tubes and then processed in 5\% potassium hydroxide $(\mathrm{KOH})$ for 10 minutes to remove humic acids. After rinsing the $\mathrm{KOH}$, samples were decanted, vortexed, and then processed in glacial acetic acid $\left(\mathrm{CH}_{3} \mathrm{CO}_{2} \mathrm{H}\right)$ to remove all remaining water before acetolysis. Acetolysis destroys remaining organics in the sample as well as oxidizing the sporopollenin exine. This process eliminates any remaining cellular protoplasm, the cellulose inner pollen wall (intine), and outer proteins and lipids, increasing the clarity of identifying structural features (Traverse 1988). Acetolysis mix is composed of acetic anhydride $\left(\mathrm{C}_{4} \mathrm{H}_{6} \mathrm{O}_{3}\right)$ and $95 \%$ sulfuric acid $\left(\mathrm{H}_{2} \mathrm{SO}_{4}\right)$ at a $7: 1$ 
ratio. Once this volatile mixture was added, the test tubes were placed in boiling water for six to ten minutes and stirred every two minutes. Following rinsing, the acetylated samples could either be directly transferred into glycerin, or put through heavy density separation with zinc bromide $(\mathrm{ZnBr})$ in order to separate the pollen from inorganic particles with a higher specific gravity that may have escaped digestion during processing. All samples were put through heavy density separation unless the undigested portion of the sample was unusually small relative to the other samples at this stage in processing or if there did not appear to be any heavier, inorganic particles left to separate.

After processing, all samples were stored in vials with approximately 8 drops of glycerin until analysis. Samples were analyzed on semi-permanent glycerin slides under a Leitz Wetzlar 733845 compound light microscope at magnifications of 250x for more rapid scanning, and 400x as necessary for specific identification. Samples were concurrently counted to a minimum of 200 pollen grains or 300 Lycopodium tracer spores. Lycopodium tracer spores are added to a sample in a known amount so they can be used to approximate the total pollen density (grains per gram) and the density of each individual taxa (Aasen 1984; Faegri and Iverson 1989; Dean 1993; Reinhard 1993) using the following calculation:

$$
\mathrm{D}=((24200 * \mathrm{n}) / \mathrm{L}) / \mathrm{w}
$$

Where $\mathrm{D}=$ pollen density

24200 is the total number of Lycopodium tracer spores added to the sample

$\mathrm{n}=$ pollen total or individual tax on total

$\mathrm{L}=$ Lycopodium counted

$\mathrm{w}=$ dry weight in grams

Some sample counts included more than 300 Lycopodium tracers if the pollen diversity was very high, and seemed unlikely to be captured in the course of counting only 300 tracer 
spores. Furthermore, one sample (number 6) was not counted to 200 pollen grains or 300 Lycopodium due to the incredible density of Ustilago maydis (corn smut) spores present in this sample (discussed further below). It was determined that counting enough slides to reach 200 pollen grains (estimated at eight slides) would be a waste of both time and slide materials and that the overwhelming occurrence of $U$. maydis spores was the most significant data for this particular sample.

A 200-grain pollen count is a general standard (Barkley 1934; Faegri and Iverson 1989; Geib and Heitman 2015, 77), however, Lycopodium counts are less standardized. For this project, I established the protocol cut-off counting at 300 Lycopodium because this was a standard used in a previous research project to which I contributed (the Fire and Humans in Resilient Ecosystems Project) (NSF Grant Award Number 1114898; Roos et al. 2015). Further, it seemed imprudent to spend many hours trying to reach 200 pollen grains in samples with very low pollen density since the primary goal of this study is to research economic pollen in paleofeces, which would presumably occur at higher densities (Dean 1993; Reinhard 1993).

Pollen identification was aided by two standard identification keys, Pollen Analysis by Moore, Webb, and Collinson (1991) and How to Know Pollen and Spores by R.O. Kapp (1969), as well as the comparative collection housed at Southern Methodist University, some of my own comparative slides, and several online resources such as the University of Arizona's Catalog of Internet Pollen and Spore Images (http://www.geo.arizona.edu/palynology/polonweb.html) and PalDat Palynological Database (www.paldat.org). 


\section{Ustilago maydis}

Spores from various mosses, ferns, and fungi are as durable as pollen and are often (or even usually) found along with pollen during counting. Normally spores are not included in analysis or counts since, among other factors, they are produced in astonishingly high numbers, sometimes billions or even hundreds of billions per individual, (e.g., U. maydis can produce $>200$ billion teliospores per fruiting body) (Valverde et al. 1995, 202). However, in the course of this project I encountered Ustilago maydis in all but one sample, and often at incredibly high densities. U. maydis, commonly known as corn smut, is a fungal infection that exclusively affects maize. It is not harmful to humans, and is edible, nutritious, and ethnographically documented as a delicacy among some Native American groups (Juárez-Montiel et al. 2011; León-Ramírez et al. 2014; Valverde et al. 1995). In light of its potential economic relevance, and because $U$. maydis produces several orders of magnitude more spores than the any plant produces pollen, these spores were counted separately from pollen in order to estimate their density within a given sample. This was accomplished by calculating the ratio of $U$. maydis spores to Lycopodium, using a simultaneous count of $U$. maydis spores while counting to a minimum of three Lycopodium grains and 20 U. maydis spores. For samples where U. maydis was uncommon I counted to a minimum of 20 Lycopodium, instead. From these counts density was calculated using the same equation as was used for pollen. U. maydis content was also categorized based on these counts as absent, present (noted in the slide, but with a density of $<10,000$ spores/g), common $(10,000-99,999$ spores/g), very common $(100,000-999,999$ spores/g), and ubiquitous $(1,000,000+$ spores/g). 


\section{Caveats Regarding Dietary Pollen and Spores}

Pollen data are obtained through counting, then calculating percentage and density/concentration values as described above. Percentages demonstrate relative abundance of taxa within a single sample, while concentration values are an extrapolation of the actual number of grains per gram. There are two major caveats regarding pollen data from paleofeces. First, unlike the macrofossil contents, not all pollen included in a sample necessarily have an economic association since pollen can be ingested through drinking water, contamination of unassociated foods, or even inhalation (Dean 1993; Reinhard 1993). Nonetheless, it can be determined whether the inclusion of a particular taxa likely resulted from direct dietary association or ambient presence based on several factors. High concentration values (grains/g) and the presence of clustered pollen grains that have yet to break away from each other for transport are both good indicators of direct economic association. Also, the regular occurrence of insect-transported pollen and/or pollen not common in the pollen rain of the local area could provide a good indication of economic association. Insect-borne pollen is not produced in as large amounts as wind-transported pollen (Faegri and Iversen 1989), so it would not be as likely to contaminate unassociated resources or be inhaled. All of these taphonomic factors were considered when interpreting the pollen results.

The second major caveat of dietary palynology is that pollen passes through the digestive tract intermittently and gradually (Kelso 1976; Williams-Dean 1978). Although some pollen from a meal will pass completely through the digestive tract with the associated macrofossils, remnants of pollen from a given meal can continue to pass for weeks after ingestion in variable amounts (Kelso 1976; Williams-Dean 1978). Although the time since ingestion cannot be estimated, the fact that pollen found in paleofecal samples may have been ingested up to three 
weeks prior should still be considered relevant when comparing pollen with macrofossil and DNA results from the same sample.

\section{Macrobotanical Analysis}

The dried remains caught in the sieves used for pollen processing were labeled, bagged, and set aside for analysis. No further chemical processing was required for these samples. Analysis consisted of separating and weighing different macroscopic constituents, however, this process can be time consuming, sometimes taking several days or even weeks to segregate and identify. In order to conserve time and to create a more uniform base of comparison among the samples, macrobotanical remains recovered from each subsample were further subsampled. For this subsampling, approximately $1 \mathrm{cc}$ of each sample was randomly chosen for complete analysis (including division by type and weighing of separate constituents), the rest of the sample was set aside to be separately weighed and visually scanned post hoc to assess representativeness of the subsample. Any taxa or constituents that did not appear in the subsample were noted at this time. The contents of the $1 \mathrm{cc}$ sample were separated under a dissecting microscope and categorized (e.g. corn, pinyon hulls, Indian ricegrass seeds, charcoal, bone, feathers, insect parts and unidentified), each subgroup was weighed, and the percentage by weight of each type of constituent was calculated. A few samples were analyzed in their entirety, due to the fact that

they were $\leq 1 \mathrm{cc}$ in volume. The identification of the macrobotanical remains was accomplished by reference to a series of microscopic images taken of Karen Adams' botanical collection at Crow Canyon Archaeological Center and a seed-based macrobotanical reference collection compiled by Ann Woosley for the Archaeology Research Program at Southern Methodist University. 
One caveat of studying macrofossil remains is differential preservation and dietary incorporation of identifiable resource components. Some types of macrofossils are more resilient to destruction than others. For instance, certain seeds such as mustard seeds and cheno-ams have light, friable seed coats that are more likely to be chemically or mechanically destroyed than Indian ricegrass, pine nut hulls, or animal bone. On the other hand, seeds with light coats are more likely to be consumed whole, whereas pine nut hulls are not necessarily consumed with pine nuts. Furthermore, certain resources such as meat and fruit eaten without seeds are largely destroyed in the digestive tract and do not emerge as visually identifiable macrofossils. Due to this, the combination of pollen, macrobotanical, and DNA datasets are necessary to detect all the major components of the diet, but determinations of relative contribution can only be qualified as estimates due to factors such as differential preservation and lack of a means to reliably tie pollen densities to degree of seed, leaf, and fruit consumption.

\section{Other Analyses}

\section{DNA Analysis}

DNA was extracted from 20 of the samples in this study and analyzed by Dr. Deborah Bolnick and her Ph.D. students Jaime Mata-Míguez and Rick W.A. Smith at The University of Texas at Austin. DNA extractions were performed using Rohland and Hofreiter's (2007) silica

protocol, with 0.4-1 $\mathrm{g}$ of each sample taken from the center of the paleofecal specimen to lessen the possibility of contamination. One or two fragments of human mitochondrial DNA (mtDNA) were then amplified from each sample and sequenced at the UT DNA Sequencing Facility, following Bolnick et al. (2012). Human mtDNA analysis was conducted in order to confirm that the samples were from humans and that they contained endogenous ancient DNA rather than modern contamination. Contamination would have likely yielded human mtDNA sequences not 
found in Native American populations prior to European contact, since all of the researchers known to have handled these specimens are of European descent. In contrast, endogenous ancient DNA should belong to mitochondrial haplogroup A, B, C, D, or X2a, all of which were present in the founding Native American populations (Achilli et al. 2013; Forster et al. 1996; Torroni et al. 1993). The presence of nonhuman DNA from several possible dietary sources, was assessed through PCR using primers that targeted several taxa of interest: turkey, deer, and lagomorph mtDNA, as well as yucca and Cucurbitaceae (squash family) chloroplast DNA (cpDNA) (Table 4.1). Faunal and plant PCR products were sequenced at the UT DNA Sequencing Facility, and the source of each sequence was determined through comparison to sequences in the NIH GenBank genetic sequence database using a nucleotide BLAST search. Accepted procedures were followed at all stages of the analysis to minimize contamination and detect it if present (Bolnick et al. 2012).

Table 4.1. PCR Primers and Associated Citations

\begin{tabular}{|l|l|l|l|}
\hline Primer & Forward & Reverse & Citation \\
\hline Deer & CCCCTAGATCACGACTTAAC & TAGGTGAGATGGCCCTGAAGAAAG & \\
\hline Rabbit & Rabbit-Forward-1 (RabCytB F) & TGTGTCYGAKGTATAGTGT ${ }^{2}$ & $\begin{array}{l}\text { Adams et al. } \\
2011: 809\end{array}$ \\
\hline Turkey & T15533F D-Loop 1 & T15750R D-Loop 1 & $\begin{array}{l}\text { Speller et al. } \\
2010, \text { SI:12 }\end{array}$ \\
\hline Squash & CCCTCTTTGGCTCTACCCAT & GAACGGACTAAGAGGGTCAGC & \\
\hline Yucca & CCAAATCGCGCTGCAAAAAC & ATCCCCTCTCGTTTCATCTCT & \\
\hline
\end{tabular}

1. Both the forward and reverse deer primers were designed by Jaime Mata-Míguez using primers described in Rosvold et al. 2012, 193 as templates.

2. Rabbit-Forward-1 is RabCytB F in Adams et al. 2011, as described on page 809. Rabbit-Reverse-1 was designed by Jaime Mata-Míguez using primers from Adams et al. 2011 as templates.

3. Cucurbitaceae and yucca primers were designed by Rick W.A. Smith to amplify a section of rp120-rps12 region and the trnT-trnL regions, respectively. 
For the primers designed specifically for this project, the descriptions of PCR conditions were as follows.

\section{Deer}

Hold 1: 2 minutes at $95^{\circ} \mathrm{C}$

60 cycles -

Denature: 30 seconds at $95^{\circ} \mathrm{C}$,

Anneal: 30 seconds and touchdown (initially $59^{\circ} \mathrm{C}$, and then $-0.1^{\circ} \mathrm{C} /$ cycle),

Extension: 1 minute at $72^{\circ} \mathrm{C}$

Hold 2: 3 minutes at $72^{\circ} \mathrm{C}$

$\underline{\text { Rabbit }}$

Hold 1: 10 minutes at $95^{\circ} \mathrm{C}$

60 cycles -

Denature: 30 seconds at $94^{\circ} \mathrm{C}$,

Anneal: 30 seconds at $53^{\circ} \mathrm{C}$,

Extension: 1 minute at $72^{\circ} \mathrm{C}$

Hold 2: 3 minutes at $72^{\circ} \mathrm{C}$

\section{Cucurbitaceae}

Hold 1: 4 minutes at $94^{\circ} \mathrm{C}$

60 cycles -

Denature: 30 seconds at $94^{\circ} \mathrm{C}$,

Anneal: 30 seconds at $57^{\circ} \mathrm{C}$,

Extension: 30 seconds at $72^{\circ} \mathrm{C}$

Hold 2: 7 minutes at $72^{\circ} \mathrm{C}$

Hold at $4 \mathrm{C}$ indefinitely

Yucca

Initial Denaturation: $94 \mathrm{C}$ for 4 minutes 
60 cycles -

Denature: 30 seconds at $94^{\circ} \mathrm{C}$,

Anneal: 30 seconds at $60^{\circ} \mathrm{C}$,

Extension: 30 seconds at $72^{\circ} \mathrm{C}$

Hold 2: 7 minutes at $72^{\circ} \mathrm{C}$

Hold at $4 \mathrm{C}$ indefinitely

AMS Dating

Although this midden was dated in previous studies, portions of the chronology were unresolved at the time of my analysis. Previous radiocarbon assays of the midden produced several contradictory dates from the same strata or even within the same layer. For these reasons, and to determine when the paleofeces incorporated into this study were deposited, eight of the macrobotanical samples from the paleofeces were selected for Accelerator Mass Spectrometry (AMS) dating by DirectAMS in Bothell, Washington. These eight specimens were chosen based on their distribution within the midden. Some were chosen in order to date layers that had not previously been dated, while others were chosen with the goal of clarifying stratigraphic associations and from layers with confusing results from previous radiocarbon dating. At least one sample was dated from all four of the midden strata, with one sample each from Strata A and C and three samples each from B and D. Specimen size was not given much consideration when choosing samples for AMS dating since only about $50 \mathrm{mg}$ of sample was required for analysis. Dates were calibrated with the Cologne Radiocarbon Calibration and Paleoclimate Research Package (CalPal) using the CalPal-2007 $7_{\text {Hulu }}$ calibration curve based on speleothem records from Hulu Cave, China in conjunction with the Greenland ${ }_{\text {Hulu }}$ timescale and Cariaco marine ${ }^{14} \mathrm{C}$ age calibration (Weninger and Jöris 2008). 


\section{Comparative Data}

To determine the economic value of plants used by the BMII occupants of Turkey Pen Ruin, I used published return rates on plants (e.g., Barlow 2002; Ferguson 2007; Simms 1985). In addition to data derived by my own analyses, I also used comparative data derived from Aasen's (1984) analyses and another coprolite study from sites in the surrounding area (Androy 2003). However, Aasen's data are not incorporated into the statistical analyses and results of this dissertation because her methods were not directly comparable with my own and her data are reported only in the form of percentages in-text and by a pollen percentage diagram in her thesis. Although general trends within her findings can be compared with the data reported here, without complete counts of her palynological data it would be problematic to add these data to my own tables and multivariate analyses. Aasen's thesis does include raw macrofossil data, but since I was unable to assess inter-observer error, and her samples were not standardized to $1 \mathrm{cc}$, these findings are not included in my statistical analyses. Since Androy (2003) analyzed paleofeces from different sites, his data will also be included only as part of the discussion rather than the results and statistical analyses. Cumulatively, the findings from Aasen (1984), Androy (2003), and from this dissertation will contribute to a better understanding of dietary breadth at Turkey Pen Ruin and regionally during the BMII period.

\section{Statistical Analyses}

Results of the analyses described above were statistically analyzed using Microsoft Excel ${ }^{\circledR}$ and PolPal pollen analysis software. Palyonological, macroscopic, and aDNA data were separately organized into tables and bar charts. DNA data were represented only as the presence or absence of a taxon, but botanical data were organized according to percentage of each taxa 
present in samples as well as weights for macrobotanical samples, and raw counts and densities for pollen.

Pollen results were tabulated and analyzed based on 1) the taxa present, 2) associated season of bloom, and 3) by plant community association. The latter refers to the ecological setting where these plants are most commonly found. To explore the diversity of pollen taxa, I conducted one analysis using only the simple taxonomic designations assigned during the counting phase of the project (e.g., juniper, cheno-am, Sambucus racemosa). While a second set of analyses divided all of the taxa into four categories: cultigen, arboreal pollen, non-arboreal pollen, and aquatic pollen. These analyses assessed more common taxa (those which represented $\geq 1 \%$ of the total pollen counts for all samples) individually, and combined less representative taxa according to their grouping, e.g., "other arboreal pollen."

In order to assess foraging patch-choice, I assigned individual plant taxa to some of the plant community associations as described in Chapter 3 . While not all taxa could be reliably assigned to a given ecological setting, plant species that were dominant in a particular community (and not any others) were assigned to that designation, and taxa commonly found in only found in one vegetation zone were counted as evidence of exploitation of that patch. Five ecological patches were designated based on a combination of West's (1978) vegetation community descriptions for Cedar Mesa and Daubenmire's (1943) Southwestern altitudinal zonations: 1) pinyon-juniper woodland, 2) sage parkland and surrounding desert, 3) canyon bottom zones, 4) disturbed/field context, and 5) aquatic/wetland settings. The specific plants identified as evidence for use of each of these patches can be seen in Table 4.2. I did not include grasses in any of these zones because grasses can be commonly found in most of these ecological settings. 
Table 4.2. Ecological Patches and Associated Plants

\begin{tabular}{|l|l|}
\hline Pinyon-Juniper Woodland & pinyon/pine, juniper \\
\hline Sage Parkland and Desert Zones & $\begin{array}{l}\text { sage, greasewood, saltbush, creosote bush (Larrea } \\
\text { tridentata), Acacia }\end{array}$ \\
\hline Canyon Bottom Zones & $\begin{array}{l}\text { willow, cottonwood, oak, boxelder (Acer negundo), } \\
\text { mountain mahogany, hackberry, elm, snowberry, St. } \\
\text { Johnswort (Hypericum spp.) }\end{array}$ \\
\hline Disturbed/Field Settings & $\begin{array}{l}\text { chenopodium, amaranth, mustards, asters, corn, squash, } \\
\text { purslane }\end{array}$ \\
\hline Aquatic/Wetland Settings & sedge, cattail, equisetum \\
\hline
\end{tabular}

Although almost all of the plants associated with the various ecological vegetation zones in this area can occasionally be found in other zones, each zone is also dominated by one or a few species that should be common in the pollen and/or macrobotanical evidence if that particular ecological patch was regularly exploited. Further, none of the plants that are defining taxa of the ecological patches in this dissertation are common in any other vegetative zone.

Ultimately, results of these analyses were then compared within and across datasets to determine correlations between taxa representation and potential patch-based or ecological strategies.

\section{Conclusion}

The processing methods used here were based on previous standards with adjustments to suit the needs of this particular project. All sample processing and analyses were carried out with the intent of efficiently gathering data, but also with a mind toward preserving portions of each sample for future research. The statistical analyses were chosen in order to best understand the pollen, macrobotanical, and DNA datasets individually, but also with comparative analysis in mind in order to interpret the correspondence of the independent lines of evidence examined in this project. 


\section{CHAPTER 5}

\section{Hypotheses and Expectations}

My hypotheses apply concepts derived from human behavioral ecology (HBE) to explain maize reliance among the Basketmaker II people at Turkey Pen Ruin. Since maize is already established as a dietary staple at the site (Aasen 1984; Matson 1991, 90-6), my questions focus primarily on the consumption of uncultivated, putatively wild resources. Specifically, by applying diet-breadth and patch-choice models I test whether high levels of maize reliance were motivated by: 1) a pull toward high agricultural productivity, 2) a push to create a resource safety net due to reduced foraging productivity, and/or 3) a pull toward the field as a highly efficient ecological patch, from the combined use of domesticates and weedy plants. The differences between these hypotheses are subtle, but testable by evaluating data from paleofecal analysis, since each of these scenarios would result in different dietary breadths and the use of distinct sets of wild resources to supplement maize.

According to diet-breadth model, individuals incorporate a greater variety of foods, including low-ranked resources, when encounter rates with high-ranking resources decrease (Charnov and Orians 1973, 39; Hames and Vickers 1982; Lupo 2007, 147-8; MacArthur and

Pianka 1966, 608). So a pull toward agricultural productivity (hypothesis 1) should result in a more narrow diet breadth than a push to make ends meet (hypothesis 2 ). The third hypothesis for this project is centered on the relative importance of weedy plants growing in fields compared with plants that grow in more distant patches. Using patch-choice model, this hypothesis will test 
whether the field patch, which includes crops, weedy plants, and certain animal species drawn to crop plants, could be more efficiently exploited than the surrounding natural patches, thereby encouraging an emphasis on farming by increasing the motivation to spend time in fields. This hypothesis is independent of 1 and 2, which are mutually exclusive. This hypothesis can be supported or disproved regardless of which of the first two hypotheses are supported. A positive result for this hypothesis in conjunction with hypothesis 1 would result in a strong focus on uncultivated, but field-friendly plants to the exclusion of low-ranked resources from other natural patches. Such a diet would be broader than expected under hypothesis 1, exclusively, and more ecologically narrow than expected for hypothesis 2 . A positive result for this hypothesis in combination with hypothesis 2 would result in a broad diet overall, but with a strong emphasis on field-based resources.

Although this chapter is focused on the three hypotheses and corresponding expectations tested by this research, it begins with a discussion of important caveats regarding the inadequacy of maize-based nutrition and how this might have impacted subsistence and foraging strategies at Cedar Mesa. Both the push and pull assumptions inherent to most of the theories regarding food production (described in Chapter 2), are predicated on the idea that horticulture and intensification of farming are ultimately driven by the productivity of wild resources relative to the crop(s) being grown (Barlow 2002; 2006; Childe 1951; Lee and DeVore 1968). If this is so, then wild resource use during the early farming period can reveal much about the evolution of the Puebloan agricultural economy and the impetus for the development of farming in the northern Southwest. Furthermore, since maize-based diets require augmentation to meet basic human nutritional needs, the supplemental nutrients (or lack thereof) provided by wild resources may be as relevant to understanding the productivity of local forage as caloric efficiency. 


\section{Why Mix Foraging and Farming?}

As discussed in Chapter 2, most applications of diet-breadth and patch-choice models use energetic currencies to measure productivity and assume that maximization of caloric efficiency is the overall goal. But for farmers who rely on a limited number of crops, calories may not be the only currency of value (Winterhalder and Kennett 2006, 13). Without bean horticulture, corn, which is limited in essential amino acids, vitamins, and minerals, was the only BMII staple crop. Although corn is a satisfactory staple in terms of macronutrients (carbohydrates, fat, protein), the relative proportions of carbohydrates to other nutrients are too high, and more importantly it lacks sufficient micronutrients (Table 5.1). Corn has approximately 8-10 g of protein per $100 \mathrm{~g}$, but this protein is poor quality, because it is deficient in some essential amino acids (amino acids that cannot be synthesized by the human body and so must be obtained through diet) (Ellwood et al. 2012; Holstad 2010; Latham 1997). Several studies show that diets based only on corn are nutritionally incomplete (Bressani et al. 2002; Ellwood et al. 2012; Holstad 2010; Latham 1997). Humans cannot thrive without certain vitamins, minerals, and essential amino acids such as lysine, tryptophan, and methionine (Otten et al. 2006). The lack of vitamins and essential amino acids in corn would necessitate supplementation with wild resources to prevent ailments like lysine deficiency, scurvy, anemia, and folate deficiency (Table 5.1 and 5.2). Thus, maize farming would not eliminate the need for hunting and gathering regardless of its caloric efficiency.

One potential nutritional problem among corn reliant farmers is vitamin $\mathrm{C}$ deficiency. Corn is harvested seasonally but has highly storable seeds that can serve as a dietary staple yearround. Corn does not contain much vitamin $\mathrm{C}$ even when fresh (Table 5.1), and storage can degrade that small amount via oxidation (Stešková et al. 2006). This means that seasonal 
deficiencies in vitamin $\mathrm{C}$ between harvests could be problematic for populations without alternative fresh supplementary resources.

Note that although niacin and calcium are also poorly represented in corn, these deficits were likely mediated by nixtamalizing maize (discussed in Chapter 3 ). This process makes the niacin in maize digestively accessible and increases the calcium content of corn by $400-750 \%$ (Bressani et al. 2002; Ellwood et al. 2012; Holstad 2010). The absence of ceramics during this period means that limestone boiling, as documented on Cedar Mesa (Ellwood et al. 2012; Holstad 2010), was likely used for many resources that could not be cooked directly over a spit. Limestone boiling also releases methionine, tryptophan, and lysine from corn, but not consistently across maize varieties (Ellwood et al. 2012; Holstad 2010), or necessarily at levels that would eliminate the need for augmentation with other resources. However, since up to $89 \%$ of the required amount of methionine can be replaced by cysteine (Ball et al. 2006), it was not likely a limiting nutrient.

Table 5.1. Selected Essential Nutrient Content for 100g Raw Corn with Corresponding EARs

\begin{tabular}{l|ccc|cccc} 
& \multicolumn{3}{|c|}{ Amino Acids } & \multicolumn{4}{c}{ Vitamins and Minerals } \\
& Isoleucine & Lysine & Tryptophan & Vitamin A & Vitamin C & Folate & Iron \\
& $\mathrm{g}$ & $\mathrm{g}$ & $\mathrm{g}$ & $\mathrm{IU}$ & $\mathrm{mg}$ & $\mathrm{mg}$ & $\mathrm{mg}$ \\
\cline { 2 - 8 } Corn, raw & 0.129 & 0.137 & 0.023 & 187 & 6.8 & 42 & 0.52 \\
\hline EAR (F) & $\mathbf{0 . 9 2 5}$ & $\mathbf{1 . 8 8 7}$ & $\mathbf{0 . 2 5 9}$ & 1667 & 60 & 320 & $\mathbf{8 . 1}$ \\
EAR (M) & 1.3 & 2.652 & $\mathbf{0 . 3 6 4}$ & 2083 & 75 & 320 & 6
\end{tabular}

Estimated Average Requirement (EAR) - estimated average daily intake required by of half of the healthy individuals in a group, the amounts here are for adults 19-30. Amino Acid EARs = protein EARs $x$ Dietary Reference Intakes for $\mathrm{mg}$ amino acid per $\mathrm{g}$ of protein. Information from the Food and Nutrition Board, Institute of Medicine National Academies. 
Taking nutrition into consideration does not alter the predictions of the hypotheses since both high- and low-ranked resources can provide essential nutrients necessary to supplement maize-based nutrition (Table 5.2). However, determining whether or not people were able to obtain all necessary nutrients, rather than just calories, from available resources is important to my interpretations. If the evidence does not indicate BMII diet at Turkey Pen Ruin was nutritionally complete, then neither hypothesis 1 nor 3 can be supported. If, on the other hand, evidence indicates the diet was nutritionally complete, the adequacy of local forage can be inferred based on whether people could obtain the supplemental essential nutrients listed in Tables 5.1 and 5.2 via more or less favorable resources. If most of the wild resources supplementing maize-based nutrition are as high or higher ranked than maize, it would indicate a pull toward farming to raise overall subsistence efficiency, allowing people to drop lower return resources out of the diet, in support of hypothesis 1 . Although it is not possible to determine the precise intake of a specific nutrient strictly from paleofecal analysis, it is possible to determine what resources may have supplied which nutrients based on their nutritional content and relative abundance across samples. 
Table 5.2. Percentage of Essential Nutrients Compared to Raw Corn

\section{$\underline{\text { Isoleucine }} \underline{\text { Lysine }} \underline{\text { Tryptophan }} \underline{\text { Vitamin A }} \underline{\text { Vitamin C }}$ Folate $\underline{\text { Iron }}$}

\begin{tabular}{|c|c|c|c|c|c|c|c|}
\hline Agave*, cooked & $0 \%$ & $0 \%$ & $0 \%$ & $60 \%$ & $4 \%$ & $7 \%$ & $683 \%$ \\
\hline Agave*, raw & $11 \%$ & $20 \%$ & $35 \%$ & $20 \%$ & $59 \%$ & $17 \%$ & $346 \%$ \\
\hline Amaranth Leaves, boiled & $79 \%$ & $80 \%$ & $117 \%$ & $1481 \%$ & $604 \%$ & $136 \%$ & $435 \%$ \\
\hline Amaranth Leaves, raw & $92 \%$ & $93 \%$ & $135 \%$ & $1560 \%$ & $637 \%$ & $202 \%$ & $446 \%$ \\
\hline Amaranth Seeds, raw & $451 \%$ & $545 \%$ & $787 \%$ & $1 \%$ & $62 \%$ & $195 \%$ & $1463 \%$ \\
\hline Quinoa*, cooked & $122 \%$ & $174 \%$ & $226 \%$ & $3 \%$ & $0 \%$ & $100 \%$ & $287 \%$ \\
\hline Quinoa*, raw & $391 \%$ & $559 \%$ & $726 \%$ & $7 \%$ & $0 \%$ & $438 \%$ & $879 \%$ \\
\hline Chenopodium leaves, raw & $196 \%$ & $258 \%$ & $165 \%$ & $6203 \%$ & $1176 \%$ & $71 \%$ & $231 \%$ \\
\hline Chokecherries & $0 \%$ & $0 \%$ & $0 \%$ & $23 \%$ & $10 \%$ & $24 \%$ & $77 \%$ \\
\hline Meat - Lamb Liver, raw & $681 \%$ & $804 \%$ & $1026 \%$ & $13161 \%$ & $59 \%$ & $548 \%$ & $1417 \%$ \\
\hline Meat - Rabbit, boiled & $1215 \%$ & $2110 \%$ & $1896 \%$ & $0 \%$ & $0 \%$ & $19 \%$ & $933 \%$ \\
\hline Meat - Venison, boiled & $1011 \%$ & $1801 \%$ & $1170 \%$ & $0 \%$ & $0 \%$ & $21 \%$ & $787 \%$ \\
\hline Mustard Greens & $0 \%$ & $0 \%$ & $0 \%$ & $1617 \%$ & $1029 \%$ & $29 \%$ & $315 \%$ \\
\hline Mustard Seed & $917 \%$ & $1346 \%$ & $1113 \%$ & $17 \%$ & $104 \%$ & $386 \%$ & $1771 \%$ \\
\hline Pinyon, raw & $349 \%$ & $317 \%$ & $635 \%$ & $16 \%$ & $29 \%$ & $138 \%$ & $588 \%$ \\
\hline Prickly Pear, raw & $0 \%$ & $0 \%$ & $0 \%$ & $23 \%$ & $206 \%$ & $14 \%$ & $58 \%$ \\
\hline Purslane Leaves, raw & $0 \%$ & $0 \%$ & $0 \%$ & $706 \%$ & $309 \%$ & $29 \%$ & $383 \%$ \\
\hline Squash Seeds, raw & $993 \%$ & $902 \%$ & $2504 \%$ & $9 \%$ & $28 \%$ & $138 \%$ & $1696 \%$ \\
\hline Squash Seeds, roasted & $981 \%$ & $891 \%$ & $2474 \%$ & $4 \%$ & $26 \%$ & $136 \%$ & $1552 \%$ \\
\hline Sunflower Seeds, raw & $883 \%$ & $684 \%$ & $1513 \%$ & $27 \%$ & $21 \%$ & $540 \%$ & $1010 \%$ \\
\hline Sunflower Seeds, toasted & $667 \%$ & $517 \%$ & $1143 \%$ & $5 \%$ & $21 \%$ & $567 \%$ & $1310 \%$ \\
\hline Corn, boiled & $103 \%$ & $103 \%$ & $100 \%$ & $1 \%$ & $91 \%$ & $48 \%$ & $106 \%$ \\
\hline Corn, dried & $376 \%$ & $364 \%$ & $409 \%$ & $140 \%$ & $0 \%$ & $264 \%$ & $502 \%$ \\
\hline
\end{tabular}

*Agave used as a proxy for yucca, as well. Quinoa used as a proxy for chenopodium seeds.

\section{Corn Fungus}

People both consciously and subconsciously make decisions based on the potential economic benefit of pursuing a given resource against the opportunity cost - the lost opportunity of pursuing a different possible resource (Lupo 2007, 146; Stephens and Krebs 1986, 11). 
Following the rationale outlined above, one such tradeoff is the choice to pursue a more nutritious resource in lieu of a resource with larger caloric returns. A potential example of this from Turkey Pen Ruin is the tolerance or perhaps encouragement of corn smut (Ustilago maydis) growth on maize plants even though it reduces harvests.

Corn smut or corn fungus is a parasitic fungal infection that exclusively affects maize and teosinte (Valverde et al. 2015, 7). It grows into tumor-like galls on various parts of the plant, but is generally eaten when it grows in the actual kernels as opposed to the leaves or stems. Because corn smut takes its nutrients from the plant it infects, it can only grow on living plants and will not infect corn stores or plants that have already been harvested (Christensen 1963; Valverde et al. 2015). However, like corn, corn smut may be eaten fresh or dried and stored for later consumption. If growing on the leaves or stem, corn smut might be obvious and easily removed, although depending on its location on the stem this may be impossible without killing the plant. However, when an ear becomes infected it is obscured by the husk and is therefore not necessarily obvious until the gall is either mature or close to maturity. Because it is parasitic, a corn smut infection can diminish overall crop returns by an approximate average of $10 \%$.

However, under the right (or wrong) circumstances, infection rates of more susceptible landraces have been recorded as high as $60-80 \%$, which would result in much higher crop losses, but such a high rate of infection is rare unless encouraged (Christensen 1963, 7; Pataky and Snetselaar 2006). Crop losses are tied to, but do not perfectly coincide with infection rate. Losses can be direct through damage to infected ears, but also indirect through the lower output of plants that are infected, and in modern agribusiness through the contamination of farming equipment and by tarnishing uninfected ears (Christensen 1963; Pataky and Snetselaar 2006). Although U. maydis negatively impacts maize growth, it also fundamentally alters the nutritional value of the corn in 
such a way that it is complementary to maize-based nutrition, but reduces caloric output. Corn smut contains high amounts of some of the very nutrients that corn lacks, such as lysine and folate (Juarez-Montiel et al. 2011; Valverde et al. 2015). If the growth of corn smut was encouraged or tolerated by the occupants at Turkey Pen Ruin it may indicate that the population was more constrained by a lack of nutrients, than calories.

Since corn smut can grow with or without encouragement, it may have been consumed incidentally (with corn), or intentionally to make up for a nutrient shortfall. Since it produces incredibly high numbers of microscopic spores (up to more than 200 billion per gall) (Valverde et al. 2012, 202), some could easily enter the digestive system even if the fungus itself was not being directly consumed. However, since corn smut is a visually obvious infection, and the galls could easily be avoided by those not wishing to consume it, high amounts of spores in the digestive system, with densities above that of the economic pollen present, would strongly indicate intentional consumption; spore densities below that of the economic pollen could more likely indicate incidental ingestion. Evidence for corn smut can provide an indication of how certain nutrients may have been obtained, and if it was commonly consumed, this would most strongly support hypothesis 3 (see below). Moreover, very common consumption could support encouragement of growth for this potentially important dietary supplement.

\section{Faunal Resources}

Faunal resources are generally the most energetically dense foods available in any given environment and would be an ideal source of protein and amino acids (Table 5.2 and 5.3). But previous research from Turkey Pen Ruin and other BMII sites on Cedar Mesa suggests that these populations did not commonly consume meat (Aasen 1984; Chisholm and Matson 1994; Coltrain et al. 2007; Coltrain and Janetski 2013; Matson and Chisholm 1991). Some researchers even 
argue that the BMII inhabitants of Turkey Pen Ruin were practically vegetarian (Matson and Chisholm 1991). Although Turkey Pen Ruin is one of the earliest sites of turkey husbandry in the Southwest (Lipe et al. 2016, 98-101; Nott 2010; Speller et al. 2010), research suggests these animals were not being used as food, but were raised exclusively for secondary products especially feathers that were used to make blankets and robes and that they potentially held some sort of ritual significance (Cooper et al. 2016; Lipe et al. 2016, 100).

Table 5.3. Local Faunal Resources at Cedar Mesa and Their Caloric Return Rates

\begin{tabular}{lll} 
Resources & Scientific names & Kcal/hr. \\
\hline Deer & Odocoileus hemionus & $17,971-31,450$ \\
\hline Bighorn Sheep & Ovis canadensis & $17,971-31,450$ \\
\hline Pronghorn & Antilocapra americana & $15,725-31,450$ \\
\hline Lagomorphs & Sylvilagus auduboni \& & $8,983-15,400$ (Encounter) \\
& Lepus spp. & $415-4,243$ (Trapping) \\
\hline Turkey & Meleagris gallopavo spp. & $1,700-5,200^{* *}$ \\
\hline Rodent (trapping) & Various & $468-2,340$ \\
**For turkey, the amounts listed are estimates based on return rates for encounter hunting similarly sized fowl, \\
including Canada geese, eider duck and general water fowl (see Ugan 2005: Table 1).
\end{tabular}

Since lagomorphs are not as high-ranked as larger-sized prey such as deer using traditional, atlatl hunting, use of rabbit could indicate a low occurrence of higher ranked big game, particularly since methods of capture used during BMII such as snares and nets actually decrease the caloric returns of these resources (Matson 1991, 29; Ugan 2005). However, lagomorphs are still a higher return resource than local plant resources when hunted upon encounter, so regular inclusion of game meat (large or small) would indicate a productive environment. Furthermore, when hunted in large drives lagomorphs have return rates disproportionally high for their body size (Schmitt et al. 2004, 93; Simms 1987). However, as shown in Table 5.4a, the returns for trapping range from very low to only moderately high. The 
effort put into checking traps across multiple locations greatly decreases these returns (Ugan 2005). Garden hunting and trapping could reduce the travel costs associated with that effort.

\section{Hypothesis 1 - A Pull toward Food Production}

Hypothesis 1 is based on the traditional assumption that foragers are drawn to adopt and increase their investment in agriculture by greater energetic return rates of domesticated resources, even when ideal foraging conditions prevail. This hypothesis assumes that food production is adopted and intensified because mixed farming and foraging is a more efficient means of subsistence than wild resource procurement, alone. However, this does not necessarily mean that farming is more efficient than all wild resources, rather farming is assumed to be more efficient than average foraging returns. Here I propose that BMII people increased their reliance on farming because it produced higher yields than many regularly accessible wild resources, and thereby raised mean subsistence returns resulting in the exclusion of lower ranked resources from the diet. This reasoning leads to the following hypothesis.

H1. If BMII peoples increased their reliance on maize farming because it was highly efficient, then the diet breadth should be narrow-exclusively focused on cultigens and high-ranked wild resources with returns equal to or higher than simple maize farming (Table 5.4a and b).

If adding cultigens to their subsistence strategy increased efficiency to a level that allowed people to focus supplemental foraging efforts on high-return resources, this should be reflected in a narrow dietary breadth apparent in paleofecal contents. Here "narrow" dietary breadth does not indicate reliance on only a few resources, but means that the diet should narrow toward the higher end of the energetic spectrum (Winterhalder 1981). At Turkey Pen Ruin, the 
diet should include high-ranked wild resources such as wild game, pine nuts (Pinus edulis), tansy mustard (Descurainia spp.), and bitterroot (Lewisia rediviva), with very little or no inclusion of low-ranked wild plants such as Indian ricegrass (Achnatherum/Oryzopsis hymenoides), dropseed, chenopodium, and amaranth (cheno-ams) (Table 5.4a and b).

Table 5.4a. Comparison of Caloric Return Rates for Selected Resources on the Colorado Plateau

\begin{tabular}{|c|c|c|c|c|c|c|}
\hline FORAGED RESOURCES & $\begin{array}{l}\text { SIMMS 1985, } \\
\quad 1987\end{array}$ & $\begin{array}{c}\text { DIEHL } \\
1997\end{array}$ & $\begin{array}{l}\text { BARLOW } \\
2002\end{array}$ & $\begin{array}{l}\text { UGAN } \\
2005\end{array}$ & $\begin{array}{l}\text { FERGUSON } \\
\quad 2007\end{array}$ & $\begin{array}{l}\text { RILEY } \\
2012\end{array}$ \\
\hline DEER \& BIGHORN SHEEP & $17,971-31,450$ & & & & & \\
\hline PRONGHORN & $15,725-31,450$ & & & & & \\
\hline $\begin{array}{l}\text { LAGOMORPHS } \\
\text { (ENCOUNTER) }\end{array}$ & $8983-15,400$ & & & & & \\
\hline LAGOMORPHS (TRAPPING) & & & & $415-4243$ & & \\
\hline $\begin{array}{l}\text { TYPHA LATIFOLIA } \\
\text { (CATTAIL) POLLEN }\end{array}$ & $2750-9360$ & & & & & \\
\hline RODENT (TRAPPING) & & & & $468-2340$ & & \\
\hline PINE NUTS & $841-1408+$ & & $1200-1700$ & & & \\
\hline $\begin{array}{l}\text { QUERCUS GAMBELLI } \\
\text { ACORNS }\end{array}$ & 1488 & & & & & \\
\hline OPUNTIA (CACTUS) FRUIT & & & & & & $1394 *$ \\
\hline $\begin{array}{l}\text { DESCURAINIA SPP. (TANSY } \\
\text { MUSTARD) }\end{array}$ & 1307 & 477 & $900-1300$ & & & \\
\hline $\begin{array}{l}\text { LEWISIA REDIVIVA } \\
\text { (BITTERROOT) }\end{array}$ & 1237 & & & & & \\
\hline ATRIPLEX SPP. (SALTBUSH) & $1033-1200$ & & & & & \\
\hline AGAVE & & & & & & $1014^{*}$ \\
\hline SUNFLOWER SEEDS & $467-504$ & & $300-900$ & & & \\
\hline POA SPP. (GRASS) SEEDS & $418-491$ & & & & & \\
\hline INDIAN RICEGRASS & $301-392$ & & $300-900$ & & & \\
\hline $\begin{array}{l}\text { LEPIDIUM SPP. } \\
\text { (PEPPERWEED) }\end{array}$ & 537 & & & & & \\
\hline
\end{tabular}


CHENO-AMS

SPOROBOLUS SPP.

(DROPSEED)

CAREX SPP. (SEDGE SEEDS)
497

$165-370$

$100-300$

ALLIUM SPP. (ONION)

*Maximum rate of return. Post-encounter return rates are based on reported caloric gains ( $\mathrm{kcal} / \mathrm{hr}$.) required to pursue, collect, and process each resource; search times are not included. This list is not inclusive of all possible resources at Cedar Mesa, but includes those for which I could find calculated return rates.

Table 5.4b. Caloric Return Rates for Maize Farming

\begin{tabular}{l|l} 
MAIZE PRODUCTION & KCAL/HR. \\
\hline SIMPLE HORTICULTURE & $1300-1700$ \\
SLASH-AND-BURN & $1100-1500$ \\
TYPICAL AGRICULTURE & $100-1100$ \\
INTENSIVE AGRICULTURE & $50-350$
\end{tabular}

Simple horticulture defined as plant and harvest (investment of approx. $50 \mathrm{hr}$./acre); slash-and-burn (investment of approx. $200 \mathrm{hr}$./acre); typical subsistence agriculture (approx. $400 \mathrm{hr}$./acre); intensive agriculture (including soil preparation, weeding, and activities throughout the growing season, investment of approx. $800 \mathrm{hr}$./acre). These return rates, obtained through studies of modern farmers in Central America, include food processing times. Returns from Barlow 2002.

\section{Hypothesis 2 - A Push toward Food Production}

Hypothesis 2 is predicated on the assumption that farming is less efficient than foraging and is only adopted and intensified when high-return wild resources become less available on the landscape, whether due to anthropogenic processes such as over exploitation or natural processes including climate change (Barlow 2002; 2006; Cordell and Gumerman 2006). This hypothesis proposes that resource depression (decreased encounter rates with high-ranked resources) pushed BMII peoples to increase their dependence on cultigens.

H2. If the focus on food production increased in response to diminished occurrence of high-value resources, then I expect a broad diet including low-ranking wild resources, indicative of intensified foraging to supplement maize-based nutrition (Table 5.1, 5.2, and 5.4a). 
Assuming that BMII maize farming had return rates between 1100 and $1700 \mathrm{kcal} / \mathrm{hr}$. (after Barlow 2002), people should only pursue wild resources at similar or higher rates of return under ideal foraging conditions and should not pursue resources that would lower the average rate of returns. If maize farming was adopted and intensified because the availability of high ranked wild resources was declining, then average foraging returns would have been lower than $1100-1700 \mathrm{kcal} / \mathrm{hr}$. In this case, wild resources brought into the diet to supplement maize will include lower ranked resources such as Indian ricegrass, cheno-ams, sedge seeds (Carex spp.), dropseed, and sunflower seed (Helianthus annuus). These foods would not be included in the diet if higher value resources were available. If people regularly supplemented maize-based nutrition with low ranking wild resources, then overall foraging conditions at Cedar Mesa were not ideal and perhaps inadequate without farming. Furthermore, if one or more of the nutrients required to supplement maize (see Table 5.1 and 2) does not appear in the diet, then that would be strong evidence against ideal foraging conditions on Cedar Mesa. Low inclusion of highreturn meat packages such as deer and bighorn sheep (Ovis canadensis) would support a push toward creating a resource safety net using farming, but only if high-return plant resources are also not commonly found.

During the Paleolithic and Archaic periods, prior to the advent of agriculture, there is little evidence for the occupation of Cedar Mesa, possibly because it was a naturally unfavorable environment for hunting, foraging, or both (Matson 1991, 92, 220). If this is true then it is also possible that high value resources were unavailable during the BMII period, and could explain why large game animals comprise a seemingly small contribution to the diet (Matson 1991, 92, 221-3). Movement into this area during the late BMII period may indicate population growth leading to expansion from more preferred adjacent territory. This would be consistent with 
demographic mortuary data indicating that the BMII period was a time of increasing population in the Northern San Juan/Four Corners Region (Kohler and Reese 2012). Furthermore, as

described in Chapter 3, there is some evidence for drought in this area during the BMII.

Regardless of the cause, resource depression or low occurrence of high-return resources should result in an increased diet breadth (Broughton 1999; Broughton et al. 2010) detectable in paleofecal analysis.

\section{Hypothesis 3 - The Field Patch}

Instead of focusing strictly on diet breadth, hypothesis 3 emphasizes patch choice. This hypothesis tests whether plants and animals that naturally invade fields may have encouraged an increased focus on farming activities. Horticultural activities (including clearing and burning) often stimulate localized growth of uncultivated plants, so that successional colonizers that thrive in disturbed contexts tend to grow in greater densities in fallow/abandoned fields than in nonanthropogenic habitats (Adams 2004, 176; Ford 1984; 2000). I propose that these plants may have favorably enhanced the returns of food production during BMII times by increasing the marginal values of farming investments. The growth of nutritious disturbance plants (such as purslane and amaranth) in working and fallow maize fields may have provided an incentive for farmers to focus greater attention on this newly created patch and incorporate plants colonizing their fields into the diet along with corn and squash.

H3. If the combined concentration of disturbance plants with cultigens increased overall subsistence efficiency of fields above the average efficiency for other ecological patches, then the resources growing in that patch should become a large focus of the diet. 
Although this hypothesis is based in niche construction - the idea that organisms impact their environment in ways that influence their evolution (Odling-Smee et al. 1996)—in order to test it I apply the tenants of patch-choice model (Charnov 1976; Charnov et al. 1976; Charnov and Orians 1973; MacArthur and Pianka 1966). Patch-choice model is premised on the fact that resources do not occur randomly across the landscape, but often occur in patches (Charnov 1976; Charnov et al. 1976; Charnov and Orians 1973; MacArthur and Pianka 1966). Here I focus on an anthropogenic patch — the field setting — relative to other local ecological patches such as pinyon-juniper woodland. I argue that the added value of non-domesticated plants associated with fields increased the returns of food production activities by making the fields and surrounding area into a new kind of patch (i.e., the field patch) that contained cultigens and wild resources, which complement a maize-based diet and could be exploited before or after harvest, and from fields left fallow. Although this hypothesis does not offer an explanation for the initial adoption of farming, it can explain the increasing emphasis placed on farming during the BMII period. Given that this population likely brought farming with them to Cedar Mesa, their initial adoption of agriculture took place elsewhere and presumably they would have come to Cedar Mesa with prior knowledge of this patch.

If this hypothesis is correct, then weedy disturbance plants such as purslane, cheno-ams, asters, and members of the family Brassicaceae should figure prominently in the diet as a complement to maize (Table 5.5). Further, if this hypothesis is correct and hypothesis 2 is incorrect, then there should be very little to no inclusion of low-ranked, wild resources that do not thrive in disturbed/field contexts such as sagebrush, juniper, chokecherry (Prunus virginiana), dropseed, and Indian ricegrass. There may be greater evidence for animals that can be easily exploited close to agricultural fields such as cottontail and deer, rather than animals like 
bighorn sheep that shy away from anthropogenic landscapes (Adams 2004; Ford 1984; Szuter 1989).

Encouragement of corn smut growth and its inclusion in the diet would also support this hypothesis. Since corn smut meets some of the nutritional needs not met by corn, regular consumption of corn smut could support greater reliance on fields for both staple foods and supplemental nutrients. Table 5.5 includes a list and description of annual disturbance plants that are native to the Four Corners and are often found in fields. These plants are likely to grow in fields whether or not they are purposely planted since they are successional colonizers that rapidly take root where other plants have been removed or have not yet grown, and are capable of withstanding repeated disturbance (Liebman et al. 2001). Part of the appeal of the field patch may have been its sustainability, since colonizing disturbance plants characteristically replenish their numbers rapidly (Baker 1965; 1974).

Indian ricegrass is sometimes associated with disturbed contexts, but it requires welldrained sandy soils (Hurst et al. 2011; Minnis 2000; Ogle et al. 2013; Tirmenstein 1999), and so is unlikely to be found in well-watered corn fields, and is not considered as part of the field patch. Furthermore, Indian ricegrass grows in abundance in areas of Grand Gulch and other parts of Cedar Mesa that are not associated with fields and human disturbance. Although certain species of grass are commonly associated with the field patch, Indian ricegrass was most commonly found by Kate Aasen (1984). If my results also show that Indian ricegrass was commonly consumed, these findings would offer greater support for hypothesis 2 , rather than this hypothesis.

If hypothesis 3 is incorrect, and the inclusion of disturbance resources in fields had little impact on BMII subsistence at Turkey Pen Ruin, then these plants will likely be uncommon 
dietary inclusions. Mustard is a high-return weedy disturbance plant that might still feature prominently in the diet even if this hypothesis is unsupported. Also, if these resources are less common than other lower-return plant resources not associated with the field patch, such as sedge and dropseed, this would support hypothesis 2 , instead of 3 . This prediction of a technically broad diet with narrow focus allows a positive result of this hypothesis to be distinguished from a result supporting hypothesis 1 or 2 , exclusively.

The complementary use of weedy disturbance plants in agricultural fields proposed here is not without precedence in the ethnographic record. The Tarahumara of northern Mexico eat weedy plants such as amaranth, chenopodium, purslane, and wild mustard greens that grow in and around fields as a supplement to agricultural resources (Bye 1979; 2000; Kahl 1987; Minnis 2000). Studies show that the Tarahumara meet or exceed daily recommended intakes of essential nutrients with a largely plant-based diet centered on corn, beans, and quelites (wild greens that grow in the fields) (Cerqueira et al. 1979). Although the people of Turkey Pen Ruin did not have bean horticulture, their diet otherwise may have been remarkably similar to the modern Tarahumara diet, since they also exhibited low meat intake and high dependence on plants for protein and nutrients to supplement corn (Aasen 1984; Matson 1991; Matson and Chisholm 1991). Furthermore, the quelites used by the Tarahumara are some of the same genera (e.g., Amaranthus and Portulaca) and species that may have been important to the inhabitants of Turkey Pen Ruin, both for nutritious greens and high-protein seeds, and are some of the same plants that have been recorded as being important among later Puebloan peoples (Aasen 1984; Huckell and Toll 2004; Hurst et al. 2011). 
Table 5.5. Plants Native to Cedar Mesa Commonly Associated with Field Settings

\begin{tabular}{llll} 
Family & Genus species & Common Name & Pollination \\
\hline Asteraceae & Helianthus annuus & Sunflower & Zoophilous \\
\hline Asteraceae & Other & Asters & Both \\
\hline Chenopodiaceae & Chenopodium spp. & Goosefoot & Anemophilous \\
\hline Amaranthaceae & Amaranth spp. & Pigweed & Anemophilous \\
\hline Portulacaceae & Portulaca/Talinum spp. & Purslanes & Zoophilous \\
\hline Brassicaceae & Descurainia spp. & Tansy Mustard & Zoophilous \\
\hline Brassicaceae & Lepidium spp. & Pepperweed & Zoophilous \\
\hline Cleomaceae & Cleome spp. & Beeweed & Zoophilous/Self
\end{tabular}

See Table 5.4a for associated return rates of plants listed in bold. I was unable to find return rates associated with purslane, but regarding the consumption of leaves, although nutritious (an excellent source of vitamin A, C, etc.), they are very low in calories, so the return rates are low even though little harvesting and processing effort is required (Hollenbach 2009, 209).

Disturbance plants have also been adopted as cultigens in some contexts. For example Helbaek (1960) proposed that barley was likely first cultivated in the Levant due to its propensity to grow as a weed within wheat fields. Amaranth and chenopodium are both weedy disturbance plants that were farmed and cultivated elsewhere in the Americas (Das 2014; Heiser and Nelson 1974; Piperno 2011). Furthermore, it has been suggested by some scholars that people during the Grand Gulch Phase of BMII began cultivating weedy annuals (e.g., Hurst et al. 2011, 96), although this cannot be proved using paleofecal evidence.

Time invested in farming is often tied to marginal returns, meaning initial and continual labor investments in the fields (such as watering and weeding) lead to a better harvest at a later time, but do not have an immediate payoff (Barlow 2006; Phillips 2009). The presence of weedy plants can add benefits to maize farming by providing a complementary short-term payoff to the long-term investment of field cultivation. Pioneer plants that naturally grow in disturbed soil can be incorporated into the diet through normal gardening tasks that people do anyway. If this 
model is correct, it implies that foraging and farming activities can be conducted simultaneously and are not mutually exclusive activities as many models assume (Barlow 2006). If weeding is also foraging then a person can simultaneously forage for immediate returns, while increasing their marginal returns for later harvest. If foraged resources are part of the same resource patch as the cultigens, then people can harvest wild plants while concomitantly caring for or harvesting their cultivated crops; in essence, weeding is foraging. Furthermore, search and travel costs can be reduced if a farmer is foraging in the fields he or she already tends.

Food production can create a desirable patch because it provides a means by which patch renewal can be controlled thereby creating a unique opportunity. People can control the location of a field and some, but not all, of its contents. Some weeds can be a nuisance and need to be eliminated, but edible weeds are beneficial because they grow naturally and do not require maintenance. Since pioneer plant growth depends primarily on increased sun exposure, weedy annuals will grow in disturbed field settings created by simple horticulture, slash-and-burn farming, or intensified agriculture. Furthermore, disturbance plants can grow in fields that are in current use or in areas that are fallow. Although maize has high demands for soil nutrients, some local perennial pioneer plants, such as New Mexico bird's-foot trefoil/deervetch (Lotus plebeius), are legumes that fix nitrogen (Gage 2004; Masson-Boivin et al. 2009). Although mildly toxic, the young seeds pods of this plant can be eaten in small amounts (Kunkel 1984). This plant and others like it would be particularly beneficial for soil enrichment during fallow periods. Amaranth, on the other hand, is a nitrate accumulator that can bring nitrogen up from deep in the soil also making it more accessible for other plants (McMahon 2005). Legumes and amaranth are both considered good companion plants for corn, and expand the resources in the fields without negatively impacting harvests (McMahon 2005). Among the Tarahumara, for 
example, disturbance plants are harvested prior to maturity, leading some scholars to argue that the timing is calculated to avoid competition with maize plants (Blanco and Hernandez X 1972, as cited in Bye 1981; Bye 2000, 207; Kahl 1987; Minnis 2000). For example, Blanco and Hernandez X (1972) demonstrated that quelites such as amaranth and asters, which have shallow root systems, did not begin to compete with deeper-rooted maize plants for resources until reaching maturity, so that harvesting them prior to this (at around 6-8 weeks into maize growth) allows them to grow as long as possible without impacting the eventual maize harvest.

\section{Conclusion}

Hypotheses 1 and 2 are mutually exclusive since one is premised on a draw toward farming even in times of high environmental productivity and the other is couched in environmental degradation and instability. However, either of these hypotheses could be supported alongside hypothesis 3 . Hypothesis 1 is centered an agricultural adoption eliminating the need for low-return resources. If this hypothesis and hypothesis 3 are both correct, then it should result in a diet with high-return wild resources complemented by field-based resources, to the exclusion of low-return wild resources. Hypothesis 2 explains that the adoption of agriculture and increasing focus on farming was a result of a need to supplement environmental circumstances that were not ideal. Hypothesis 3 is focused on how fields as larger patches could provide higher returns and greater nutritional balance than the surrounding environment by foraging for weedy plants that naturally grow in disturbed areas to supplement corn. Further, the inclusions of these plants increases the marginal returns of field maintenance, because harvesting them can be done through weeding, which increases future maize growth/output. So both of these hypotheses could be supported in combination if people were pushed to increase their reliance on agriculture to augment lacking environmental resources, while simultaneously 
coming to rely on the ecological advantages created by disturbance patches. This would result in a high focus on field-based resources complemented by high and low-ranked resources from other patches. A result supporting both hypotheses 2 and 3 would include some low-ranked resources from other patches, but with a clear dependence on the weedy disturbance plants to meet nutritional or caloric needs in supplementing maize farming.

If traditional assumptions are correct that dependence on agriculture arose from a draw to farming due to its high efficiency, that should be reflected in a narrow dietary breadth focused only on cultigens and high-ranking wild resources. Opposing models suggest that farming developed in response to resource depression, as a supplement to foraging that was otherwise generally lucrative. Under this model diet should be broader and regularly include low-ranked wild resources. Finally, if resources drawn to disturbance from farming activity in fields increased the value of that patch, it should also increase subsistence focus on that patch. In this case, I expect a focus on resources associated with that particular patch, that either includes only higher-ranked wild resources (supporting hypotheses 1 and 3), or still includes lower-ranked wild resources (supporting hypotheses 2 and 3). 


\section{CHAPTER 6}

\section{Results and Analyses}

This chapter presents the tabulated pollen, macrobotanical, DNA, and AMS data. While Chapter 7 discusses the interpretations and significance of these findings in relation to archaeological contexts, this chapter presents summary tables and describes important trends within the data. Data tables too extensive to be included in this chapter are found in Appendices A-D, which show the pollen, macrofossil, and aDNA data, respectively. Since pollen, macrofossil, and DNA datasets are not measured by the same metric (counts for pollen, weights

for macrofossils, and presence/absence for DNA), these results and their analyses are broken into subsections according to dataset followed by a synthesis that examines patterns that cross-cut datasets.

\section{Palynological Results}

\section{Counts and Percentages}

Pollen from 81 separate taxa were identified in the 44 samples analyzed for this project, but overall counts and individual specimens were generally dominated by only a few of these. Table 6.1 demonstrates that non-arboreal pollen dominate the counts for all of the samples combined. Two taxonomic categories — cheno-am and aster pollen - make up nearly $47 \%$ of the total pollen count, and generalized non-arboreal pollen types comprise nearly $70 \%$ of all pollen 
identified. However, non-arboreal pollen are not uniformly distibuted across all samples (Figure 6.1, Table 6.2), for instance, Populus spp. pollen is dominant in several specimens.

Table 6.1. Combined Pollen Results Divided into Standard Taxonomic Groupings

\begin{tabular}{|c|c|c|c|}
\hline Category & Type & Total Count & \% Representation \\
\hline \multirow{3}{*}{ 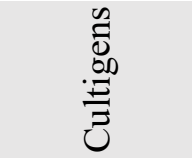 } & Zea mays & 76 & $1.16 \%$ \\
\hline & Cucurbita & 42 & $0.64 \%$ \\
\hline & & 118 & $1.81 \%$ \\
\hline \multirow{6}{*}{ 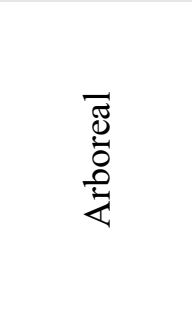 } & Populus & 803 & $12.29 \%$ \\
\hline & Pinus & 153 & $2.34 \%$ \\
\hline & Juniper & 141 & $2.16 \%$ \\
\hline & Acacia & 129 & $1.97 \%$ \\
\hline & Other arboreal & 81 & $1.24 \%$ \\
\hline & & 1307 & $20.01 \%$ \\
\hline \multirow{9}{*}{ 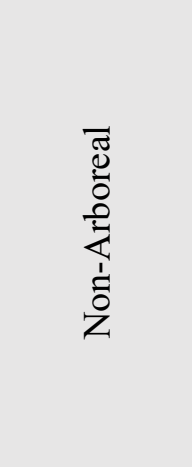 } & Cheno-am & 1735 & $26.56 \%$ \\
\hline & Asters & 1297 & $19.86 \%$ \\
\hline & Bird's-foot trefoil & 354 & $5.42 \%$ \\
\hline & Mustard & 317 & $4.85 \%$ \\
\hline & Grass & 292 & $4.47 \%$ \\
\hline & Allium & 195 & $2.99 \%$ \\
\hline & Apiaceae & 65 & $1.00 \%$ \\
\hline & Other non-arboreal & 302 & $4.62 \%$ \\
\hline & & 4557 & $69.76 \%$ \\
\hline Aquatic & All aquatic & 65 & $1.00 \%$ \\
\hline Unidentified & & 485 & $7.42 \%$ \\
\hline
\end{tabular}

Pollen types with $<1 \%$ total representation were grouped according to the larger associated plant type, (e.g., other arboreal pollen). Asters include ragweed, sunflower, and other members of Asteraceae, but do not include sagebrush. Although a member of the same family, sagebrush pollen yields a different interpretation than plants such as sunflower and ragweed, so was categorized separately.

Some of the pollen taxa with high overall representation had median counts of zero, since they did not occur in the majority of samples, but were found at very high densities in a few. Examples of these taxa include bird's-foot trefoil, mustard family, and corn pollen. Cottonwood pollen, was found in exactly half of the samples with a median representation of $0.2 \%$ and a mean representation of $8.1 \%$. Grass, sagebrush, and pine, on the other hand, were found in most samples, but typically at much lower percentages/densities. Juniper had a slightly lower mean 
percentage representation than pine, but had higher average densities and a much higher maximum representation in both percent and density (Table 6.2 and 6.4). Cheno-am pollen and aster pollen were found in almost every sample and generally at moderate to high percentage representation. Table 6.2 elucidates the variation between samples by showing the average percentage representation, medians, standard deviations, and maximum values for each of the major pollen types. Figure 6.1 visually displays the percentage distributions within each sample in a stacked bar chart. Together, Table 6.1,6.2 and Figure 6.1 reveal important details regarding overall trends and variation between samples.

Table 6.2. Pollen Taxa Distributions between Samples

\begin{tabular}{|c|c|c|c|c|c|}
\hline & \% Representation & Mean & St. Dev. & Median & Maximum \\
\hline \multirow{2}{*}{ Cultigens } & Zea mays & $1.16 \%$ & $2.7 \%$ & 0 & $14.71 \%$ \\
\hline & Squash & $0.65 \%$ & $2.0 \%$ & 0 & $9.52 \%$ \\
\hline \multirow{10}{*}{ 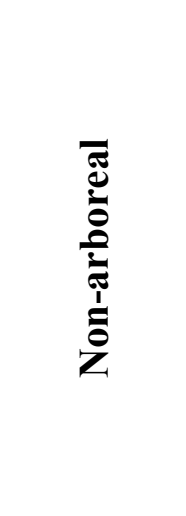 } & Cheno-Am & $25.73 \%$ & $25.2 \%$ & $19.4 \%$ & $86.80 \%$ \\
\hline & Asters & $18.07 \%$ & $25.4 \%$ & $9.3 \%$ & $100 \%$ \\
\hline & Mustard & $4.23 \%$ & $12.0 \%$ & 0 & $50.71 \%$ \\
\hline & Cleome & $0.43 \%$ & $1.7 \%$ & 0 & $10.58 \%$ \\
\hline & Apiaceae & $1.38 \%$ & $7.3 \%$ & 0 & $48.48 \%$ \\
\hline & Lotus spp. & $4.26 \%$ & $15.2 \%$ & 0 & $94.58 \%$ \\
\hline & Allium & $2.52 \%$ & $11.1 \%$ & 0 & $62.19 \%$ \\
\hline & Grass & $4.09 \%$ & $10.3 \%$ & $1.0 \%$ & $59.05 \%$ \\
\hline & Artemisia & $1.44 \%$ & $2.7 \%$ & $0.5 \%$ & $13.79 \%$ \\
\hline & Other non-arboreal & $4.87 \%$ & $7.3 \%$ & $2.4 \%$ & $32.14 \%$ \\
\hline \multirow{5}{*}{$\begin{array}{l}\bar{\Xi} \\
\vdots \\
\vdots \\
\vdots\end{array}$} & Pine & $3.99 \%$ & $4.9 \%$ & $2.0 \%$ & $20.69 \%$ \\
\hline & Juniper & $3.81 \%$ & $8.0 \%$ & $1.4 \%$ & $43.06 \%$ \\
\hline & Populus & $8.10 \%$ & $22.7 \%$ & $0.2 \%$ & $95.32 \%$ \\
\hline & Acacia & $1.55 \%$ & $9.2 \%$ & 0 & $61.08 \%$ \\
\hline & Other arboreal & $2.01 \%$ & $3.7 \%$ & $0.8 \%$ & $20 \%$ \\
\hline \multirow[t]{2}{*}{ Aquatic } & All aquatic & $1.15 \%$ & $1.6 \%$ & $0.7 \%$ & $6.90 \%$ \\
\hline & Unidentified & $10.51 \%$ & $8.5 \%$ & $9.0 \%$ & $40 \%$ \\
\hline
\end{tabular}




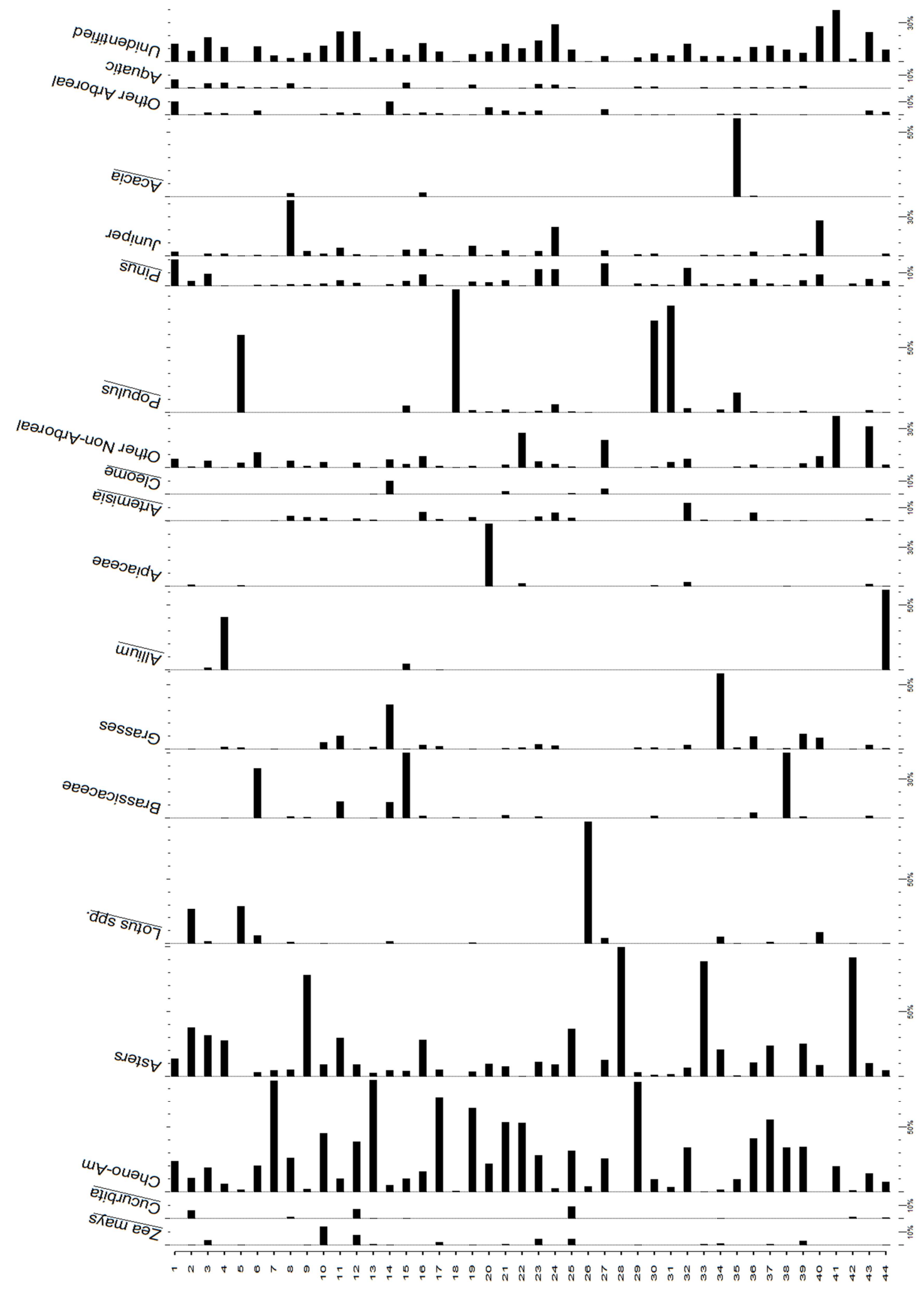

Figure 6.1. Pollen percentages for major taxa by sample. 


\section{Pollen Densities}

Pollen density (estimated number of grains/g) varied tremendously across samples with a range of $274-4,068,949$ grains/g., but most samples tended to fall mostly toward the lower end of that spectrum (Figure 6.2, Table 6.3). However, one very densely populated specimen skewed the results so greatly that it more than doubled the mean. Including sample 18 , the average density across all specimens is 163,702 grains/g, but excluding this specimen, the mean density drops to 72,882 grains/g. Total pollen counts, percentages, and densities from all samples can be found in Appendix B.

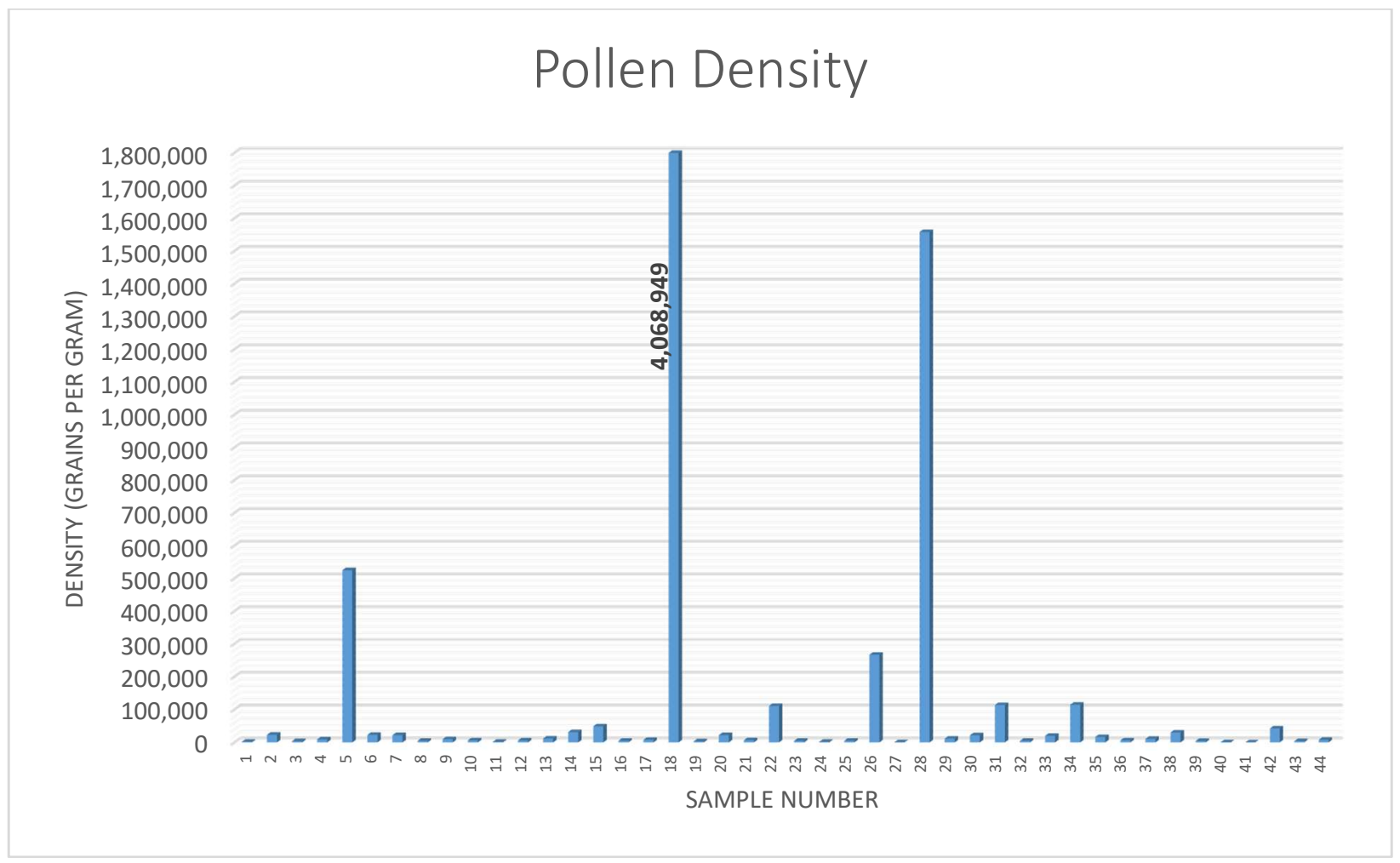

Figure 6.2. Bar chart of pollen density by sample. 
Table 6.3. Pollen Densities Ordered Lowest to Highest

\begin{tabular}{|c|c|}
\hline Sample & Grains/g \\
\hline 41 & 274 \\
\hline 40 & 587 \\
\hline 27 & 682 \\
\hline 24 & 1633 \\
\hline 11 & 1768 \\
\hline 1 & 1918 \\
\hline 19 & 3245 \\
\hline 3 & 3958 \\
\hline 43 & 4002 \\
\hline 39 & 4415 \\
\hline 8 & 4761 \\
\hline 32 & 4763 \\
\hline 23 & 4862 \\
\hline 16 & 4985 \\
\hline 25 & 5252 \\
\hline 12 & 6026 \\
\hline & \\
\hline
\end{tabular}

\begin{tabular}{|c|c|}
\hline 10 & 6256 \\
\hline 36 & 6300 \\
\hline 17 & 6771 \\
\hline 44 & 7929 \\
\hline 4 & 8082 \\
\hline 9 & 9222 \\
\hline 37 & 9996 \\
\hline 29 & 10695 \\
\hline 13 & 11574 \\
\hline 35 & 11919 \\
\hline 33 & 16471 \\
\hline 30 & 20162 \\
\hline 7 & 21546 \\
\hline 20 & 22102 \\
\hline 6 & 22208 \\
\hline 2 & 23106 \\
\hline & 23392 \\
\hline
\end{tabular}

\begin{tabular}{|c|c|}
\hline 38 & 30062 \\
\hline 14 & 31392 \\
\hline 42 & 42513 \\
\hline 15 & 49062 \\
\hline 22 & 111086 \\
\hline 31 & 113862 \\
\hline 34 & 114795 \\
\hline 26 & 267036 \\
\hline 5 & 525007 \\
\hline 28 & 1558243 \\
\hline 18 & 4068949 \\
\hline
\end{tabular}

Grouped by shading:

$<1,000$ grains/g - no shading, $<10,000$ grains/g - light gray,

$10-50,000$ grains/g - medium gray, $>100,000$ grains $/ g$ - dark gray.

Table 6.4. Statistics on Pollen Density by Taxa

\begin{tabular}{|c|c|c|c|c|c|}
\hline & Density (grains/g) & Mean & St. Dev. & Median & Maximum \\
\hline \multirow{2}{*}{ Cultigens } & Zea mays & 167 & 444 & 0 & 2365 \\
\hline & Squash & 92 & 268 & 0 & 1502 \\
\hline \multirow{10}{*}{ 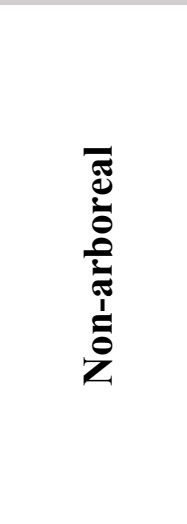 } & Cheno-Am & 5,503 & 11,086 & 1,900 & 59,546 \\
\hline & Asters & 38,285 & 234,582 & 549 & $1,558,243$ \\
\hline & Mustard & 2,251 & 7,848 & 0 & 43,910 \\
\hline & Cleome & 82 & 500 & 0 & 3,320 \\
\hline & Apiaceae & 442 & 1,797 & 0 & 10,768 \\
\hline & Lotus spp. & 9,647 & 44,236 & 0 & 252,566 \\
\hline & Allium & 261 & 1,001 & 0 & 5,026 \\
\hline & Grass & 2,112 & 10,314 & 125 & 67,783 \\
\hline & Artemisia & 95 & 146 & 35 & 657 \\
\hline & Other non-arboreal & 2,220 & 6,882 & 149 & 30,023 \\
\hline \multirow{5}{*}{ 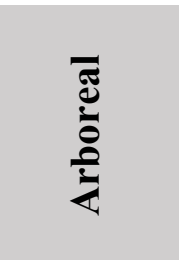 } & Pine & 346 & 402 & 214 & 1,860 \\
\hline & Juniper & 982 & 4,403 & 159 & 29,273 \\
\hline & Populus & 98,055 & 585,269 & 20 & $3,878,674$ \\
\hline & Acacia & 237 & 1,516 & 0 & 10,061 \\
\hline & Other arboreal & 614 & 2,259 & 66 & 14,637 \\
\hline \multirow[t]{2}{*}{ Aquatic } & All aquatic & 298 & 1,097 & 55 & 7,095 \\
\hline & Unidentified & 2,012 & 4,642 & 768 & 29,273 \\
\hline
\end{tabular}


Analysis

The overall pollen results are consistent with Aasen's (1984) findings (Figure 6.3), but differ significantly from the general makeup of surface sample pollen collected from Cedar Mesa in the late 1970s (West 1978). Since soil samples from Cedar Mesa exhibit a higher arboreal to non-arboreal pollen ratio dominated by pine and juniper, the greater occurrence of non-arboreal pollen in paleofecal specimens likely indicates dietary choices rather than incidental ingestion related to environmental pollen distributions. In particular, the pollen taxa representations suggest that cheno-ams, asters, mustards, and cottonwood were regularly incorporated into the diet.

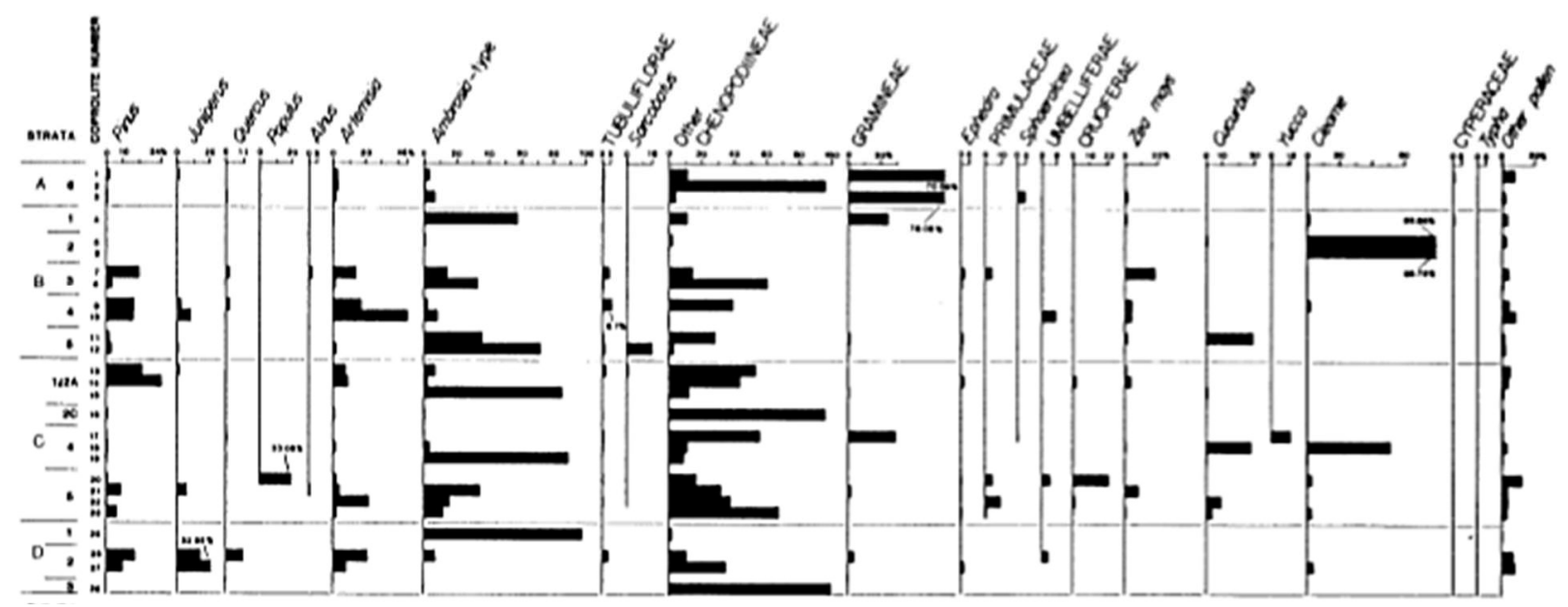

Figure 6.3. Results from Aasen 1984.

Aasen (1984, 35, Figure 7). Note: Ambrosia-type is a low-spine aster, Tubuliflorae is now known as Asteroideae and is a subfamily of Asteraceae, Gramineae is now Poaceae (grass), Cruciferae is now Brassicaceae, and Umbelliferae is now Apiaceae.

The presence of clusters (naturally aggregated pollen grains from the same plant) in several specimens further supports direct consumption of the plants listed above. Since clusters disaggregate as pollen dries prior to natural transport (West 1978, 127), their incorporation into paleofeces suggests ingestion of pollen that was still attached to the plant. Clusters of cheno-am, 
low-spine aster, cottonwood, pine, and mustard family pollen were all present. Furthermore, some of the mustard pollen grains identified were not yet fully developed. Consumption of these immature grains is unlikely to result from ingestion of ambient pollen since immature pollen is not naturally released by plants. Inclusion of under-developed grains can be linked to ingesting the plant directly or cooking with a portion of the plant that included unopened buds.

The non-arboreal pollen results also generally agree with Aasen's (1984) findings, except that the samples used in my analyses contain relatively lower amounts of Cleome and relatively higher amounts of mustard pollen. The arboreal pollen data, on the other hand, differ in several key ways from Aasen's. Specifically, pollen from the genus Populus rather than pine, was the most abundant arboreal pollen overall, and comprised $>10 \%$ of the total pollen counted (Table 6.1). This is not because cottonwood pollen occurred in more samples than pine, but is instead driven by the overwhelming presence of cottonwood in a few samples (Figure 6.1).

Pine pollen was pretty evenly spread across samples, but generally occurred in low frequencies. The highest percentage of pine pollen was from sample 1, in which pine was $20.7 \%$ of the counted pollen. However, sample 1 had a low overall pollen density, so that $20.7 \%$ was only comprised of six grains of pine pollen; for comparison, the maximum raw count of pine pollen for any sample was 16 grains in sample 23 . In spite of its ubiquity across samples, only two samples (23 and 33) contained clusters of pine pollen. Since pine pollen is wind-blown and extremely common on Cedar Mesa (West 1978), but occurred at a maximum of only 16 grains in these samples, much of the pine pollen identified in these samples may have been incorporated by incidental ingestion of ambient pollen through inhalation or drinking water, rather than solely through direct ingestion of the associated plant. I would expect pollen primarily derived from an economic association to occur at high levels in some specimens and not to be evenly spread at 
low levels. Although some of the pine present may have been ingested directly (particularly that in sample 23), the ubiquity of pine in the samples paired with low concentrations point toward incidental, rather than direct, ingestion.

This contrasts markedly with the data for cottonwood pollen, which was found in only half of the paleofecal samples examined, but 10 of these 22 samples were characterized by only a single grain. The high values for both percentage representation and density were largely driven by four specimens that had counts of more than 100 cottonwood grains each, including one sample that contained 265 counted grains.

Twenty-three of the 44 samples analyzed had density estimates below 10,000 grains/g, which is relatively low for paleofecal specimens (see Aasen 1984; Kelso 1976, 60-61; Reinhard et al. 1991 for comparison), but high compared with sub-surface archaeological soil samples from the area (West 1974, 59). Although only seven samples had estimated densities of more than 100,000 grains/g, two of these contained more than 1 million grains/g-extremely high concentration values.

As indicated in Chapter 4, high densities (estimated number of grains/g) of specific pollen types from paleofecal samples often points toward direct consumption. In particular, high concentrations of zoophilous (insect-transported) pollen strongly indicates economic association since these grains are produced in lower numbers and are less likely to be inhaled or incorporated into drinking water (Bryant 1974; Reinhard and Bryant 1992). Pollen densities in paleofecal specimens can also inform on seasonal association, both through the bloom period of highconcentration pollen, and by overall pollen density, where specimens with lower pollen density may be associated with seasons with low pollen counts. So the low median density values of these samples may reflect some of the samples coming from winter or early spring. 
Pollen from known cultigens (corn and squash) is generally uncommon across specimens (Figure 6.1, Table 6.4, Appendix B). High representation of cultigen pollen ( $>1 \%$ ), particularly corn, is strongly linked with low overall pollen density $(<10,000$ grains/g). To illustrate, samples with $<1 \%$ cultigen pollen had mean density values of 247,181 grains/g, samples with $>1 \%$ cultigen pollen had an average density of 17,923 , and those with $>3 \%$ cultigen pollen had an average density of only 7,737 . Thus, high percentages of cultigen pollen may reflect fewer grains of competing pollen taxa inflating relative representation in some samples, rather than increased intake of cultigens (see Dean 1993). For example, sample 3 is $3.8 \%$ corn pollen and contains an estimated 149 grains/g of that pollen, where sample 5 has only $0.5 \%$ corn pollen, but with an estimated density of 2365 grains/g. Because pollen from squash is produced in low quantities, and both squash and maize pollen are unlikely to end up on the actual fruit that is ingested, it is possible for cultigen pollen to occur in very low concentrations even when corn and squash make a very large contribution to the diet, as seen in other paleofecal studies (Aasen 1984; Androy 2003).

\section{Corn Fungus}

One of the unexpected findings of this research was the prevalence of Ustilago maydis (corn smut) spores (Table 6.5). Corn smut spores were identified in all but one of the specimens analyzed for this dissertation. Most contained spores at an estimated density of more than 50,000 spores/g, and nearly half (20 samples) had estimated densities of $>100,000$ spores/g. These

concentration values are higher on average and greatly exceed the maximum for pollen identified in the analysis. The highest estimated pollen density was 4,068,949 grains/g (Figure 6.2, Table 6.3) and the highest $U$. maydis spore concentration was estimated at $187,064,976$ per gram (Table 6.5). 
Table 6.5. Calculated Corn Smut Densities for All Samples

\begin{tabular}{|c|c|c|c|c|c|}
\hline Sample & $\begin{array}{l}\text { Corn } \\
\text { Smut } \\
\end{array}$ & Lycopodium & Weight (g) & Categorization & $\begin{array}{l}\text { Calculated } \\
\text { Density }\end{array}$ \\
\hline 11 & 0 & 20 & 2.1025 & Absent & $\mathbf{0}$ \\
\hline 29 & 2 & 21 & 2.4467 & \multirow{7}{*}{ Present } & 942 \\
\hline 40 & 2 & 22 & 1.5023 & & 1,464 \\
\hline 36 & 2 & 20 & 1.4213 & & 1,703 \\
\hline 31 & 8 & 20 & 4.3667 & & 2,217 \\
\hline 42 & 3 & 20 & 1.1330 & & 3,204 \\
\hline 41 & 4 & 20 & 1.4703 & & 3,292 \\
\hline 27 & 16 & 37 & 2.0300 & & 5,155 \\
\hline 43 & 10 & 20 & 1.1250 & \multirow{16}{*}{ Common } & 10,756 \\
\hline 30 & 20 & 16 & 2.3137 & & 13,074 \\
\hline 19 & 20 & 16 & 1.5945 & & 18,971 \\
\hline 33 & 21 & 19 & 1.3957 & & 19,165 \\
\hline 9 & 20 & 12 & 1.9055 & & 21,167 \\
\hline 38 & 20 & 15 & 1.4490 & & 22,268 \\
\hline 44 & 20 & 10 & 1.8633 & & 25,975 \\
\hline 21 & 32 & 36 & 0.7316 & & 29,403 \\
\hline 24 & 41 & 21 & 1.5213 & & 31,057 \\
\hline 26 & 20 & 12 & 1.1498 & & 35,079 \\
\hline 1 & 21 & 11 & 1.2158 & & 38,001 \\
\hline 39 & 20 & 4 & 2.4000 & & 50,417 \\
\hline 14 & 21 & 9 & 1.0345 & & 54,584 \\
\hline 15 & 22 & 11 & 0.8195 & & 59,060 \\
\hline 17 & 26 & 4 & 2.0450 & & 76,919 \\
\hline 22 & 20 & 9 & 0.6625 & & 81,174 \\
\hline 2 & 22 & 5 & 1.0638 & \multirow{15}{*}{ Very Common } & 100,094 \\
\hline 18 & 20 & 5 & 0.8267 & & 117,092 \\
\hline 23 & 40 & 4 & 2.0340 & & 118,977 \\
\hline 7 & 20 & 3 & 1.2878 & & 125,278 \\
\hline 12 & 29 & 5 & 1.0470 & & 134,059 \\
\hline 4 & 25 & 3 & 1.2158 & & 165,878 \\
\hline 10 & 54 & 4 & 1.8789 & & 173,878 \\
\hline 3 & 23 & 3 & 1.0659 & & 174,063 \\
\hline 25 & 29 & 3 & 1.2860 & & 181,908 \\
\hline 5 & 44 & 5 & 1.1370 & & 187,300 \\
\hline 34 & 64 & 5 & 0.9624 & & 321,862 \\
\hline 20 & 20 & 4 & 0.3596 & & 336,485 \\
\hline 35 & 130 & 6 & 1.1978 & & 437,747 \\
\hline 16 & 81 & 4 & 0.6797 & & 720,980 \\
\hline 32 & 104 & 7 & 0.4879 & & 736,919 \\
\hline
\end{tabular}




\begin{tabular}{l|ccccl}
$\mathbf{2 8}$ & 48 & 3 & 0.4383 & & $\mathbf{8 8 3 , 4 1 3}$ \\
\hline $\mathbf{3 7}$ & 490 & 3 & 2.0967 & & $\mathbf{1 , 8 8 5 , 2 1 5}$ \\
$\mathbf{8}$ & 1170 & 5 & 1.2158 & Ubiquitous & $\mathbf{4 , 6 5 7 , 8 6 6}$ \\
$\mathbf{1 3}$ & 1184 & 3 & 1.3333 & & $\mathbf{7 , 1 6 3 , 6 4 8}$ \\
$\mathbf{6}$ & 45000 & 4 & 1.4554 & & $\mathbf{1 8 7 , 0 6 1 , 9 7 6}$
\end{tabular}

Present- 1-10,000 spores/g, Common- 10,001-99,999 spores/g, Very Common- 100,000-999,999 spores/g, Ubiquitous- $1,000,000+$ spores/g.

\section{Analysis}

Fungal spores in general are common inclusions on pollen slides, but are not directly incorporated into pollen counts since fungi produce such massive amounts of spores and spread them by such different means, as to render most comparisons with pollen meaningless (Faegri and Iversen 1989). Corn fungus, for instance, can produce approximately 200 billion spores per gall (fungal growth) (Valverde et al. 2012, 202). For this reason they are included in a separate section here and their estimated densities were calculated separately from that of the pollen, although using the same slides and a similar method. Although the inclusion of corn smut in paleofeces at Turkey Pen Ruin was noted by Karl Reinhard (Powers 1984, 99; Reinhard 1988, 69), it was not previously identified as a dietary component during the BMII period, since Reinhard's samples are unprovenienced and more likely associated with BMIII based on the inclusion of bean in some of them. The overwhelming presence of these spores in samples 6,8 , 13 , and 37 , and its common occurrence throughout the specimens in this analysis strongly suggests that corn smut was purposely consumed. The potential economic and nutritional contribution of corn fungus is discussed at greater length in Chapter 7.

\section{Macrofossil Results}

Fourteen plant taxa and three broadly-defined faunal taxa (rodent, insect, and bird) were identified among the macroscopic remains, along with unidentified materials and items like 
charcoal that could not be taxonomically categorized. Corn kernels were by far the most common macroscopic constituent; corn comprised nearly $70 \%$ of all macrofossils analyzed (Table 6.6, 6.7, Appendix C). Two specimens exclusively contained corn macrofossils and only one sample (sample 18) did not contain any (Figure 6.4). By weight, pine nut hulls were the second most common macrofossil identified, they were found in 12 out of the 44 samples analyzed. However, other lighter weight macrofossils such as cheno-am seeds were also recovered from a large portion of the samples. Cheno-am seeds were the second most common seed type identified and were found in 11 of the samples.

Table 6.6. Macrofossil Representation for All Specimens Combined

\begin{tabular}{|c|c|c|c|c|}
\hline Category & Type & Weight (g) & \# of Samples & $\%$ Representation \\
\hline \multirow{2}{*}{ Cultigens } & Corn & 7.0764 & 43 & $69.17 \%$ \\
\hline & Squash Seed & 0.0091 & 2 & $0.09 \%$ \\
\hline Pine & Pine Nuts & 0.985 & 12 & $9.63 \%$ \\
\hline \multirow{8}{*}{ 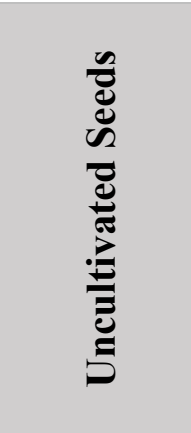 } & Cheno-Am & 0.4394 & 11 & $4.30 \%$ \\
\hline & Sunflower & 0.0542 & 7 & $0.53 \%$ \\
\hline & Indian Ricegrass & 0.0506 & 8 & $0.49 \%$ \\
\hline & Mustard & 0.0101 & 3 & $0.10 \%$ \\
\hline & Dropseed & 0.0041 & 7 & $0.04 \%$ \\
\hline & Echinocereus & 0.0003 & 1 & $0.00 \%$ \\
\hline & Sphaeralcea digitata & 0.0002 & 2 & $0.00 \%$ \\
\hline & Artemisia & 0.0001 & 1 & $0.00 \%$ \\
\hline \multirow{8}{*}{ 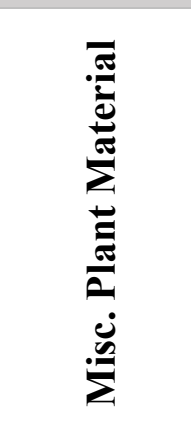 } & Purslane & 0.3482 & 21 & $3.40 \%$ \\
\hline & Plant Fiber & 0.2708 & 27 & $2.65 \%$ \\
\hline & Stems & 0.111 & 16 & $1.08 \%$ \\
\hline & Unknown Herb & 0.0317 & 12 & $0.31 \%$ \\
\hline & Unknown Fruit & 0.018 & 2 & $0.18 \%$ \\
\hline & Flower Parts & 0.0125 & 5 & $0.12 \%$ \\
\hline & Juniper Cone & 0.0021 & 2 & $0.02 \%$ \\
\hline & Equisetum Stem & 0.0006 & 1 & $0.01 \%$ \\
\hline \multirow{3}{*}{ 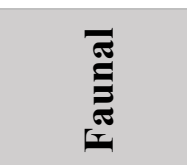 } & Bone & 0.0188 & 5 & $0.18 \%$ \\
\hline & Insect & 0.0018 & 7 & $0.02 \%$ \\
\hline & Feather & 0.0008 & 8 & $0.01 \%$ \\
\hline \multirow{2}{*}{ Other } & Charcoal & 0.025 & 39 & $0.24 \%$ \\
\hline & Unidentified & 0.7597 & 34 & $7.43 \%$ \\
\hline
\end{tabular}


Seeds are usually the most identifiable macrobotanicals in paleofeces, but some of the herbaceous material was also readily identifiable and common. Although purslane only comprised $3.4 \%$ of the total analyzed macrofossil weight, it occurred in more specimens (21) than any other taxonomically identifiable resource except corn (Table 6.6).

Table 6.7. Statistics for Macrofossil Weight by Taxa for All Specimens

$\begin{array}{lcccc}\text { \% Representation } & \text { Mean } & \text { St. Dev. } & \text { Median } & \text { Maximum } \\ \text { Corn } & 69.80 \% & 28.0 \% & 79.1 \% & 100.0 \% \\ \text { Squash } & 0.1 \% & 0.5 \% & <0.1 \% & 3.5 \% \\ \text { Pine Nuts } & 7.8 \% & 16.0 \% & <0.1 \% & 59.1 \% \\ \text { Cheno-Am } & 4.7 \% & 14.4 \% & <0.1 \% & 62.8 \% \\ \text { Mustard } & 0.1 \% & 0.5 \% & <0.1 \% & 3.4 \% \\ \text { Sunflower } & 0.6 \% & 2.7 \% & <0.1 \% & 16.4 \% \\ \text { Indian Ricegrass } & 0.7 \% & 3.2 \% & <0.1 \% & 16.6 \% \\ \text { Dropseed } & 0.1 \% & 0.3 \% & <0.1 \% & 2.1 \% \\ \text { Other Seeds } & <0.1 \% & <0.1 \% & <0.1 \% & 0.2 \% \\ \text { Plant Fibers } & 3.7 \% & 14.1 \% & <0.1 \% & 68.2 \% \\ \text { Stems } & 1.1 \% & 2.4 \% & <0.1 \% & 9.1 \% \\ \text { Unknown Herb } & 0.6 \% & 2.0 \% & <0.1 \% & 12.5 \% \\ \text { Purslane } & 3.4 \% & 6.4 \% & <0.1 \% & 26.3 \% \\ \text { Juniper Cone } & <0.1 \% & 0.1 \% & <0.1 \% & 0.4 \% \\ \text { Unknown Fruit } & 0.2 \% & 1.2 \% & <0.1 \% & 7.7 \% \\ \text { Flower Parts } & 0.2 \% & 0.8 \% & <0.1 \% & 4.7 \% \\ \text { Bone } & 0.2 \% & 0.7 \% & <0.1 \% & 4.2 \% \\ \text { Feather } & <0.1 \% & <0.1 \% & <0.1 \% & 0.1 \% \\ \text { Insect } & <0.1 \% & 0.1 \% & <0.1 \% & 0.3 \% \\ \text { Charcoal } & 0.3 \% & 0.3 \% & 0.2 \% & 1.4 \% \\ \text { Unidentified } & 6.5 \% & 13.1 \% & 1.8 \% & 79.1 \%\end{array}$

Note: Other seeds include hedgehog cactus (Echinocereus spp.), juniper globemallow (Sphaeralcea digitata), and sagebrush seeds.

Macroscopic evidence of faunal resources was uncommon; bone fragments were found in only five samples, and only one of these fragments was identifiable — a distal rodent humerus from sample 15 (Figure 6.4, Figure 6.5). Although they comprised an insignificant portion of the weight, feathers were the most common faunal macrofossil identified, they were found in eight samples. Insect remains were identified in seven samples. 


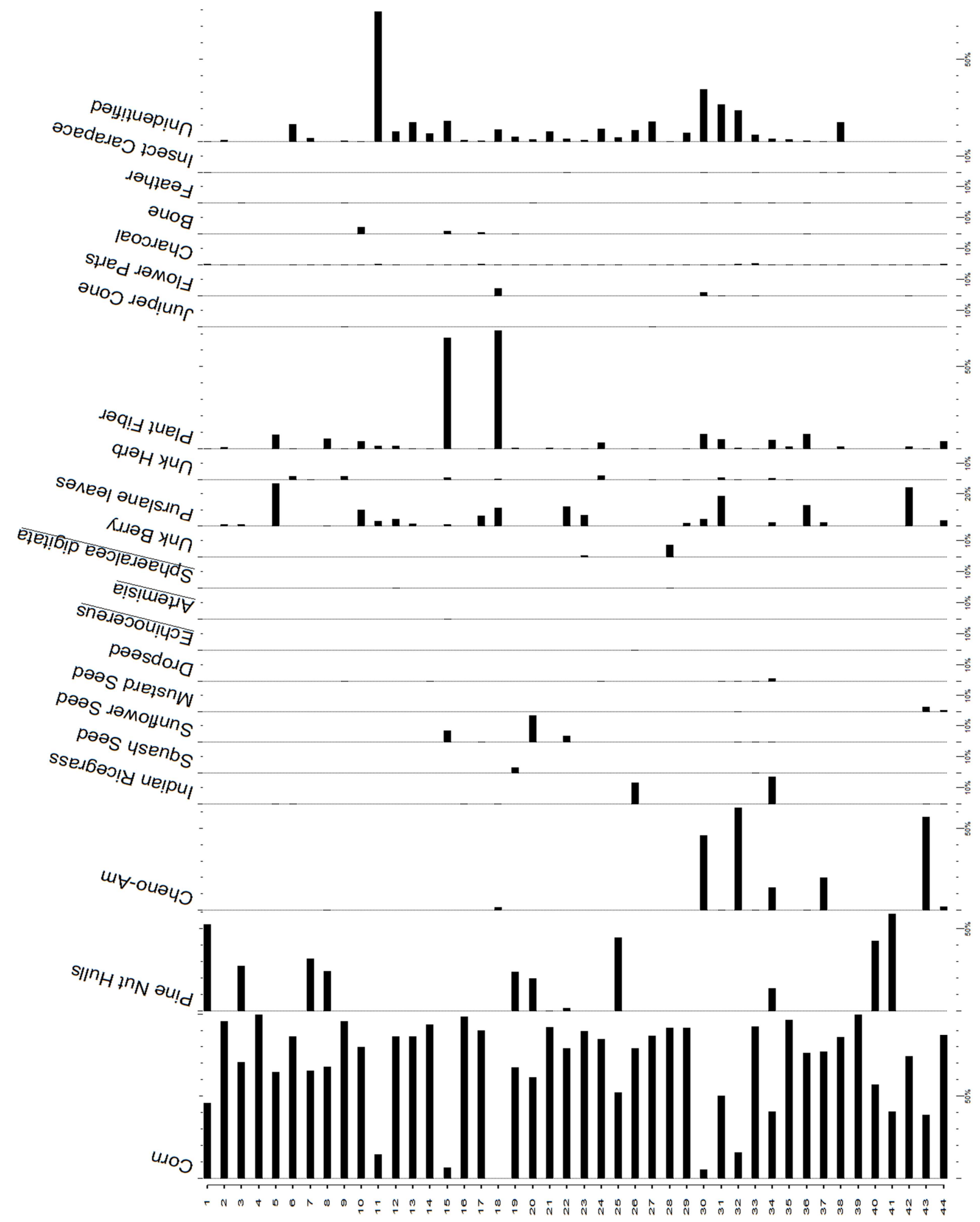

Figure 6.4. Macrofossil percentages by sample. 


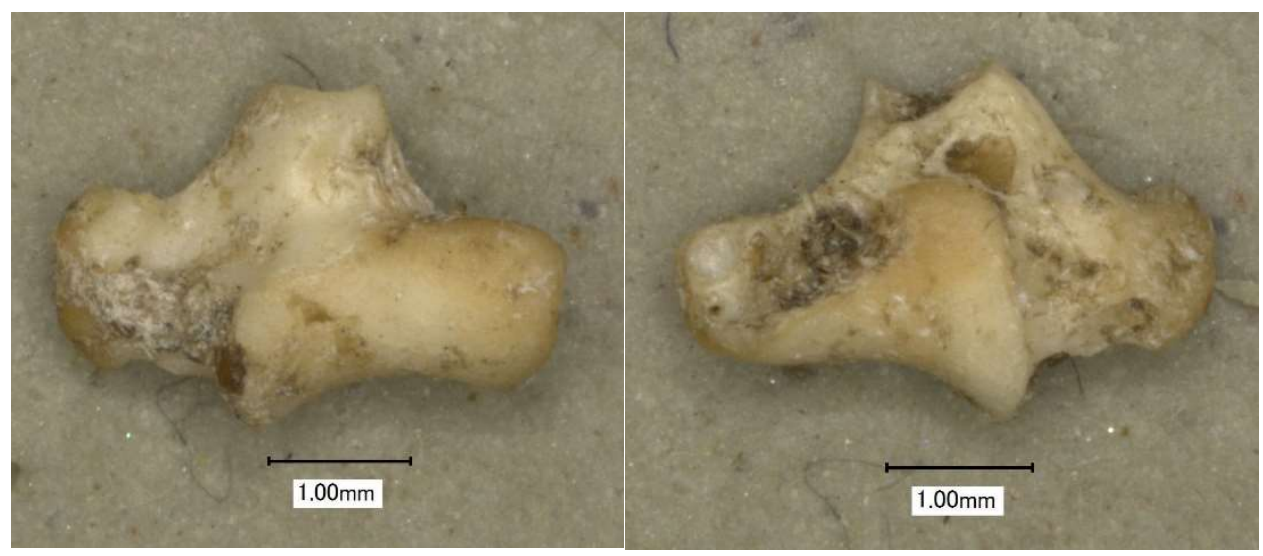

Figure 6.5. Images of the rodent humerus fragment, anterior view (left) and posterior view (right).

\section{Analysis}

The remains of cheno-am and purslane comprise less of the overall macrofossil weight, but their pervasiveness indicates that these two resources may have been eaten just as often, or more so, than pine nuts. Although weight differences among macrofossils may skew the percent representation of plant specimens, plants associated with heavier undigested fossils are also larger-sized resources that may make a more substantial caloric contribution when consumed. On the other hand, one potential representation problem with the macrofossil data is that neither Kate Aasen nor I were able to identify any actual pine nuts — only the hulls — and since the nuts can be eaten without the hulls, pine nuts may actually be under-represented in these samples.

The physical conditions of macrofossils provide insight into how they may have been prepared. Cheno-am seed coats are commonly (though not always) fragmented and may have often been ground into a meal. Pine nut hulls are also fragmented, but are generally too large to have come from a processed paste or nut meal. Most likely pine nuts were consumed raw or lightly toasted. Based on the lack of any charring, purslane leaves were most likely eaten raw as a salad (see Appendix E) or boiled in a stew. Corn appears to have been eaten in any number of 
ways: ground into meal, fresh off the cob, and even potentially popped based on the large, white starches stuck to some of the kernel hull fragments.

All of the bones extracted from these samples were highly fragmented. Although only one of them could be identified to a taxonomic or specific anatomical association, the size and general shapes of the other fragments suggest they are likely bones from rodents, very small birds, or reptiles. The feathers from these samples are difficult to interpret and are not necessarily indicative of bird meat consumption. Most were barely visible to the naked eye, so their presence could have resulted from incidental ingestion at the site where turkeys were raised rather than through actual ingestion of turkey or bird meat. Insect remains indicate a similar scenario, all insect macrofossils found (mostly dermestid beetle larvae and unidentified carapace) were very small and therefore unlikely to have been purposely incorporated into the diet. These insects were probably consumed as a result of an infestation in food stores, particularly since none of the samples containing carapaces contained enough parts to indicate the inclusion of more than one insect.

\section{DNA Results}

To help shed light on resources that may not be represented by pollen and macrobotanical evidence, dietary DNA was extracted and analyzed from 20 of the 44 specimens in this study. In order to confirm the human affinity of the specimens and to test for modern contamination after years of handling by researchers, all specimens were tested for human DNA. All specimens tested positive for human mitochondrial (mt)DNA that was associated with Native Americans or at least could not be ruled out as belonging to one of the five Native American mitochondrial haplogroups (A, B, C, D, or X2a) (Appendix D). 
Fifteen out of 20 total samples tested positive for chloroplast (cp)DNA from yucca or squash, mtDNA from faunal resources, or both (Table 6.8). Yucca was the most common resource identified through DNA analysis. Although little pollen or macrofossil evidence for yucca consumption was found, yucca cpDNA amplified in 11 out of the 20 samples tested. Squash family (Cucurbitaceae) cpDNA was found in only three specimens, all three of which also contained yucca DNA.

Only seven specimens yielded faunal DNA. All of the resources that were intentionally included in PCR analysis (turkey, rabbit, deer, yucca, and squash) were found in at least one specimen. However, three unexpected faunal resources were also discovered through PCR analysis. Dog (Canis familiaris) DNA was found in two samples via the cottontail PCR primers, and bighorn sheep and pronghorn (Antilocapra americana) amplified in three samples via the primers used to amplify deer DNA. Deer was the most common faunal resource identified and was found in six of the 20 samples tested. Notably, five out of the seven samples that tested positive for faunal DNA contained mtDNA of multiple species; the DNA of four distinct animal species was amplified from specimen 10, alone. Specimen 10 was also the only sample in which turkey DNA was identified. 
Table 6.8. Combined Faunal and Plant DNA Results

\begin{tabular}{|c|c|c|c|c|c|c|c|c|}
\hline & \multicolumn{6}{|c|}{ Animal DNA } & \multicolumn{2}{|c|}{ Plant DNA } \\
\hline Specimen & Turkey & Cottontail & Dog & Deer & $\begin{array}{l}\text { Bighorn } \\
\text { Sheep }\end{array}$ & Pronghorn & Yucca & Cucurbitaceae \\
\hline 1 & & & & & & & + & \\
\hline 2 & & & & & & & & + \\
\hline 3 & & & & & & & + & \\
\hline 4 & & & & & & & + & \\
\hline 5 & & & & & & & + & \\
\hline 6 & & & & & & & + & \\
\hline 7 & & + & + & + & & & + & \\
\hline 8 & & & + & + & & & + & + \\
\hline 9 & & & & & & & & \\
\hline 10 & + & + & & + & & + & & \\
\hline 11 & & & & & & & & \\
\hline 12 & & & & & & & + & \\
\hline 13 & & & & + & + & & & \\
\hline 14 & & & & & & & & \\
\hline 15 & & & & + & + & & + & \\
\hline 16 & & & & & & & & \\
\hline 17 & & + & & & & & & \\
\hline 18 & & & & & & & & \\
\hline 21 & & & & & & & + & + \\
\hline 26 & & & & + & & & + & \\
\hline TOTALS & 1 & 3 & 2 & 6 & 2 & 1 & 11 & 3 \\
\hline
\end{tabular}

Analysis

Not all of the human DNA could be positively attributed to a specific haplogroup because some of the samples were too fragmentary, but this is not necessarily a negative result. This actually suggests that the DNA was very unlikely to be from modern contamination, since modern fragments would have been in better condition and easily attributable to a mitochondrial haplogroup (Allentoft et al. 2012). Despite years of handling by various researchers, these results indicate that modern contamination was negligible. 
Lack of modern contamination does not exclude the possibility of contamination from within the midden, however, so the subsamples were carefully extracted from interior portions of the paleofecal specimens in order to minimize the chances of contaminant DNA. One indicator that contamination between specimens was not a problem is that turkey DNA was found in only one sample; since turkey feces, feathers, and even eggshells occurred throughout the midden (Aasen 1984, Powers 1984, Nott 2010), turkey was the most likely source of contamination. If turkey DNA had been found in many specimens, then contamination would have been the most parsimonious interpretation. Turkey was only identified in one sample, along with DNA from three other faunal species. The absence of turkey DNA from most of the samples, and its cooccurrence with multiple other species in the sample from which it was recovered offers strong support for the validity of the DNA associations from these specimens. If the DNA arose from contamination, then turkey should have been the most common resource recovered from these analyses instead of yucca and deer.

\section{Synthesis of the Data}

The various difference and concordances between datasets are key to understanding how certain resources may have been incorporated into the diet. Inconsistent representation between the pollen, macrofossil, and DNA datasets highlights the importance of combined characterization techniques for the analysis of paleofecal matter. For example, the pollen and macrofossil data do not align regarding the relative importance of pine nuts in the diet. Although it is clear from the macrobotanical data that pine nuts were eaten and may even have been one of the more common resources included in the diet, the pollen data emphasize field-based disturbance resources such as cheno-ams instead. There are some co-occurrences of pine nut hull macrofossils and relatively high representation of pine pollen in samples 1, 3, 19, 20, and 40 . 
Samples 25 and 41, on the other hand, had very high percentages of pine nut macrofossils, but contained no pine pollen. Neither of the samples that contained clusters of pine pollen contained pine nut hulls. These conflicting results could arise from several different causes: 1) economically-associated pine pollen passed through the digestive tract at a slower rate than the macrofossils, 2) the ingestion of the nuts did not often result in concomitant ingestion of pollen, and/or 3) the presence of pollen was the result of incidental ingestion due to high environmental presence.

Purslane provides a second example that is similar to pine nuts. This taxa is represented primarily by leaves and not pollen. Purslane seeds were also absent from these samples, although Aasen (1984) did identify purslane seeds in one sample. This may indicate preferential harvest of leaves not consistent with bloom period and seed development.

Yucca was identified in more than half of the DNA samples, but was not identified macroscopically and agave family pollen was found in only two samples. Ethnographic observations suggest that Native American populations (including the Hopi, Tewa, and Navajo) ate yucca fruit without seeds or as a paste, which could explain this difference in the DNA and botanical evidence (Aasen 1984, 51; Bailey 1940, 286; Hough 1897, 40; Robbins et al. 1916, 4950). Several samples did contain an unidentified sticky, amorphous, reddish-orange paste that could be the paste formed from yucca fruit. Alternatively, yucca leaves were also commonly chewed as quids by many prehistoric populations in the Southwest (LeBlanc et al. 2007), so recognizable macrobotanical remains of this taxon did not always make their way into the digestive tract.

Concordances between data sets are equally revealing. The two specimens that yielded pollen evidence of yucca (identified to the subfamily Agavoideae), also tested positive for 
cpDNA identified as Yucca brevifolia (Joshua tree). Of the three specimens that tested positive for squash DNA, one (sample 19) also contained squash seeds. The other two specimens (2 and 8) also contained Cucurbita pollen. However not all specimens that contained squash pollen tested positive for cpDNA, three specimens that contained Cucurbita pollen did not test positive for DNA from the Cucurbitaceae family.

All three samples that were tested for DNA and contained bone fragments in the macrofossil sample, tested positive for animal DNA (samples 10, 15, and 17). Interestingly, the only sample with identifiable faunal remains did not match the DNA results—sample 15 tested positive for deer and bighorn sheep DNA, but only contained the distal fragment of a rodent humerus (Figure 6.5). Two other macrofossil samples contained bone fragments (samples 19 and 36), but these were not tested for DNA.

Finally, cheno-am seeds and pollen were among the most common resources recovered in their respective datasets, and some correspondence between the pollen and macrofossil data for asters was apparent, as well. Sample 34 contained an unusually high amount of grass seed and pollen, although specimen 26 contained high amounts of seed but no grass pollen.

\section{Ecological Patch Association}

In order to assess hypothesis 3 regarding patch-choice, I attempted to assign individual plant taxa to some of the plant community associations as described in Chapters 3 and 4 . Five plantcommunities or ecological patches were designated: 1) pinyon-juniper woodland, 2) sage parkland and surrounding desert, 3) canyon bottom zones, 4) disturbed/field context, and 5) aquatic/wetland settings. While not all taxa could be reliably assigned to a given ecological setting, plant species that were dominant in a given community (and not any others) were given 
that designation, and taxa commonly found in only found in one vegetation zone were counted as evidence of exploitation of that patch (see Table 4.2 for specific plant associations). Fortunately, many of the most common plants identified in this study could be confidently assigned one of these ecological categories.

Table 6.9. Pollen Representation by Ecological Zone

$\begin{array}{clr}1 & \text { Pinyon/Juniper Woodland } & 4.86 \% \\ 2 & \text { Sage parkland and Desert Zones } & 3.29 \% \\ 3 & \text { Canyon Bottom Zones } & 15.50 \% \\ 4 & \text { Disturbed/Field Settings } & 57.37 \% \\ 5 & \text { Aquatic/Wetland Settings } & 1.07 \% \\ \text { Note: percentages exclude unidentified pollen. } & \end{array}$

Table 6.10. Macrofossil Representation by Ecological Zone

$\begin{array}{llc}1 & \text { Pinyon/Juniper Woodland } & 10.47 \% \\ 2 & \text { Sage parkland and Desert Zones } & <0.01 \% \\ 3 & \text { Canyon Bottom Zones } & - \\ 4 & \text { Disturbed/Field Settings } & 84.22 \% \\ & \text { - Excluding Corn } & 9.14 \% \\ 5 & \text { Aquatic/Wetland Settings } & 0.01 \%\end{array}$

Note: Percentages exclude unidentified plant remains, faunal remains, and charcoal.

Disturbed/field settings were the most common ecological association from the pollen evidence. High amounts of cheno-am and aster pollen, which made up just over $50 \%$ of all identifiable pollen, were the major driver for these results. Pollen from disturbed settings comprised $>57 \%$ of the pollen identified (Table 6.9). Although its inclusion would have increased the relative proportion of this patch, I did not include beeweed pollen as a disturbance plant in this analysis, because although commonly associated with disturbed settings, it is too common in other settings to confidently attribute it specifically to this patch.

The macrobotanical data exhibit similar results (Table 6.10), though largely due to the high occurrence of corn macrofossils ( $>75 \%)$ rather than cheno-am seeds and other uncultivated 
field/disturbance plants. Field plants other than corn made up approximately $9 \%$ of the identified macrobotanical remains by weight (Table 6.10).

Taxa associated with canyon bottom zones are the second most common pollen group, although pinyon-juniper woodland is the second most common ecological category of macrofossil remains (Table 6.9 and 6.10). This difference results mostly from the high concentrations of cottonwood pollen in a few samples juxtaposed against the relatively high weights of pine nut hulls. Excluding cottonwood pollen, other pollen from this patch composes only $2.27 \%$ of the pollen identified. Pinyon-juniper woodland was the only other ecological patch that significantly contributed to the diet. Nearly $5 \%$ of the pollen came from pine or juniper, but as discussed earlier much of that may have been ambient. However, the macrofossil results indicate regular incorporation of pine nuts in the diet and occasional use of juniper, as well. Evidence for all of the resources specifically associated with one of the ecological patches (see Table 4.2) from this study were found in at least one specimen, except saltbush, which was not identified in the pollen or macrofossil analyses.

\section{AMS Dating Results}

This project represents the first time human paleofecal samples were directly dated from Turkey Pen Ruin. Previous radiocarbon dates associated with the midden at Turkey Pen Ruin range from approximately $90 \mathrm{BC}$ to $\mathrm{AD} 540$ (calibrated) excluding one date of ca. $\mathrm{AD} 1045$ from layer A1 (see Chapter 3, Figure 3.6). Since the end of the White Dog Phase is generally reckoned at AD 1, 200 years prior to the commencement of Cedar Mesa's Grand Gulch Phase (Matson et al. 1988; Matson 1991; 2006a, b; Holstad 2010), cultural and subsistence patterns during this liminal period at Turkey Pen Ruin could contribute to our understanding of the culture history of Cedar Mesa. In light of this, I originally planned to incorporate direct 
radiocarbon dating of all of the samples considered here, in order to better establish a timeline for the midden and try to discern any temporal changes before and after the Grand Gulch Phase. However, the eight specimens submitted for AMS assay demonstrated that the fecal assemblage in this study dates to a relatively short time interval and does not span the entire BMII occupation of the site (Table 6.11, Figure 6.6). All of the paleofecal samples dated ca. AD 73 to AD 181 (calibrated), a period in the late BMII and just prior to the Grand Gulch phase. More recent AMS dates from corn cobs (run by Kelly Swarts) also indicate that the midden predates the Grand Gulch phase; these 14 new dates range from ca. 25 BC to AD 164 (Appendix A).

Table 6.11. AMS Dates and Associations of Paleofecal Samples

\begin{tabular}{|c|c|c|c|c|}
\hline$\underline{\text { Layer }}$ & Specimen & DirectAMS Codes & $\underline{\text { Radiocarbon Yrs. BP }}$ & Calibration \\
\hline A6 & 15 & D-AMS 005433 & $1927 \pm 26$ & AD $73(41-105)$ \\
\hline B1 & 11 & D-AMS 005431 & $1839 \pm 28$ & AD $173(135-211)$ \\
\hline B5 & 27 & D-AMS 005428 & $1897 \pm 26$ & AD $99(75-123)$ \\
\hline B5 & 17 & D-AMS 005434 & $1905 \pm 30$ & AD $93(66-120)$ \\
\hline $\mathrm{C} 4$ & 3 & D-AMS 005432 & $1833 \pm 31$ & AD $176(137-215)$ \\
\hline D2 & 1 & D-AMS 005429 & $1919 \pm 27$ & AD $81(53-109)$ \\
\hline $\mathrm{D} 2$ & 12 & D-AMS 005430 & $1938 \pm 30$ & $\mathrm{AD} 60(26-94)$ \\
\hline D3 & 19 & D-AMS 005435 & $1825 \pm 26$ & AD $181(145-217)$ \\
\hline
\end{tabular}




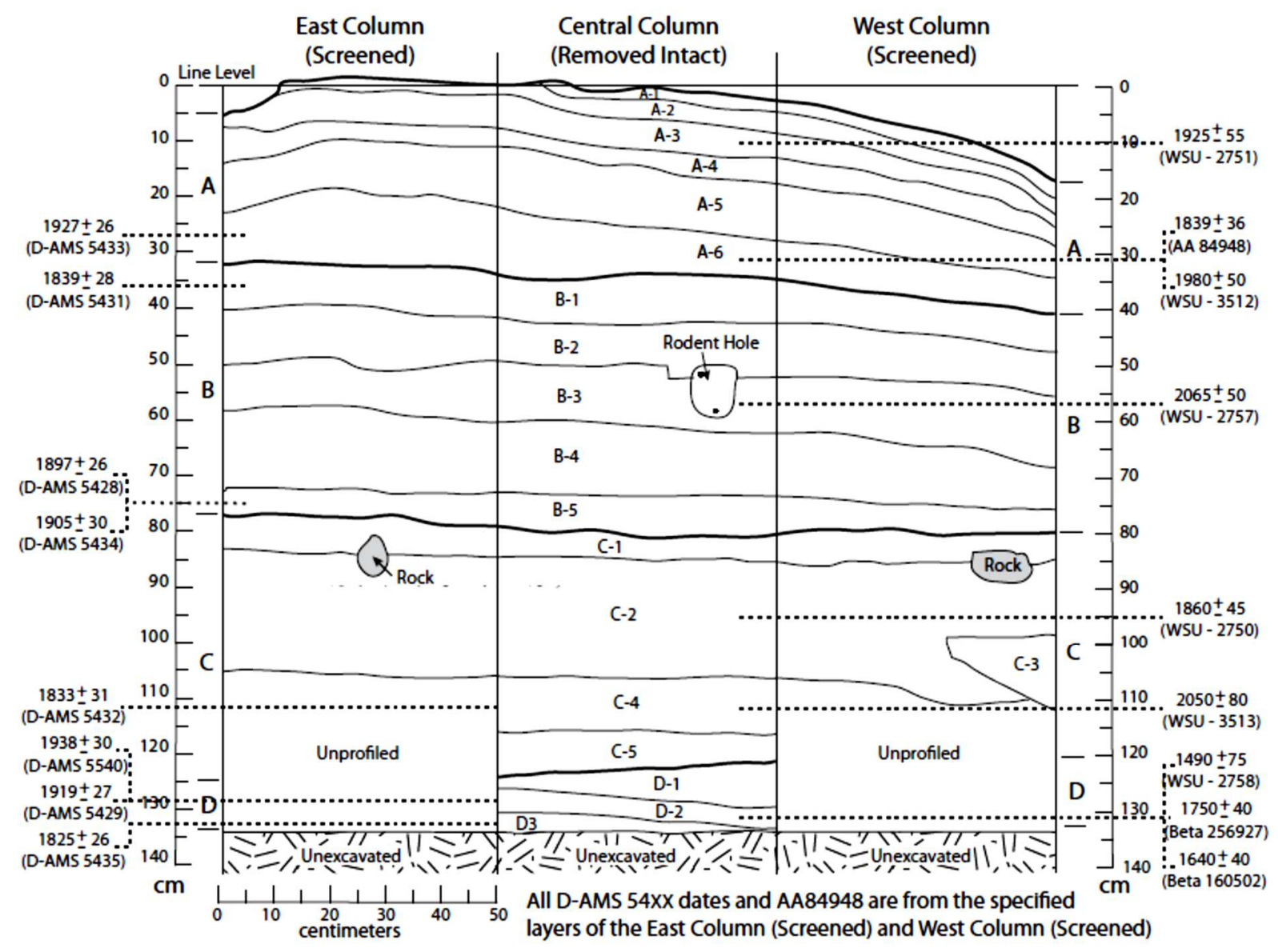

Figure 6.6. Midden profile with DirectAMS dates integrated.

Figure from Matson 2015; note: the date of 1750 BP from layer D2 should read 1900 BP.

Analysis

These results show that although the midden may have accumulated over a longer period of time, the paleofecal samples all seem to date within approximately 100 to 150 years of each other. Unfortunately, rather than clarifying the stratigraphic associations in the midden, these results further demonstrate the degree of mixing among the layers. For instance, the two earliest dates obtained (ca. AD 60 and AD 73), came from the deepest and most superficial strata, respectively, and the most recent date (AD 181) was associated with the deepest layer excavated. Although only eight of the samples (18\% of the total) were AMS dated, the proximity and 
overlap of the dates obtained, combined with the variation of strata and layer associations, suggest that all of the specimens in this project likely fall within or very close to the same timeframe. Note, all of the midden dates and specimen associations with strata and layer can be found in Appendix A.

\section{Conclusion}

Not unexpectedly, corn was the most common dietary staple by far and occurs in all but one sample. Although cultigen pollen was generally rare in these samples, the importance of corn is very obvious from the macrofossils. The importance of pine nuts is also clear from the macrofossils, though less so from the pollen. Pine nut hulls made up more than $9 \%$ of the macrofossils by weight, but they are also large and heavier than other seed hulls and coats, which potentially skews the data. The pollen and macrofossil results are both indicative of heavy reliance on cheno-ams. The fact that the relative pollen distributions in these samples does not align with that from surface samples of Cedar Mesa is strongly indicative of their relevance to dietary research. The DNA and faunal evidence demonstrates that a variety of meat was eaten, but meat consumption was not likely a daily activity. DNA evidence also demonstrates that yucca made a much greater contribution to the diet than indicated by either the pollen or macrofossil evidence. The bearing of these results on my hypotheses will be discussed in the next chapter. The low overlap between the results from the pollen, macrofossil, and DNA analyses at least partially results from the differing rates at which pollen, macroscopic constituents, and DNA move through the digestive tract as described in Chapter 4 (Deagle et al. 2010; Kelso 1976; Williams-Dean 1978).

Finally the AMS dating results indicate that in spite of the larger range of dates previously obtained from the midden, the preponderance of the paleofecal samples incorporated into this 
study appear to date within approximately 120 years of each other and to predate the Grand Gulch phase of the BMII period. This may be important for understanding the environmental circumstances that led into the final cultural phase of the BMII period and the shift toward mesatop habitations and dry farming associated with that period. 


\section{CHAPTER 7}

\section{Interpretations and Conclusions}

This chapter explains the interpretations and conclusions derived from the results presented in Chapter 6. It begins with a discussion of how the different lines of evidence either support or disprove each of the three hypotheses tested, focusing on how the results align with my expectations regarding incorporation of low-ranked resources, ecological patch use, and nutrition. The contextual relevance of the findings regarding corn fungus are integrated into this discussion, as well. Interpretations and conclusions are considered within the larger archaeological context that incorporates findings from other studies of BMII paleofeces (Aasen 1984; Androy 2003).

Consistent with previous research (Aasen 1984; Cooper et al. 2016; Matson 1991), the findings from this project indicate that corn was the most common resource in the diet. Other common resources included yucca, pine nuts, purslane, cheno-ams, and asters. Based on the DNA and macrofossil evidence, and corresponding isotopic evidence (Cooper et al. 2016), meat does not appear to have been consumed on a daily basis. These results have implications regarding my hypotheses on resource choice and the circumstances that encouraged an increased focus on farming during the BMII period.

\section{Hypothesis Testing}

Although the pollen, macrobotanical, and DNA data do not perfectly coincide, the combined narratives told by each line of evidence support the same overarching conclusions: 
resources with lower returns than corn were common inclusions in the diet, and a high proportion supplemental resources came from anthropogenic ecological patches.

Table 7.1. Resource Use and Nutritional Expectations

\begin{tabular}{|c|c|c|}
\hline & Hypothesis 1 & Hypothesis 2 \\
\hline \multirow{3}{*}{ 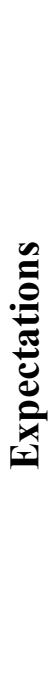 } & $\begin{array}{l}\text { Common: large game, pine nuts, } \\
\text { acorns, cactus fruit, mustard seed }\end{array}$ & $\begin{array}{l}\text { Common: grass seeds, sagebrush, } \\
\text { sedge, chokecherry, cheno-ams, juniper } \\
\text { berries, purslane, sunflower seeds, } \\
\text { rodent meat }\end{array}$ \\
\hline & $\begin{array}{l}\text { Rare or absent: grass seeds, juniper } \\
\text { berries, sagebrush, cheno-ams, } \\
\text { purslane, sunflower seeds, juniper, } \\
\text { sedge, chokecherry, rodent meat }\end{array}$ & $\begin{array}{l}\text { High return resources may or may not } \\
\text { be present. }\end{array}$ \\
\hline & $\begin{array}{l}\text { All nutritional needs are met by } \\
\text { cultigens and high-ranked wild } \\
\text { resources. }\end{array}$ & $\begin{array}{l}\text { Minimum nutritional requirements are } \\
\text { only met by including low-ranked wild } \\
\text { resources, or are not met. }\end{array}$ \\
\hline
\end{tabular}

Hypothesis 1

Hypothesis 1 tests the idea that people adopted and increased their reliance on farming because it was highly productive, and allowed them to focus their foraging efforts only on highreturn resources. If maize farming was adopted because it was highly efficient, then diet breadth should be narrow and exclusively focused on cultigens and high-ranked wild resources. Under this hypothesis people adopt agriculture to increase subsistence efficiency. Corn is nutritionally deficient, so if hypothesis 1 is correct, the resources used to supplement maize-based nutrition should augment the nutrient deficits of an all-corn diet and have caloric returns higher than, or equal to, maize farming. Resources such as pine nuts, game meat, cactus fruits, and mustard seed will be common dietary constituents, but Indian ricegrass, cheno-ams, purslane, dropseed, and 
other low-return resources should be very uncommon or absent. The results from this project do not demonstrate this.

Table 7.2. High-Ranked Wild Resource Representation

\begin{tabular}{|l|c|}
\hline Resource & Representation \\
\hline Pine nuts & High \\
\hline Deer & High \\
\hline Tansy mustard & Moderate \\
\hline Lagomorphs & Moderate \\
\hline Bighorn sheep & Low \\
\hline Pronghorn & Low \\
\hline Cactus fruit & Low \\
\hline Acorns & Absent \\
\hline Bitterroot & Absent \\
\hline Cattail Pollen & Absent \\
\hline Saltbush & Absent \\
\hline
\end{tabular}

High representation $=$ economic representation in $\geq 30 \%$, moderate $=10-29 \%$, and low representation $=<10 \%$. So for pollen and macrofossil representation high $\geq 14$ samples with macrofossil representation and/or more than 10 pollen grains per sample, moderate representation $=5-13$ samples, and low $=1-4$ samples. For DNA evidence High $=$ presence detected in $6+$ samples, Moderate $=2-5$ samples, and Low $=1$ sample.

Corn is the most common macrofossil constituent; its presence in all but one of the paleofecal samples indicates that it was eaten on a daily basis, probably multiple times a day. This further supports prior assertions that the earliest BMII inhabitants of Cedar Mesa were maize-reliant farmers (Aasen 1984; Coltrain and Janetski 2013; Matson 1991; Matson et al. 1990). It is also clear from the macrofossil data that pine nuts were an important resource, which is consistent with the ethnographic record (Robbins et al. 1916; Stevenson 1909; Whiting 1939). Other than cattail pollen, pine nuts have the highest calculated return rates of any plant resource available in this area, so their incorporation into the diet is expected. Although storable, pine nuts are seasonal and somewhat unpredictable in terms of production (Jeffers 1995). Even though they are high-ranked and provide well-balanced protein, they may have been less dependable than other resources. 
Although pine nut hulls were the second most common macrofossil constituent by weight, low-ranked cheno-ams, Indian ricegrass, and purslane leaves were also common dietary constituents, making it impossible to conclude in favor of this hypothesis (Table 7.2 and 7.3). Mustard seed and pollen were found in some samples, but none of the other high-ranked wild plant resources expected to contribute heavily to the diet under this hypothesis were found in more than a few specimens. Pine pollen was present in most of the samples, but generally at low concentrations. Given that pine pollen is wind-blown, produced in large quantities, and is ubiquitous in soil samples from Cedar Mesa (West 1978), it is likely that much of the pine pollen in these specimens was ingested incidentally. Regardless of the amount of pine nuts in the diet, small amounts of pine pollen are expected in these samples as a result of its presence it in the air, dust, and drinking water. So the pollen data do not offer much support for this hypothesis.

The lack of evidence for squash consumption was surprising. DNA from Cucurbitaceae was definitively identified in only three specimens. Although the exact species attributions are not clear (Appendix C), based on the morphology of the seeds identified in the samples, Cucurbita pepo spp. (which includes pumpkin, winter squash, and summer squash) is the most likely identification. The DNA, macrobotanical, and pollen evidence all seem to indicate relatively infrequent squash consumption. But the seeds offer an excellent supplement to the three amino acids lacking in maize (lysine, isoleucine, and tryptophan), as well as folate and iron (see Table 5.2), so their low inclusion in the diet is interesting and may indicate a lack of need for squash as a supplemental resource. The fruit, on the other hand, is relatively low-ranked and less nutritious than the seeds, so would be expected to be an uncommon inclusion in the diet under this hypothesis. One explanation for the low levels of squash in the diet may be that squash was used primarily as gourd containers, particularly since this period is preceramic. 
The majority of the DNA evidence also did not support this hypothesis. Only seven of the 20 samples tested for DNA contained faunal DNA, and only five samples contained bone fragments (three of which also tested positive for faunal DNA). These findings do not support daily meat consumption, and are in agreement with conclusions from previous studies from this site (Aasen 1984; Cooper et al. 2016). One interesting pattern, however, is that paleofeces that tested positive for faunal DNA tended to test positive for more than one taxon, indicating that meat may have been only intermittently or seasonally reliable. Deer was the most common meat found; but still only $30 \%$ of specimens tested returned a positive result for deer DNA, and since these were also some of the specimens that tested positive for pronghorn and bighorn sheep DNA, large game was only identified in six of the 20 specimens tested. Although high-ranked resources like pine nuts and deer are found in some of these samples, the inclusion of low-ranked resources determines diet breadth. The relative amounts of high- and low-ranked wild resources, therefore, do not meet the expectations set forward for this hypothesis (Table 7.1).

\section{Hypothesis 2}

This hypothesis tests the idea that farming is adopted and intensified out of necessity in an unproductive environment. If food production was adopted in response to low or diminished occurrence of high-value resources, then I expect a broad diet that includes low-ranked wild resources, indicative of intensified foraging to supplement maize-based nutrition. This hypothesis proposes that resource depression (decreased encounter rates with high-ranked resources) pushed BMII peoples to depend on horticulture. Because dependency on a maizebased diet presents nutritional deficits, I expect that foragers will attempt to target the highest ranked resources available to compensate for these deficiencies; if resources were depressed, however, they would have had to focus their energies on lower return resources to meet caloric 
and nutritional needs. If resources within the environment were truly depressed, then one or more nutrients required to supplement maize may be insufficiently provided by supplemental resources. If maize farming was adopted and intensified because the availability of high ranked wild resources was declining, then average foraging returns would have been lower than 1100$1700 \mathrm{kcal} / \mathrm{hr}$. In this case, wild resources brought into the diet to supplement maize should include lower ranked resources such as Indian ricegrass, cheno-ams, sedge seeds, and sunflower seed.

Table 7.3. Low-Ranked Wild Resource Representation

\begin{tabular}{|l|c|}
\hline Resource & Representation \\
\hline Yucca & High* \\
\hline Cheno-am & High \\
\hline Aster & High \\
\hline Purslane & High \\
\hline Indian ricegrass & Moderate $^{\wedge}$ \\
\hline Dropseed & Moderate $^{\wedge}$ \\
\hline Juniper & Low $^{*}$ \\
\hline Sedge & Low \\
\hline Onion & Low \\
\hline Rodent & Low \\
\hline
\end{tabular}

See explanation below Table 7.2.

* Yucca is included as high, although much of its representation may have come from recreational use (quid chewing).

${ }^{\wedge}$ For Indian ricegrass and dropseed the pollen evidence was not included since grass pollen was not identified to the species level. Furthermore, dropseed use is listed as moderate because it appears in seven samples, but it should be noted that these were mostly trace amounts.

This hypothesis is supported by both the pollen and macrofossil data, and is indirectly supported by the lack of high-ranked faunal resources in the DNA results. The pollen data demonstrate economic use of plant resources with much lower caloric return rates than corn 
including cheno-ams, juniper, cottonwood, and asters. Cheno-am and aster pollen were the two most common pollen types and their economic association is definitive. Deervetch and onion pollen were also relatively common, but the nature of their inclusion in the diet is not as clear. Deervetch is mildly toxic, but is edible in small quantities (Kunkel 1984) and the most common ethnographically documented use for this plant among Southwestern groups was as a medicine (Appendix E). Alternatively, because deervetch is entomophilous (insect pollinated) its presence may have originated from the consumption of honey. Onion is a very low-ranked resource, but its inclusion does not necessarily signify a need to rely on low-return resources since this plant is often chosen as a seasoning to enhance the flavor of food rather than for sustenance (Whiting 1939; Appendix E).

Economic use of low-ranked arboreal resources is also evident in the pollen data. Juniper pollen is one of the most common pollen-types on Cedar Mesa, along with pine (West 1978). It occurs in very low frequencies in most samples, possibly a result of incidental ingestion, but several fecal samples have high frequencies of juniper that more likely resulted from direct consumption. The occurrence of juniper is difficult to interpret because it can be used as a food or a medicine (see Appendix E). The miniscule amounts of associated macrobotanicals suggest that juniper may have been ingested as part of a liquid decoction, which is potentially consistent with ritual or medicinal rather than purely dietary choice.

The most prevalent arboreal pollen is cottonwood, a taxa that is not as common in Cedar Mesa soil samples. It is completely absent from half of the paleofecal specimens and occurred at very low levels in most of those samples in which it was found. However, cottonwood dominated the pollen content of a few specimens (Figure 6.1). This is significant because high densities of cottonwood pollen likely reflect the ethnographically documented practice of eating 
cottonwood buds or catkins (Ford 1968; Reinhard 1988, 68; Appendix E). Also, given the seasonal association of cottonwood blooms (winter-spring), and the absence of corn macrofossils from one of these samples, this may indicate a supplemental reliance on the canyon bottom patch for fresh food when other patches were less productive and stored food was running low. This lends support to hypothesis 2 .

The regular occurrence of low-ranked macrofossils such as cheno-am seeds, purslane leaves, Indian ricegrass (also found commonly by Kate Aasen), and sunflower further support this hypothesis. Although uncommon, dropseed was also found in a few samples. Dropseed is one of the lowest-ranked resources on the landscape and should only be included in the diet as a last resort, when other resources are unavailable. Evidence for occasional rodent consumption is consistent with this interpretation. Although return rates of rodent meat vary, rodents are the lowest-ranked prey resource and consumption may indicate a need for protein or other nutrients (such as B vitamins) not readily available from plants (see Table 5.4a).

Faunal DNA was detected in only seven out of 20 of the samples tested, and many of these were larger-sized, high-ranked prey items. Even though meat was probably not consumed on a daily basis, these data indicate that high-value prey were available on the landscape albeit either in low frequencies or sporadically. Low levels of meat consumption are in line with conclusions based on other lines of evidence (Coltrain et al. 2006; 2007; 2012; Cooper et al. 2016; Hawley et al. 1943). The relatively low frequencies of meat intake can also be interpreted as evidence against hypothesis 1 and in support of hypothesis 2 since meat generally has significantly higher returns than plant-based resources (see Table 5.4a).

Yucca was the most common resource discovered through DNA evidence and its presence may be a result of consumption of the fruit (a relatively high-ranked plant resource) or 
from chewing the leaves as quids, which would provide fewer calories and represent a more recreational use. Because specific return rates for yucca are unavailable, I used agave as a proxy which has estimated returns of $1014 \mathrm{kcal} / \mathrm{hr}$. (Riley 2012; Table 5.4a), just below the calculated return rates for slash-and-burn farming (Barlow 2002; Table 5.4b). However, the aDNA analysis identified Yucca brevifolia or Joshua tree rather than the more common and locally available $Y$. angustissima (narrow-leaf yucca) or Y. baccata (banana yucca) (Appendix D). This species association is unexpected because Joshua tree is not a current yucca varietal in this area. This might demonstrate a difference between the ancient and modern flora of Cedar Mesa because Joshua tree currently only lives in the more arid Mojave Desert, but is often found in communities of blackbrush, as well as juniper and pinyon (Gucker 2006), all of which have been identified on Cedar Mesa (West 1978). This could be a result of long-distance trade, an error in the DNA identification or the use of genetic markers that are not divergent within Yucca species, or it may support Rouston and colleagues' (2011) argument for a drought during this period, as discussed in Chapter 3. If this is evidence of harsher environmental conditions bears out, then the Joshua tree evidence supports hypothesis 2.

On the whole, the combination of plant and animal resources identified in these specimens indicate that the BMII occupants of Turkey Pen Ruin were able to obtain adequate nutrition from the resources in their environment, but only with the inclusion of very low-ranked resources such as purslane leaves. There is no specific evidence for dietary deficiencies. However, it is probable that at certain times of year it may have been more difficult to get sufficient amounts of essential nutrients, since many important supplemental resources are only available seasonally. Moreover, vitamins A and C, are difficult to obtain from stored foods, and are generally only abundant in sources such as fresh herbs and organ meat (Table 5.2). Some of 
the resources listed are also less nutritious when cooked (Table 5.2), and since stored foods are more likely to be cooked, essential amino acids, folate, and iron could have been hard to come by at times when fresh resources were scarce. Given that no particular nutrient was entirely missing from the diet or obtained solely from corn, it is impossible to conclude that the diet was nutrientdeficient, even though a nutritionally sound diet is also not definitive.

\section{Hypothesis 3}

If the combined concentration of disturbance plants with cultigens increased overall subsistence efficiency of maize fields above the average efficiency for other ecological patches, then I expect the resources growing in that patch to become a large focus of the diet. If this hypothesis is correct, then weedy disturbance plants such as purslane, cheno-ams, asters, and members of the family Brassicaceae should figure prominently in the diet as a complement to maize and there may be greater evidence for animals that can be easily exploited close to agricultural fields such as cottontail and deer. This hypothesis is not an alternative to hypothesis 1 and 2, but if this hypothesis is supported, there should be less focus on low-ranked, wild resources that do not thrive in disturbed/field contexts such as sagebrush, juniper, chokecherry, dropseed, and Indian ricegrass than on weedy annuals, regardless of their ranking. 
Table. 7.4. Expectations of Resource Use and Nutrition for Hypothesis 3

\begin{tabular}{c|c} 
Hypothesis 3 \\
\hline & $\begin{array}{c}\text { Common: cheno-ams, mustard, purslane, asters, } \\
\text { possibly corn smut }\end{array}$ \\
& $\begin{array}{c}\text { If H1 and 3, then field plants + high-return } \\
\text { resources. }\end{array}$ \\
& $\begin{array}{c}\text { If H2 and 3, then still a greater emphasis on } \\
\text { field plants, but with low-return wild resources, } \\
\text { too. }\end{array}$ \\
& $\begin{array}{c}\text { Minimal nutritional requirements are met with } \\
\text { large contributions from uncultivated field } \\
\text { plants. }\end{array}$
\end{tabular}

The paleofeces from Turkey Pen Ruin contain much higher relative amounts of pollen from plants associated with field/disturbed contexts than the ambient pollen from surface samples on Cedar Mesa (West 1978). These pollen samples were dominated by disturbance pollen, particularly cheno-am and aster (Table 6.1). These two categories of pollen occurred in relatively high densities and were present in the majority of specimens. Based on archaeological pollen, as well as the high amount of seeds recovered at sites, West $(1978,146)$ concluded that cheno-ams may have been economically important on Cedar Mesa and others have even suggested that they were cultivated (Hurst et al. 2011, 96). Although the actual evidence for cultivation is lacking, the regular use of cheno-ams and other disturbance plants is strongly supported by the pollen and macrofossil data. 
Table 7.5. Field Resource Representation

\begin{tabular}{|l|l|}
\hline Resource & Representation \\
\hline Cheno-am & High \\
\hline Aster & High \\
\hline Purslane & High \\
\hline Corn fungus & High \\
\hline Mustard & Moderate \\
\hline
\end{tabular}

See explanation below Table 7.2.

Plants from the mustard family (Brassicaceae), are also associated with disturbed contexts on Cedar Mesa (West 1978). Mustard pollen was found in 20 samples and was the dominant pollen in two. Since mustard plants are insect pollinated, their pollen does not travel far in large amounts; it should only be found at high concentrations in paleofeces through direct ingestion of the seeds, blossoms, or leaves of the plant, or possibly from honey consumption.

The high occurrence of cheno-am, aster, and mustard pollen across the majority of samples, including clusters of attached grains in some samples, indicates that direct consumption of these taxa was common. Although cheno-am and aster pollens (particularly ragweed) are potentially windblown, the most logical interpretation of their common occurrence is direct consumption because it is unlikely that much of the pollen from these resources would contaminate the edible portions of cultigens in the same field. Corn has a thick, external husk that would protect the internal kernels. Many American squash varietals are covered by a thick rind that is not generally eaten but is used for utilitarian purposes. However, the potential for minimal pollen contamination does exist if disturbance pollen blew directly onto cultivated plants. 
Uncultivated field plants (cheno-ams, sunflower, purslane, and mustard) make up nearly $36 \%$ of the macrofossils, excluding corn, unidentified remains, and charcoal. These plants made up nearly as much of the macrofossils by weight as pine nut remains, and significantly more than Indian ricegrass and other low-ranked wild resources (Table 6.6). Although they contributed less to the overall weight than cheno-am seeds, purslane leaves were the most common uncultivated macrobotanical identifiable to a taxonomic level (i.e., not including miscellaneous plant fibers, charcoal, or unidentified material). Purslane leaves were found in 20 of the 44 samples tested, suggesting they were consumed on a very regular basis.

Mustard seeds were not found in as many specimens as cheno-am seeds, but mustard seed coats are extremely thin and friable, so their preservation may have been lower than other plant seed coats. Mustard seeds are also actually relatively high-ranked among plant resources; although their calculated return rates are variable based on the source. Both Barlow (2002) and Simms (1987) estimate maximum returns for mustard seeds at around $1300 \mathrm{kcal} / \mathrm{hr} .$, placing them on par with returns for corn farming. Like cheno-ams and sunflower seeds, they also offer a complementary suite of nutrients to corn, and are very high in essential amino acids and iron (Table 5.2). Mustard greens were not identified in these specimens, but are an excellent source of vitamins A and C. It is possible that some of the mustard pollen identified in the paleofecal specimens came from leaf consumption, but without identified macrofossils this cannot be confirmed.

Given the pollen data described above, and the fact that purslane leaves occurred in nearly half of the samples, and mustard pollen and seeds were found in several samples, field patches were probably an important focus of foraging activities, as well as farming. Nutritionally speaking, weedy annuals may have had more to offer than higher-ranked local plant resources 
such as yucca and pine nuts. While calorically superior, pine nuts and yucca do not contain as wide an array or as high amounts of supplemental amino acids, vitamins, folate, and iron as field-based resources (Table 5.2). In fact, many of the uncultivated plants that commonly grow in fields are excellent supplements to a maize-centered diet. Neither sunflower/aster, nor cheno-am seeds and leaves are ranked as highly as corn, but they do provide a complementary suite of nutrients. Both resources are excellent supplements to five of the seven of the nutrients highlighted in Chapter 5, and though the sunflower and cheno-am seeds do not provide vitamin A or C, the leaves do provide these nutrients (Table 5.2). Cheno-am leaves were not detected during my analyses, but they were identified by Kate Aasen (1984). Regardless of leaf consumption, these were clearly an important source of essential amino acids, folate, and iron, since there is evidence of seed consumption. One potential caveat to this is that cheno-am seeds are much more nutritious raw than cooked (Table 5.2), so stored cheno-am seeds would have been less nutritious than freshly harvested seeds consumed raw. Purslane leaves are significant sources of iron and vitamins $\mathrm{A}$ and $\mathrm{C}$ (Table 5.2). The regular inclusion of purslane may indicate that it was an important source of these two vitamins. The regular consumption of a resource that is so calorically inefficient, however, may also mean that this was one of the only options for a regular source of vitamins $\mathrm{A}$ and $\mathrm{C}$.

The faunal DNA and macrofossil evidence suggest a focus on certain ecological patches often associated with specific elevations. For instance, the presence of cottontail in lieu of jackrabbit (Lepus spp.) DNA indicates that people were hunting in more mesic environments at mid-range elevations, since jackrabbits prefer low-elevation, arid environments (Cowan et al. 2012, 132). Deer was the most common animal DNA and was identified in six samples. The higher proportion of deer than other meat resources is consistent with the faunal remains 
identified from this site (Powers 1984, Appendix L, 89-95) and further indicates that hunting efforts were focused on more mesic, higher elevations, where deer were more abundant (Cowan et al. 2012, 132). However, the inclusion of rabbit, deer, and rodent bone could also be indicative of field hunting, since all three of these taxa are drawn to disturbed/field contexts (Adams 2004; Ford 1984; Szuter 1989), whereas animals such as bighorn sheep and pronghorn are not. Garden hunting was also hypothesized by Androy (2003) for the BMII occupation at Boomerang Shelter. Androy based his assessment on faunal remains from the site, but it is an apt comparison since it temporally overlaps with Turkey Pen Ruin's BMII occupation. As mentioned above, the low inclusion of faunal resources supports hypothesis 2 , but given the high inclusion of animals that often favor anthropogenic environments, this evidence also potentially supports hypothesis 3 .

The findings related to corn smut consumption are significant for several reasons. Although corn smut was previously associated with Turkey Pen Ruin by Karl Reinhard (Powell 1984, 99; Reinhard 1988, 69), it was not been explicitly linked to the Basketmaker II period, and the potential nutritional significance of these findings have not been explored. The specific association of corn smut consumption with the Basketmaker II period is significant due to the need to supplement maize-based nutrition prior to bean horticulture as discussed in Chapter 5 . Because U. maydis produces a massive amount of spores per gall (>200 billion) (Valverde et al. 2012, 202), and because pollen (and ostensibly spores) can take multiple weeks to completely pass through the digestive tract (Kelso 1976; Williams-Dean 1978), it is difficult to estimate how commonly and in what quantities corn smut may have been consumed. However, it is clear from the evidence that corn smut was purposely consumed and likely with some regularity given that spores were found in all but one specimen and were often found at higher concentration values than economic pollen species (Table 6.8). 
The tolerance and consumption of corn fungus may support either hypothesis 1 or 2 . By modern estimates corn smut infection decreases overall maize output by an average of $10 \%$ (Christensen 1963). Maize outputs for simple horticulture and slash-and-burn farming for this region are estimated to range from $2-15$ bushels per acre $(50.8-381 \mathrm{~kg})$ (Barlow 2002, 79-80), so a $10 \%$ loss could range from $5.08-38.1 \mathrm{~kg}$ of corn per acre - that is a potential loss in caloric output of 19,609 - 147,066 calories. This could support the idea the crops were not needed to make ends meet. Of course these are likely over-estimates since the infected ears were still consumed. Estimates also are based strictly on calories and not caloric return rates. On the other hand, if the environment was very unproductive, nutrients may have been a larger limiting factor than calories, in which case the consumption of corn smut would support hypothesis 2 . The dietary inclusion of corn smut as a nutritional supplement to corn most strongly supports hypothesis 3 , since it represents the use of a resource that naturally occurs in the field to augment maize-based nutrition.

As outlined in Chapter 5, corn fungus provides a complementary source of amino acids to corn, particularly lysine, and is high in other essential nutrients such as folate. In light of this, it comes as no surprise that BMII agriculturalists included corn fungus in their diet, despite the reduction in crop output. If the nutrients available from corn smut were a stronger limiting factor than calories, then corn fungus growth should be encouraged or at least tolerated and it should be a regular part of the diet.

\section{Discussion and Conclusions}

Based on the variety of resources included in the diet, I conclude that people living at Turkey Pen Ruin during the BMII period were most likely able to obtain adequate nutrients. However, judging from the presence of low-ranked resources, including Indian ricegrass, 
purslane, and rodent meat, it was likely difficult to get adequate calories and/or nutrients from available resources and food stores during some periods. Samples such as 9, 18, and 26 indicate that high-return resources were not always available to supplement maize. Further, specimen 18, which contained no corn, suggests that perhaps even maize stores were not entirely reliable. Several samples had higher amounts of low-return resources such as cheno-ams and Indian ricegrass than corn, under these circumstances, hypothesis 1 cannot be supported.

The consumption of low-return resources such as Indian ricegrass, cheno-ams, dropseed, purslane, rabbit, and rodent meat all lend support to hypothesis 2 . From this evidence it appears that early farmers on Cedar Mesa intensified farming efforts (and perhaps initially adopted cultivation) due to unfavorable environmental circumstances and in order to make ends meet. If environmental circumstances were more favorable, the wild resources incorporated into the diet should have higher return rates and resources such as Indian ricegrass and cheno-ams would not have been necessary to supplement the diet. Given these data, I conclude that people were pushed to adopt and intensify food production at Cedar Mesa. Since many of the items identified in this study are low-return resources, and some of the most common inclusions are associated with anthropogenic niche-construction. In light of the above, it seems unlikely that Cedar Mesa could have supported a population of hunter-gatherers. This is not a new suggestion, R.G. Matson (1991) suggested that hunting on Cedar Mesa would not have been a favorable endeavor. This explains the lack of evidence for much Archaic occupation on Cedar Mesa and further supports the idea that expansion into this area may have resulted from population growth in other, more productive areas.

This research also provides strong support for hypothesis 3 since the majority of resources included that are ranked lower than corn are associated with the field patch. Resources 
strongly associated with fields and human disturbance such as chenopodium, amaranth, purslane, and corn fungus were important supplements to the incomplete suite of essential nutrients in maize. This indicates that productivity of the field as a larger patch (including uncultivated resources) encouraged increased reliance on agriculture. These resources increased nutritional and caloric output from the fields and provided more immediate returns from field work (by harvesting weeds), to complement the marginal returns derived from caring for maize plants. The high percentage representation of cheno-am, aster, and other disturbance pollen, combined with the relatively common occurrence of cheno-am seeds, purslane leaves, and potentially the inclusion of rodent and cottontail support a high dependence on the field as a patch including cultigens as well as wild plants and animals (hypothesis 3 ). Since the preponderance of supplemental resources (and nutrients) seems to have come from uncultivated field-based resources and resources higher ranked than corn, it is impossible to conclude solely in support of hypothesis 2 .

Turkey Pen Ruin is one of the earliest permanent occupations of the Cedar Mesa area (Lipe et al. 2011; Matson et al. 1990). Its small size, lack of grandiose architecture, and remote location perhaps belie the important role that studies of this site have played in developing our understanding of Southwestern archaeology and particularly the BMII period. The numerous paleofeces and well-preserved organic remains from Turkey Pen provide an excellent opportunity to study the subsistence and cultural developments that presuppose the final cultural phase of BMII — the Grand Gulch phase, which is most famously associated with Cedar Mesa. Evidence from this site was pivotal in establishing the independent development of turkey domestication in the U.S. Southwest (Speller et al. 2010), and it has been important to underscoring the centrality of corn to the BMII diet. The ancestral Puebloans that lived on and 
around Cedar Mesa helped to lay the cultural foundations for Puebloan subsistence and economics (Coltrain et al. 2006; 2007; 2012; Matson 1991; 2006a, b; Matson and Chisholm 1991), ritual and material culture (Eddy 1961; 1966; Lipe et al. 2016; Speller et al. 2010), and even settlement patterns (Dohm 1994). The high level of maize dependence evident among the earliest Cedar Mesa Basketmakers is consistent with the migration model for maize adoption (Matson 1999, 2002). However, the data from this project demonstrate that the earliest farming populations on Cedar Mesa were living in marginal environmental conditions, under such circumstances populations that were once more dependent on foraged resources should increase their focus on food production. Meaning this is also in line with expectations from the indigenous adoption model, which states that maize reliance should be contingent upon environmental circumstances (Irwin-Williams 1973; Roth 2017). Furthermore, the high inclusion of weedy disturbance plants is consistent with expectations regarding maize's incorporation into Archaic subsistence strategies (Roth 2017, 36-37), as is the continued use of other plants like Indian ricegrass that were staples of the Archaic diet in the region. As such, the evidence from this project does not conclusively support either model for the movement of maize into the Southwest, rather it demonstrates that the initial level of agricultural dependence at Cedar Mesa does not conflict with the expectations of the indigenous adoption model given the environmental circumstances.

Investigation of the midden contents at Turkey Pen Ruin provides a rare opportunity to focus on the subsistence practices of the earliest occupants of this area. Data from the paleofecal specimens examined here provide strong support for a largely sedentary farming population, regular use of uncultivated, field-based resources, and the earliest evidence for the use of corn fungus in the Southwest. These results demonstrate the motivating factors for the adoption and 
intensification of food production at Cedar Mesa. This project also reveals the nature of economic decisions and practical motivations of Basketmaker II farmers and can help shape future understanding of the process of development of the Puebloan agricultural complex in the northern Southwest. 


\section{BIBLIOGRAPHY}

Aasen, Diane K. 1984. "Pollen, Macrofossil, and Charcoal Analyses of Basketmaker Coprolites from Turkey Pen Ruin, Cedar Mesa, Utah.” M.A. thesis, Washington State University.

Achilli, Alessandro, Ugo A. Perego, Hovirag Lancioni, Anna Olivieri, Francesca Gandini, Baharak Hooshiar Kashani, Vincenza Battaglia, Viola Grugni, Norman Angerhofer, Mary P. Rogers, Rene J. Herrera, Scott R. Woodward, Damian Labuda, David Glenn Smith, Jerome S. Cybulski, Ornella Semino, Ripan S. Malhi, and Antonio Torroni. 2013. "Reconciling migration models to the Americas with the variation of North American native mitogenomes." PNAS 110, no. 35 (August): 14308-14313. Accessed May 16 2016; doi:10.1073/pnas.1306290110.

Adams, J.R., C.S. Goldberg, W.R. Bosworth, J.L. Rachlow, and L.P. Waits. 2011. "Rapid species identification of pygmy rabbits (Brachylagus idahoensis) from faecal pellet DNA." Molecular Ecology Resources 11: 808-812.

Adams, Karen R. 2004. "Anthropogenic Ecology of the North American Southwest." In People and Plants in Ancient Western North America, edited by Paul E. Minnis, 167-204. Washington, D.C.: Smithsonian Books.

Allentoft, Morten E., Matthew Collins, David Harker, James Haile, Charlotte L. Oskam, Marie L. Hale, Paula F. Campos et al. 2012. "The half-life of DNA in bone: measuring decay kinetics in 158 dated fossils." Proceedings of the Royal Society of London B: Biological Sciences 279: 4724-4733.

Ammerman, Albert J. and Luigi Luca Cavalli-Sforza. 1973. "A population model for the diffusion of early farming in Europe." In The Explanation of Culture Change: Models in Prehistory, edited by Colin Renfrew, 343-358. London: Duckworth.

Ammerman, Albert J. and Luigi Luca Cavalli-Sforza. 1984. The Neolithic Transition and the Genetics of Populations in Europe. Princeton: Princeton University Press.

Androy, Jerry. 2003. "Agriculture and mobility during the Basketmaker II period: the coprolite evidence.” M.A. thesis, Northern Arizona University.

Bailey, Flora L. 1940. "Navaho foods and cooking methods." American Anthropologist 42, no. 2: $270-290$.

Baker, H.G. 1965. "Characteristics and mode of origin of weeds." In The Genetics of Colonizing Species, edited by H.G. Baker and G.L. Stebbins, 147-172. New York: Academic Press. 
Baker, H.G. 1974. "The Evolution of Weeds." Annual Review of Ecology and Systematics Vol. 5 (November): 1-24.

Ball, Ronald O., Glenda Courtney-Martin, and Paul B. Pencharz. 2006. "The In Vivo Sparing of Methionine by Cysteine in Sulfur Amino Acid Requirements in Animal Models and Adult Humans." The Journal of Nutrition 136: 1682S-1693S.

Bar-Yosef, Ofer. 1998. "The Natufian Culture in the Levant: Threshold to the Origins of Agriculture." Evolutionary Anthropology 6: 159-177

Bar-Yosef, O. and A. Belfer-Cohen. 2000. "Early sedentism in the near east." In Life in Neolithic Farming Communities: Social Organization, Identity, and Differentiation, edited by Ian Kuijt, 19-37. New York: Kluwer Academic/Plenum Publishers.

Barkley, Fred A. 1934. "The statistical theory of pollen analysis.” Ecology 13, no. 3 (July): 283289.

Barlow, K. Renee. 2002. "Predicting Maize Agriculture among the Fremont: An Economic Comparison of Farming and Foraging in the American Southwest." American Antiquity 67, no. 1: 65-88.

Barlow, K. Renee. 2006. "A Formal Model for Predicting Agriculture among the Fremont." In Behavioral Ecology and the Transition to Agriculture, edited by Douglas J. Kennett and Bruce Winterhalder, 87-102. Berkeley and Los Angeles: University of California Press.

Battillo, Jenna, Karen Lupo, Jaime Mata-Miguez, Deborah Bolnick, Bill Lipe, and R.G. Matson 2014. "No bones about it: aDNA sequencing of dietary remains from human paleofeces." Paper presented at the International Conference on Archaeozoology Meetings, San Rafael, Argentina, September 22-27.

Battillo, Jenna, Karen Lupo, Jaime Mata-Miguez, Rick W.A. Smith, and Deborah Bolnick. 2016. "Botanical and aDNA Analysis of the Dietary Contents of Human Paleofeces from Turkey Pen Ruin, Utah." Poster presented at the annual Society for American Archaeology meetings, Orlando, Florida, April 6-10.

Bedell, Melanie Lynne. 2000. "Late Pueblo II and Pueblo III Cliff Dwellings and Community Patterns in the Grand Gulch, Southeastern Utah." MA thesis, Washington State University.

Bellwood, Peter. 2001. Early agricultural population diasporas? Farming, languages, and genes. Annual Review of Anthropology 30:181-207. 
Benson, Larry V. 2011.” Factors Controlling Pre-Columbian and Early Historic Maize Productivity in the American Southwest, Part 1: The Southern Colorado Plateau and Rio Grande Regions." Journal of Archaeological Method and Theory 18: 1-60. USGS Staff -Published Research. Paper 745. Accessed May 28, 2016; http://digitalcommons.unl.edu/usgsstaffpub/745.

Berry, Claudia F. and Michael S. Berry. 1986. Chronological and Conceptual Models of the Southwestern Archaic. In Anthropology of the Desert West: Essays in Honor of Jesse D. Jennings, edited by Carol J. Condie and Don D. Fowler, 253-327. Anthropological Papers No. 110. Salt Lake City: University of Utah Press.

Binford, Louis R. 1968. "Post-Pleistocene Adaptations." In New Perspectives in Archaeology, edited by Sally R. Binford and Louis R. Binford, 313-41. Chicago: Aldine.

Bird, D., and J.F. O'Connell. 2006. "Behavioral ecology and archaeology." Journal of Archaeological Research 14: 143-188.

Blanco, Alcalde, and E. Hernandez X. 1972. "Estudio preliminar sobre la competencia nutrimental entre arvenses y el maiz, y sus efectos sobreel rendimientodel cultivo." Resumes, I Congreso Latinoamericano, 94-96. Sociedad Botanical de Mexico, S.C.

Bolnick Deborah.A., Holly.M. Bonine, Jaime Mata-Míguez, Brian M. Kemp, Meradeth H. Snow, and Steven A. LeBlanc. 2012. "Nondestructive sampling of human skeletal remains yields ancient nuclear and mitochondrial DNA." American Journal of Physical Anthropology 147: 293-300.

Boserup, Ester. 1965. The Conditions of Agricultural Growth. London: Earthscan.

Borgerhoff Mulder, M. 1988. "Is the polygyny threshold model relevant to humans? Kipsigis evidence." In Human Mating Patterns, edited by C.G.N. Mascie-Taylor and A.J. Boyce, 209230. Cambridge: Cambridge University Press.

Borgerhoff Mulder M. 1992. “Women’s strategies in polygynous marriage: Kipsigis, Datoga, and other East African cases." Human Nature 3: 45-70.

Boyd, Robert, and Peter J. Richerson. 1985. Culture and the Evolutionary Process. Chicago: University of Chicago Press.

Braidwood, Robert J. 1963. "Summary of prehistoric investigations in Kurdistan in relation to climatic change." Changes of Climate: 251-54.

Braidwood, Robert J. and Howe, B. 1960. Prehistoric Investigations in Iraqi Kurdistan. Chicago: University of Chicago Press. 
Bressani, Ricardo, J.M. Gonzáles, J. Zúñiga, M. Breuner, and L.G. Elías. 1987. "Yield selected chemical composition and nutritive value of 14 selections of amaranth grain." Journal of the Science of Food and Agriculture 38, no. 4 (January): 347-356.

Bressani, Ricardo, Lloyd W. Rooney, Ximena Quintero, and Sergio O. Serna Saldivar. 1997. "Fortification of Corn Masa Flour with Iron and/or Other Nutrients: A Literature and Industry Experience Review." Report for SUSTAIN, Washington, D.C.

Bressani, Ricardo, J. C. Turcios, and A. S. C. De Ruiz. 2002. "Nixtamalization effects on the contents of phytic acid, calcium, iron and zinc in the whole grain, endosperm and germ of maize." Revista de Agaroquimica y Tecnologia de Alimentos 8, no. 2: 81-86.

Broughton, Jack M., 1999. Resource Depression and Intensification during the Late Holocene San Francisco Bay: Evidence from the Emeryville Shellmound. Berkeley: University of California Press.

Broughton, Jack M., Michael D. Cannon, and Eric J. Bartelink. 2010. "Evolutionary ecology, resource depression, and niche construction theory: applications to central California huntergatherers and Mimbres-Mogollon agriculturalists." Journal of Archaeological Method and Theory 17, no. 4: 371-421.

Broughton, Jack M., and James F. O'Connell. 1999. "On evolutionary ecology, selectionist archaeology, and behavioral archaeology." American Antiquity 64, no. 1: 153-165.

Bryant, Vaughn M., Jr., 1974. "Prehistoric diet in southwest Texas: the coprolite evidence." American Antiquity 39, no. 3: 407-420.

Bryant, Vaughn M., Jr., and Stephen A. Hall. 1993. "Archaeological palynology in the United States: a critique." American Antiquity 58, no. 2 (April): 277-286.

Bryant, Vaughn M., Jr., and Karl J. Reinhard. 2012. "Coprolites and Archaeology: The Missing Links in Understanding Human Health." In Vertebrate Coprolites, edited by Adrian P. Hunt, Jesper Milàn, Spencer G. Lucas, and Justin A. Spielmann. Albuquerque: New Mexico Museum of Natural History and Science, Bulletin 57.

Burger, Oskar, Marcus J. Hamilton, and Robert Walker. 2005. "The prey as patch model: optimal handling of resources with diminishing returns." Journal of Archaeological Science 32: 1147-1158.

Bye, Robert A., Jr. 1979. "Incipient domestication of mustards in northwestern Mexico." Kiva 44: $237-256$.

Bye, Robert A., Jr. 1981. "Quelites - Ethnoecology of Edible Greens Past, Present, and Future." Journal of Enthnobiology 1, no. 1: 109-123. 
Bye, Robert A., Jr. 2000. “Quelites-Ethnoecology of Edible Greens-Past, Present and Future.” In Ethnobotany: A Reader, edited by Paul Minnis, 197-213. Norman: University of Oklahoma Press.

Callen, Eric O., and T. W. M. Cameron. 1960. "A prehistoric diet revealed in coprolites." New Scientist 8, no. 190: 35-40.

Commission for Environmental Cooperation (CEC). 1997. Ecological Regions of North America: Toward a Common Perspective.

Cerqueira, Maria T., Martha McMurry Fry, M. S., and William E. Connor. 1979. "The food and nutrient intakes of the Tarahumara Indians of Mexico." The American Journal of Clinical Nutrition 32: 905-915.

Charles, Mona C. and Sally J. Cole. 2006. "Chronology and Cultural Variation in Basketmaker II." Kiva 72, no. 2: 167-216.

Charnov, E. L. 1976. "Optimal foraging: the marginal value theorem.” Theoretical Population Biology 9: 129-136.

Charnov, E.L., and G.H. Orians. 1973. "Optimal Foraging: Some Theoretical Explorations.” Manuscript, Department of Biology, University of Utah, Salt Lake City.

Charnov, E. L., G.H. Orians, and K. Hyatt. 1976. "Ecological implications of resource depression." American Naturalist, 110: 247-259.

Chisholm, Brian and R.G. Matson. 1994. "Carbon and Nitrogen Isotopic Evidence on Basketmaker II diet at Cedar Mesa, Utah.” Kiva 60, no. 2: 239-256.

Childe, V. Gordon. 1928. The Most Ancient East: A Study of Indo-European Origins. London: Kegan Paul.

Childe, V. Gordon. 1935. New Light on the Most Ancient East. London: Routledge and Kegan Paul.

Childe, V. Gordon. 1951. Man Makes Himself. New York: The New American Library, Inc.

Christensen, Jonas Jergon. 1963. “Corn smut caused by Ustilago maydis.” Monographs. American Phytopathology Society, No. 2.

Cohen, Mark Nathan. 1977. The Food Crises in Prehistory: Overpopulation and the Origins of Agriculture. New Haven: Yale University Press.

Cohen, Mark Nathan, and George J. Armelagos. eds., 1984. Paleopathology at the Origins of Agriculture. Cambridge, MA: Academic Press. 
Cole, Sally J. 1993. "Basketmaker Rock Art at the Green Mask Site, Southeastern Utah." In Anasazi Basketmaker, Papers from the 1990 Wetherill-Grand Gulch Symposium, edited by Victoria Atkins, 192-220. Cultural Resource Series 24. Bureau of Land Management, Salt Lake City, Utah.

Coltrain, Joan. Brenner, and Joel C. Janetski. 2013. "The stable and radio-isotope chemistry of southeastern Utah Basketmaker II burials: dietary analysis using the linear mixing model SISUS, age and sex patterning, geolocation and temporal patterning." Journal of Archaeological Science 40, no. 12: 4711-4730.

Coltrain, Joan Brenner, Joel C. Janetski and Shawn Carlyle. 2006. "The stable and radioisotope chemistry of eastern Basketmaker and Pueblo groups in the Four Corners regions of the American Southwest: Implications for Anasazi diets, origins and abandonments." In Stories of Maize: Multidisciplinary approaches to the prehistory, biogeography, domestication and evolution of maize, edited by John Staller, Robert Tykot and Bruce Benz, 276-287. San Diego: Elsevier.

Coltrain, Joan Brenner, Joel Janetski and Shawn Carlyle. 2007. "The Stable-and Radio-isotope chemistry of western Basketmaker burials: Implications for early Puebloan diets and origins." American Antiquity, 72 no. 2: 311-321.

Coltrain, Joan Brenner, Joel C. Janetski, and Michael D. Lewis. 2012. "A re-assessment of Basketmaker II cave 7: massacre site or cemetery context." Journal of Archaeological Science, 39 no. 7: 2220-2230.

Colwell-Chanthaphonh, Chip. 2010. Living Histories: Native Americans and Southwestern archaeology. Lanham, Maryland: AltaMira Press.

Cooper, Catherine, Colin Smith, Karen Lupo, R.G. Matson, and Michael Richards. 2013 "Short Term Diet Change at Turkey Pen Ruins: Examining Stable Isotope Patterns in Archaeological Hair." Poster presented at the annual Society for American Archaeology meetings, Honolulu, Hawaii, April 3-7.

Cooper, Catherine, Karen Lupo, R.G. Matson, William D. Lipe, Colin Smith, and Michael P. Richards. 2016. "Short-Term variability of human diet at Basketmaker II Turkey Pen Ruins, Utah: Insights into domesticate use and supplementation from bulk and single amino acid isotope analysis of hair." Journal of Archaeological Science: Reports, 5: 10-18.

Cordas, Emily. 2000. “The Analysis of Macroplant Remains from a Midden Deposit in Turkey Pen Ruin in Cedar Mesa, Utah.” M.A. thesis, University of British Columbia, Vancouver.

Cordell, Linda S., and George J. Gumerman. 2006. "Cultural Interaction in the Prehistoric Southwest." In Dynamics of Southwest Prehistory, edited by Linda Cordell and George Gumerman, 1-18. Tuscaloosa: The University of Alabama Press. 
Cordell, Linda S., and Maxine E. McBrinn. 2012. Archaeology of the Southwest. Walnut Creek, California: Left Coast Press, Inc.

Cowan, Justin A., Timothy A. Kohler, C. David Johnson, Kevin Cooper, and R. Kyle Bocinsky. 2012. "Supply, demand, return rates, and resource depression: hunting in the Village Ecodynamics world." In Emergence and Collapse of Early Villages: Models of Central Mesa Verde Archaeology, edited by Timothy A. Kohler and Mark D. Varien, 129-143. Berkeley: University of California Press.

da Fonseca, Rute R., Bruce D. Smith, Nathan Wales, Enrico Cappellini, Pontus Skoglund, Matteo Fumagalli, José Alfredo Samaniego, Christian Carøe, María C. Ávila-Arcos, David E. Hufnagel, Thorfinn Sand Korneliussen , Filipe Garrett Vieira, Mattias Jakobsson, Bernardo Arriaza, Eske Willerslev, Rasmus Nielsen, Matthew B. Hufford, Anders Albrechtsen, Jeffrey Ross-Ibarra, and M. Thomas P. Gilbert. 2015. "The origin and evolution of maize in the Southwestern United States.” Nature Plants: Letters 1 (January): 14003.

Darwin, Charles. 1859. On the Origin of Species by Natural Selection. London: Murray.

Das, Saubhik. 2014. "Domestication, phylogeny and taxonomic delimitation in underutilized grain Amaranthus (Amaranthaceae) - a status review.” Feddes Repertorium 123, 4: 273-282.

Daubenmire, R. F. 1943. "Vegetational zonation in the Rocky Mountains." The Botanical Review 9, no.6: 325-393.

Davis, William E. and Jonathan D. Till. 2014. "The Lime Ridge Clovis Site." Archaeology Southwest 28, no. 3 and 4: 23-24.

Deagle, Bruce E., André Chiaradia, Julie McInnes, and Simon N. Jarman. 2010. "Pyrosequencing faecal DNA to determine diet of little penguins: is what goes in what comes out?" Conservation Genetics 11, no. 5: 2039-2048.

Dean, Glenna. 1993. "Use of Pollen Concentrations in Coprolite Analysis: An Archaeobotanical Viewpoint with a Comment to Reinhard et al. 1991." Journal of Ethnobiology 13, no. 1: 102114.

Diamond, Jared. 1997. Guns, Germs, and Steel: The Fates of Human Societies.

Diamond, Jared, and Peter Bellwood. 2003. "Farmers and their languages: the first expansions." Science 300, no. 5619: 597-603. New York: W. W. Norton \& Company, Inc.

Diehl, Michael W. 1997. "Rational behavior, the adoption of agriculture, and the organization of subsistence during the Late Archaic Period in the Greater Tucson Basin." Archeological Papers of the American Anthropological Association 7, no. 1: 251-265.

Doebley, John. 2004. "The genetics of maize evolution.” Annual Review of Genetics 38 (December): 37-59. 
Dohm, Karen M. 1994. "The Search for Anasazi Village Origins: Basketmaker II Dwelling Aggregation on Cedar Mesa." Kiva 60, no. 2: 257-277.

Douglass, Andrew Ellicott. 1929. "The secret of the Southwest solved by talkative tree rings." National Geographic Magazine 56:736 -770.

Dozier, Edward P. 1964. "The Pueblo Indians of the Southwest: A Survey of the Anthropological Literature and a Review of Theory, Method, and Results." Current Anthropology 5, no. 2: 79-97.

Drake, Brandon L., W.H. Wills, and Erik B. Erhardt. 2012. "The 5.1 ka aridization event, expansion of piñon-juniper woodlands, and the introduction of maize (Zea mays) in the American Southwest.” The Holocene 22, no. 12 (December): 1-8.

Eddy, Frank W. 1961. Excavations at Los Pinos Phase Sites in the Navajo Reservoir District. Museum of New Mexico. Santa Fe, New Mexico: Papers in Anthropology, No. 4.

Eddy, Frank W. 1966. Prehistory of the Navajo Reservoir District, Northwestern New Mexico. Santa Fe, New Mexico: Museum of New Mexico Papers, 15.

Eggan, Fred. 1950. Social Organization of the Western Pueblos. Chicago, Illinois: University of Chicago Press.

Ellwood, Emily C., M. Paul Scott, William D. Lipe, R.G. Matson, and John G. Jones. "Stoneboiling maize with limestone: experimental results and implications for nutrition among SE Utah pre-ceramic groups." Journal of Archaeological Science, 40 no. 1 (2013): 35-44.

Emlen, J.M. 1966. "The Role of Time and Energy in Food Preference." American Naturalist 100: 611- 617.

Faegri, K. and J. Iversen. 1989. Textbook of Pollen Analysis, Fourth Edition by K. Faegri, P.E. Kaland, and K. Krzywinski. New York: John Wiley \& Sons.

Ferguson, Jeffrey R., 2007. “A Seasonal Foraging Model for Food Resource Utilization in Central California and the Eastern Woodlands." PhD diss., University of Colorado.

Fish, Suzanne K. 2004. "Corn, crops, and cultivation in the North American Southwest." In People and Plants in Ancient Western North America, edited by Paul E. Minnis, 115-166. Washington, D.C.: Smithsonian.

Flannery, K.V. 1969. "Origins and ecological effects of early domestication in Iran and the Near East." In The Domestication and Exploitation of Plants and Animals, edited by P. J. Ucko and G.W. Dimbleby, 73-100. London: Duckworth. 
Flannery, K.V. 1973. "The origins of agriculture." Annual Review of Anthropology 2: 271-310.

Flannery, K.V., ed. 1976 The Early Mesoamerican Village. Walnut Creek: Left Coast Press, Inc.

Flannery, K.V. 1986. Guila Naquitz. Orlando: Academic Press.

Flannery, K.V. 1994. "Childe the evolutionist: a perspective from Nuclear America." The archaeology of V. Gordon Childe: contemporary perspectives, edited by David R. Harris, 101-120. Chicago: University of Chicago Press.

Ford, Richard I. 1968. "An Ecological Analysis Involving the Population of San Juan Pueblo, New Mexico.” PhD diss., University of Michigan.

Ford, Richard I. 1984. "Ecological Consequences of Early Agriculture in the Southwest." In, Papers on the Archaeology of Black Mesa, Arizona, edited by Stephen Plog and Shirley Powell, Vol. 2, 127-138. Carbondale, Illinois: Southern Illinois University Press.

Ford, Richard I. 2000. "Human Disturbance and Biodiversity: A Case Study from Northern New Mexico." In Biodiversity and Native America edited by Paul Minnis and W. J. Elisens, 207222. Norman, Oklahoma: University of Oklahoma Press.

Forster, Peter, Rosalind Harding, Antonio Torroni, and Hans-Jurgen Bandelt. 1996. "Origin and evolution of Native American mtDNA variation: a reappraisal." American Journal of Human Genetics 59, no. 4: 935-945.

Fowler, Don D. 2000. A Laboratory for Anthropology: Science and Romanticism in the American Southwest, 1846-1930. Albuquerque, New Mexico: University of New Mexico Press.

Fry Gary F. 1976. "Analysis of prehistoric coprolites from Utah.” University of Utah Anthropology Papers, 97. Salt Lake City: University of Utah Press.

Fu, Qiaomei, Pavao Rudan, Svante Pääbo, and Johannes Krause. 2012. "Complete mitochondrial genomes reveal Neolithic expansion into Europe.” PLoS One 7, no. 3: e32473.

Gage, Daniel J. 2004. "Infection and invasion of roots by symbiotic, nitrogen-fixing rhizobia during nodulation of temperate legumes." Microbiology and Molecular Biology Reviews 68, no. 2: 280-300.

Galef, Bennett G., and Luc-Alain Giraldeau. 2001."Social influences on foraging in vertebrates: causal mechanisms and adaptive functions." Animal Behaviour 61, no. 1: 3-15.

Gebhardt, S.E., and R.G. Thomas. 2007. "Nutrient Composition of Amaranth, Kamut, Quinoa, Spelt and Teff." Paper presented at the AACC International Annual Meeting, San Antonio, Texas, October 7-10. 
Geib, Phil R., and Dale Davidson. 1994. "Anasazi origins: A perspective from preliminary work at Old Man Cave." Kiva 60, no. 2: 191-202.

Geib, Phil R., and Carrie C. Heitman. 2015. "The Relevance of Maize Pollen for Assessing the Extent of Maize Production in Chaco Canyon." In Chaco Revisited: New Research on the Prehistory of Chaco Canyon, New Mexico, edited by Carrie C. Heitman and Stephen Plog, 66-95. Tucson: University of Arizona Press.

Geib, Phil R., and Kimberly Spurr. 2000. "Basketmaker II-III Transition on the Rainbow Plateau." In Foundations of Anasazi Culture: The Basketmaker-Pueblo Transition, edited by Paul F. Reed, 175-200. Salt Lake City, Utah: University of Utah Press.

Geib, Phil R., and Kimberly Spurr. 2002. "Forager to Farmer Transition on the Rainbow Plateau." In Traditions, Transitions, and Technologies: Themes in Southwestern Archaeology, edited by Sarah Schlanger, 224-244. Boulder, Colorado: University of Colorado Press.

Gottfried, Gerald J., Thomas Swetnam, Craig D. Allen, Julio Betancourt, and Alice L. ChungMacCoubrey. 1995. “Chapter 6: Pinyon-Juniper Woodlands.” In Ecology, Diversity, and Sustainability of the Middle Rio Grande Basin, edited by Deborah M. Finch, Joseph A. Tainter, 95-132. Fort Collins: USDA Forest Service Technical Report.

Grayson, Donald K. 1984a. "Archaeological associations with extinct Pleistocene mammals in North America.” Journal of Archaeological Science 11: 213-221

Grayson, Donald K., 1984b. "Nineteenth century explanations of Pleistocene extinctions: A review and analysis.” In Quaternary Extinctions: A Prehistoric Revolution, edited by Paul S. Martin and R.G. Klein, Tucson: University of Arizona, Press.

Grayson, Donald K. 2011. The Great Basin: A Natural Prehistory. Berkeley: University of California Press.

Grayson, Donald K., and David J. Meltzer. "A requiem for North American overkill." Journal of Archaeological Science 30, no. 5 (May): 585-593.

Green, Dee F., and Herrick Hanks. 1985. "Prosecuting Without Regulations: ARPA Successes and Failures." American Archeology 5, no. 2:103-107.

Gremillion, Kristen J. 2004. "Seed processing and the origins of food production in eastern North America." American Antiquity 69: 215-234.

Gremillion, Kristen J., and Dolores R. Piperno. 2009. "Human behavioral ecology, phenotypic (developmental) plasticity, and agricultural origins: insights from the emerging evolutionary synthesis." Current Anthropology 50, no. 5: 615-619. 
Gucker, Corey L. 2006. Yucca brevifolia. In: Fire Effects Information System, [Online]. U.S. Department of Agriculture, Forest Service, Rocky Mountain Research Station, Fire Sciences Laboratory (Producer). Available:

http://www.fs.fed.us/database/feis/plants/tree/yucbre/all.html. Accessed April 8, 2017.

Guernsey, Samuel James, and Alfred Vincent Kidder. 1921. Basket-maker caves of northeastern Arizona: Report on the explorations, 1916-17. Vol. 8. Cambridge, Massachusetts: The Museum.

Haas, William Randall, Jr. 2006. "The Social Implications of Basketmaker II Cordage Design Distribution." Kiva 71, no. 3: 275-298.

Haase IV, William Rudolph. 1983. "Pueblo II and Pueblo III settlement patterns on Cedar Mesa, southeastern Utah." MA thesis, Washington State University.

Hall, Stephen A. 2010. "Early Maize Pollen from Chaco Canyon, New Mexico, USA." Palynology 34, no. 1: 125-137.

Hames, Raymond B., and William T. Vickers. 1982. "Optimal diet breadth theory as a model to explain variability in Amazonian hunting." American Ethnologist 9, no. 2 (May): 358-378.

Hard, Robert J., Raymond P. Maudlin, and Gerry R. Raymond 1996. "Mano size, stable carbon isotopes, and macrobotanical remains as multiple lines of evidence for maize dependence in the American Southwest." Journal of Archaeological Method and Theory 3, no. 4: 253-318.

Harlan, Jack R. 1971. "Agricultural origins: centers and noncenters.” Science, New Series 174, no. 4008 (October): 468-474.

Harlan, Jack R. 1976. "Genetic resources in wild relatives of crops." Crop Science 16, no. 3 : $329-333$.

Harlan, Jack R. 1992. "Origins and processes of domestication." In Grass Evolution and Domestication, edited by Geoffrey Peter Chapman, 159-175. Cambridge: Cambridge University Press.

Harlan, Jack R. 1995. The Living Fields: Our Agricultural Heritage. Cambridge: Cambridge University Press.

Harris, David R. 1989. "An evolutionary continuum of people-plant interaction.” In Foraging and Farming: The Evolution of Plant Exploitation, edited by David R. Harris, Gordon C. Hillman, 11-26. London: Unwin Hyman, Ltd.

Haury, Emil W. 1962. "The Greater American Southwest.” In Courses Toward Urban Life, edited by R.J. Braidwood and G.R. Willey, 106-131. Chicago, Illinois: Aldine. 
Hawkes, Kristen, and James F. O’Connell. 1981. “Affluent Hunters? Some Comments in Light of the Alyawara Case." American Anthropologist 83, no. 3: 622- 626.

Hawkes, Kristen, and James F. O'Connell. 1992. "On optimal foraging models and subsistence transitions." Current Anthropology 33, no. 1: 63-66.

Hawkes, K., J.F. O’Connell, N.G. Blurton Jones, H. Alvarez, and E.L. Charnov. 1998. "Grandmothering, menopause, and the evolution of human life histories." PNAS 95, no. 3: $1336-1339$.

Hawley, Florence, Michel Pijoan, and C. A. Elkin. 1943. "An inquiry into food economy and body economy in Zia Pueblo.” American Anthropologist 45, no. 4: 547-556.

Hayden, Brian. 1990. "Nimrods, piscators, pluckers and planters: the emergence of food production." Journal of Anthropological Research 9: 31-69.

Hayden, Brian. 1992. "Models of Domestication". In Transitions to Agriculture in Prehistory, edited by Anne Birgitte Gebauer and T. Douglas Price, 11-18. Madison: Prehistory Press.

Hayden, Brian, and Suzanne Villeneuve. 2011. "A Century of Feasting Studies." Annual Review of Anthropology Vol. 40 (October): 433 -449.

Heiser, Charles B., and David C. Nelson. 1974. "On the origin of the cultivated chenopods (Chenopodium)." Genetics 78, no. 1: 503-505.

Helbaek, Hans, 1960. "The paleoethnobotany of the Near East and Europe." In Prehistoric Investigations in Iraqi Kurdistan, edited by R.J. Braidwood and B. Howe, 99-113. Chicago: University of Chicago Press.

Hill, Jane H. 2001. Proto-Uto-Aztecan: A Community of Cultivators in Central Mexico? American Anthropologist 103: 913-934.

Hill, Jane H. 2002. Toward a Linguistic Prehistory of the Southwest: “Azteco-Tanoan” and the Arrival of Maize Cultivation. Journal of Anthropological Research 58: 457-475.

Hill, K., and A.M. Hurtado. 1991. "The evolution of premature reproductive senescence and menopause in human females: an evaluation of the "grandmother hypothesis." Human Nature 2: 313-350.

Hobbes, Thomas. Leviathan. London: Penguin Books, 1651. http://www.classicly.com/readleviathan-online-free. Accessed March 8, 2016.

Hollenbach, Kandace D. 2009. Foraging the Tennessee River Valley, 12,500 to 8,000 Years Ago. Tuscaloosa: University of Alabama Press. 
Holstad, Emily C. 2010. "Basketmaker II Stone-boiling Technology at Cedar Mesa, Utah: An experimental study.” M.A. Thesis, Washington State University.

Hough, Walter. 1897. "The Hopi in relation to their plant environment." American Anthropologist 10, no. 2: 33-47.

Huber, E.K., and C. Van West, eds. 2005. Archaeological data recovery in the New Mexico transportation corridor and first five-year permit area, Fence Lake Coal Mine Project, Catron County, New Mexico, 5 Vols, Technical Series 84. Tucson: Statistical Research Incorporated (SRI).

Huckell, Bruce B. 1995. Of Marshes and Maize: Preceramic Agricultural Settlements of the Cienega Valley, Southeastern Arizona. Anthropological Papers No. 59. Tucson: University of Arizona Press.

Huckell, Bruce B., Lisa W. Huckell, and Karl K. Benedict. 2002. "Maize Agriculture and the Rise of Mixed Farming-Foraging Economies during the Second Millennium B.C." In Traditions, Transitions, and Technologies: Themes in Southwestern Archaeology, edited by Sarah H. Schlanger, 136-159. Boulder: University Press of Colorado.

Huckell, Lisa W. 2006. "Ancient maize in the American Southwest." In Histories of Maize: Multidisciplinary Approaches to the Prehistory, Biogeography, Domestication, and Evolution of Maize, edited by J.E. Staller, R.H. Tykot, and B.F. Benz, BF, 97-107. San Diego: Elsevier.

Huckell, Lisa W., and Mollie S. Toll. 2004. "Wild plant use in the North American Southwest." In People and Plants in Ancient Western North America, edited by Paul Minnis, 37-114. Washington, DC: Smithsonian Books.

Hurst, W., F. E. Smiley, and M. R. Robins. 2011. "Early Farmers at the Earth's Backbone: Basketmaker II in the Comb Ridge Area.” Southwestern Lore 77, no. 2: 89-101.

Irwin-Williams, Cynthia. 1973. The Oshara Tradition: Origins of Anasazi Culture. Contributions to Anthropology Vol. 5, no. 1. Portales: Eastern New Mexico University Press.

Jeffers, Richard M. 1995. "Piñon Pine Seed Production, Collection, and Storage." In Desired Future Conditions for Piñon-Juniper Ecosystems, edited by D.W. Shaw, E.F. Aldon, and C. LoSapio, 191-197. Fort Collins: US Department of Agriculture, Forest Service, Rocky Mountain Forest and Range Experimental Station.

Jensen, Kim, David Mayntz, Søren Toft, Fiona J. Clissold, John Hunt, David Raubenheimer, and Stephen J. Simpson. 2012. "Optimal foraging for specific nutrients in predatory beetles." Proceedings of the Royal Society of London B: Biological Sciences 279, no. 1736: 22122218. 
Jones John G. 1983. "Analysis of the Coprolites Recovered from the Dolores Archaeological Program." Report on file at the Department of Anthropology, Texas A\&M University.

Juárez-Montiel, Margarita, Sandra Ruiloba de León, Griselda Chávez-Camarillo, César Hernández-Rodríguez, and Lourdes Villa-Tanaca. 2011. "Huitlacoche (corn smut), caused by the phytopathogenic fungus Ustilago maydis, as a functional food." Revista Iberoamericana de Micología 28, no. 2: 69-73.

Kahl, H. 1987. "Allelopathic Effects in the Maize-Quelites-Agroecosystem of the Tarahumara Indians." Journal of Agronomy and Crop Science 158, no. 1: 56-64.

Kalinova, Jana and Eva Dadakova. 2009. "Rutin and Total Quercetin Content in Amaranth (Amaranthus spp.)." Plant Foods for Human Nutrition 64, no. 1: 68-74.

Kantner, John. 2004. Ancient Puebloan Southwest, Vol. 5. Cambridge: Cambridge University Press.

Kaplan, David. 2000. "The darker side of the 'original affluent society'.” Journal of Anthropological Research 56, no. 3: 301-324.

Kaplan, Hillard, and Kim Hill. 1992. "The evolutionary ecology of food acquisition.” In Evolutionary ecology and human behavior, edited by E. A. Smith and B. Winterhalder, 167201. New York: de Gruyter.

Kapp, R.O. 1969. How to Know Pollen and Spores. The Pictured Key Nature Series. Dubuque: Wm C. Brown Company Publishers.

Kay, Adam. 2002. "Applying optimal foraging theory to assess nutrient availability ratios for ants." Ecology 83, no. 7: 1935-1944.

Keegan, Marcia. 1999. Pueblo People: Ancient Traditions, Modern Lives. Santa Fe: Clear Light Publishers.

Kelly, R.L. 1995. The Foraging Spectrum: Diversity in Hunter-Gatherer Lifeways. Clinton Corners: Eliot Werner Publications, LLC.

Kelso, Gerald Kay. 1976. "Absolute pollen frequencies applied to the interpretation of human activities in northern Arizona." PhD diss., University of Arizona.

Kemp, Brian M., A. Gonzalez-Olivier, R.S. Mathis, Cara Monroe, K.B. Schroeder, J. McDonough, G. Rhett, A. Resendez, R.I. Peñaloza-Espinosa, L. Buentello-Malo, C. Gorodesky, and D.G. Smith. 2010. Evaluating the Farming/Language Dispersal Hypothesis with Genetic Variation Exhibited by Populations in the Southwest and Mesoamerica. Proceedings of the National Academy of Sciences Vol. 107, no. 15: 6759-6764. 
Kemp Brian M., Cara Monroe, William D. Lipe, and R.G. Matson. 2009. "Genetic analysis of Basketmaker II coprolites from the Turkey Pen Ruins site in Southeastern Utah." Paper presented at the Society for American Archaeology Annual Meeting, Atlanta, GA April 2226.

Kennett, D.J., and Bruce Winterhalder, eds. 2006. Behavioral Ecology and the Transition to Agriculture. Berkeley: University of California Press.

Kidder, Alfred V. 1927. "Southwestern Archaeological Conference." Science 66, no. 1716: 48691.

Kidder, Alfred Vincent, and Samuel James Guernsey. 1919. Archeological explorations in northeastern Arizona. Vol. 572, no. 65. Washington, D.C.: US Government Printing Office.

Kirchhoff, Paul. 1954. "Gatherers and Farmers in the Greater Southwest: A Problem in Classification.” American Anthropologist 56 no. 4: 529-550.

Kliks, M.M. 1985. "Studies on the traditional herbal anthelmintic Chenopodium ambrosioides: ethnopharmacological evaluation and clinical field trials." Social Science Medicine 21, no. 8: 879-886.

Kohler, Timothy A., and Kelsey Reese. 2012. "Long and spatially variable Neolithic Demographic Transition in the North American Southwest." PNAS 111, no. 28: 1010110106.

Kohler, Timothy A., Mark D. Varien, and Aaron M. Wright, editors. 2010. Leaving Mesa Verde: Peril and Change in the Thirteenth-Century Southwest. Tucson: The University of Arizona Press.

Krebs, J.R., and N.B. Davies. 1987. An Introduction to Behavioral Ecology, 2nd ed. Sunderland: Sinauer.

Kunkel, Günther. 1984. Plants for Human Consumption. Oberreifenberg: Koeltz Scientific Books.

Larson, Greger, Elinor K. Karlsson, Angela Perri, Matthew T. Webster, Simon YW Ho, Joris Peters, Peter W. Stahl, Phillip J. Piper, Frode Lingaas, Merete Fredholm, Kenine E. Comstock, Jaime F. Modiano, Claude Schelling, Alexander I. Agoulnik, Peter A. Leegwater, Keith Dobney, Jean-Denis Vigne, Carles Vilà, Leif Andersson, and Kerstin Lindblad-Toh. 2012. "Rethinking dog domestication by integrating genetics, archeology and biogeography." PNAS 109, no. 23: 8878-8883.

Latham, M.C. 1997. "Human nutrition in the developing world (No. 29).” Rome: Food \& Agriculture Org. Corporate Document Repository. 
LeBlanc, Steven A., Lori S. Cobb Kreisman, Brian M. Kemp, Francis E. Smiley, Shawn W. Carlyle, Anna N. Dhody, and Thomas Benjamin. 2007. "Quids and aprons: Ancient DNA from artifacts from the American Southwest." Journal of field Archaeology 32, no. 2: 161175.

Lee, Richard B. and Irven. DeVore. 1968. Man the Hunter. Chicago: Aldine.

Liebman, Matt, Charles L. Mohler, and Charles P. Staver, eds. 2001. Ecological Management of Agricultural Weeds. Cambridge: Cambridge University Press.

Leithead, H.L., L.L. Yarlett, and T.N. Shiflett. 1976. 100 Native Forage Grasses in 11 Southern States. USDA SCS Agriculture Handbook No. 389. Washington, DC: United States Department of Agriculture.

Lekson, Steve. 1985. "Largest settlement size and the interpretation of socio-political complexity at Chaco Canyon, New Mexico." Haliksa'i: UNM Contributions to Anthropology, 4: 68-75.

León-Ramírez, Claudia G., José Alejandro Sánchez-Arreguín, and José Ruiz-Herrera. 2014."Ustilago maydis, a delicacy of the aztec cuisine and a model for research." Natural Resources 5, no. 8: 256-267.

Lepofsky, Dana. 1986. "Preliminary Analyses of Flotation Samples from the Turkey Pen Ruin, Cedar Mesa, Utah." Manuscript on file, Laboratory of Archaeology, University of British Columbia.

Lipe, William D. 1966. "Anasazi Culture and its Relationship to the Environment in the Red Rock Plateau Region, Southeastern Utah.” Ph.D. diss., Yale University.

Lipe, William D. 1999a. History of Research. In Colorado prehistory: a context for the Southern Colorado River Basin, edited by William D. Lipe, Mark D. Varien, and R.H. Wilshusen, 5194. Denver: Colorado Council of Professional Archaeologists.

Lipe, William D. 1999b. “Basketmaker II (1000 B.C.-A.D. 500).” In Colorado prehistory: a context for the Southern Colorado River Basin, edited by William D. Lipe, Mark D. Varien, and R.H. Wilshusen, 132-165. Denver: Colorado Council of Professional Archaeologists.

Lipe, William D. 2006. "Notes from the North." In The Archaeology of Chaco Canyon, an Eleventh-Century Pueblo Regional Center, edited by Stephen H. Lekson, 261-313. Santa Fe: School of American Research Press.

Lipe, William D., R.G. Matson, and Brian M. Kemp. 2011. "New Insights From Old Collections: Cedar Mesa, Utah, Revisited." Southwestern Lore, Journal of Colorado Archaeology 77, no. 2:103-111. 
Lipe, William D., R. Kyle Bocinsky, Brian S. Chisholm, Robin Lyle, David M. Dove, RG Matson, Elizabeth Jarvis, Kathleen Judd, and Brian M. Kemp. 2016. "Cultural and Genetic Contexts for Early Turkey Domestication in the Northern Southwest." American Antiquity 81, no. 1: $97-113$

Lupo, Karen D. 2007. "Evolutionary foraging models in zooarchaeological analysis: recent applications and future challenges." Journal of Archaeological Research, 15:143-189.

MacArthur, R.H. and E.R. Pianka. 1966. "On optimal use of a patchy environment." The American Naturalist 100, no. 916 (November-December): 603-609.

MacNeish, Richard S., and Mary W. Eubanks. 2000. "Comparative analysis of the Rio Balsas and Tehuacan models for the origin of maize." Latin American Antiquity 11, no. 1 (March): $3-20$.

Malhi, Ripan S., H.M. Mortensen, J.A. Eshleman, J.G. Lorenz, F.A. Kaestle, J.R. Johnson, C. Gorodesky, and D.G. Smith. 2003. Native American mtDNA prehistory in the American Southwest. American Journal of Physical Anthropology 120: 108-124.

Martin, Paul S. 1967. "Prehistoric overkill." In: Pleistocene Extinctions: The Search for a Cause, edited by P.S. Martin and H.E. Wright Jr., 75-120. New Haven: Yale University Press.

Martin, Paul S. 1973. "The discovery of America." Science 179: 969-974

Martin, Steve L. 1999. "Virgin Anasazi Diet as Demonstrated through the Analysis of Stable Carbon and Nitrogen Isotopes." Kiva 64, no 4. (January): 495-514.

Masson-Boivin, Catherine, Eric Giraud, Xavier Perret, and Jacques Batut. 2009. "Establishing nitrogen-fixing symbiosis with legumes: how many rhizobium recipes?" Trends in Microbiology 17, no. 10: 458-466.

Matson, R.G. 1991. The Origins of Southwest Agriculture. Tucson: University of Arizona Press.

Matson, R.G. 1999. The Spread of Maize to the Colorado Plateau. Archaeology Southwest 13: $10-11$.

Matson, R.G. 2002. The Spread of Maize Agriculture in the U.S. Southwest. In Examining the Farming/Language Dispersal Hypothesis, edited by Peter Bellwood and Colin Renfrew, 341356. Cambridge: McDonald Institute for Archaeological Research, University of Cambridge.

Matson, R.G. 2006a. "Basketmaker II and Cedar Mesa." In Tracking Ancient Footsteps: William D. Lipe's Contributions to Southwestern Prehistory and Public Archaeology, edited by R.G. Matson and Timothy A. Kohler, 45-62. Pullman: Washington State University Press.

Matson, R.G. 2006b. "What is BMII?” Kiva 72, no. 2: 149-165. 
Matson, R.G. 2015. “Turkey Pen Excavation.” Paper on the Washington State University Libraries, Cedar Mesa Project Research Exchange. http://hdl.handle.net/2376/5302.

Matson, R.G. 2016. "The nutritional context of the Pueblo III depopulation of the northern San Juan: Too much maize?” Journal of Archaeological Science: Reports 5: 622-631.

Matson, R.G., and Brian Chisholm. 1991. "Basketmaker II Subsistence: Carbon Isotopes and Other Dietary Indicators from Cedar Mesa, Utah.” American Antiquity 56, no. 3: 444-459.

Matson, R.G., and Brian Chisholm. 2007. "Basketmaker II Subsistence." Poster presented at the annual Society for American Archaeology meeting, Austin, Texas, April 25-29.

Matson, R.G., William D. Lipe, and William R. Haase, IV. 1988. "Adaptational Continuities and Occupational Discontinuities: The Cedar Mesa Anasazi.” Journal of Field Archaeology 15, no. 3: 245-264.

Matson, R.G., William D. Lipe, and William R. Haase, IV. 1990. Human Adaptations on Cedar Mesa, Southeastern Utah. Manuscript available at URI: http://hdl.handle.net/2376/5014.

Matuz, J., T. Bartók, K. Mórocz-Salamon, and L. Bóna. 2000. "Structure and potential allergenic character of cereal proteins. I. Protein content and amino acid composition." Cereal Research Communications 28 no. 3: 263-270.

McMahon, Gerry. 2005. "Fact Sheet: Companion Planting." Department of Primary Industry, Fisheries, and Mines, Darwin: Northern Territory Government.

Meggers, Betty J. 1954. "Environmental limitation on the development of culture." American Anthropologist 56, no. 5 (October): 801-824.

Mensing, S. A., Smith, J., Allan, M., Norman, K. B. 2008. "Extended drought in the Great Basin western North America in the last two millennia reconstructed from pollen records." Quaternary International 188: 79-89.

Mensing, Scott A., Saxon E. Sharpe, Irene Tunno, Don W. Sada, Jim M. Thomas, Scott Starratt, Jeremy Smith. 2013. "The Late Holocene Dry Period: multiproxy evidence for an extended drought between 2800 and 1850 cal yr BP across the central Great Basin, USA." Quaternary Science Reviews 78: 266-282.

Merriam, C. Hart. 1889. "Life zones and crop zones of the United States." U.S.D.A. Division of Biological Survey Bulletin 10: 9-79.

Merrill, W.L., R.J. Hard, J.B. Mabry, G.F. Fritz, K.R. Adams, J.R. Roney, and A.C. MacWilliams. 2009. "The Diffusion of Maize to the Southwestern United States and its Impact.” PNAS 106, no. 50: 21019-21026. 
Minnis, Paul E. 1985. "Domesticating People and Plants in the Greater Southwest in Prehistoric Food Production in North America." Anthropological Papers 75: 309-339.

Mininis, Paul E. 1989. "Prehistoric Diet in the Northern Southwest: Macroplant Remains from Four Corners Feces." American Antiquity, 54, no.3: 543-563.

Minnis, Paul E. 2000. "Prehistoric agriculture and anthropogenic ecology of the North American Southwest." In The Archaeology of Drylands: Living at the Margin, edited by G. Barker and D. Gilbertson, 271-287. London: Routledge.

Moore, P.D., J.A. Webb, and M.E. Collinson. 1991. Pollen Analysis, Second Edition. Oxford: Blackwell Scientific Publications.

Morris, E. H., and R. F. Burgh. 1954. Basket Maker II Sites Near Durango, Colorado. Publication No. 604. Washington, D.C.: Carnegie Institution of Washington.

Nagaoka, Lisa. 2002a. "Explaining subsistence change in southern New Zealand using foraging theory models." World Archaeology 34, no. 1 (April): 84-102.

Nagaoka, Lisa. 2002b. "The effects of resource depression on foraging efficiency, diet breadth, and patch use in southern New Zealand." Journal of Anthropological Archaeology 21, no. 4 (December): 419-442.

Nelson, R. J. 1994. "Basketmaker II Lithic Technology and Mobility Patterns on Cedar Mesa, Southeast Utah." Kiva 60, no. 2: 277-288.

Nott, Breanne M. 2010. "Documenting Domestication: Molecular and Palynological Analysis of Ancient Turkey Coprolites from the American Southwest.” M.A. thesis, Washington State University.

O’Connell, J.F., K. Hawkes, and N.G. Blurton Jones. 1999. "Grandmothering and the evolution of Homo erectus." Journal of Human Evolution 36: 461-485.

Odling-Smee, F. John, Kevin N. Laland, and Marcus W. Feldman. 1996. "Niche construction." The American Naturalist 147, no. 4: 641-648.

Odling-Smee, F. John, Kevin N. Laland, and Marcus W. Feldman. 2003. Niche construction: the neglected process in evolution. No. 37. Princeton: Princeton University Press.

Odum, E.P., and H.T. Odum. 1959. Fundamentals of ecology, $2^{\text {nd }}$ ed. Philadelphia: Saunders.

Ogle, D., L. St. John, L., and T. Jones., eds. 2013. "Plant Guide for Indian Ricegrass (Achnatherum hymenoides)." Aberdeen: USDA-Natural Resources Conservation Service. 
Ortiz, A., ed. 1979. Handbook of North American Indians, vol. 9, Southwest. Washington D.C.: Smithsonian Institution.

Ortman, Scott G. 2012. Winds from the North: Tewa Origins and Historical Anthropology. Salt Lake City: University of Utah Press.

Otten, Jennifer J., Jennifer Pitzi Hellwig, and Linda D. Meyers, eds. 2006. Dietary Reference Intakes: the essential guide to nutrient requirements. Washington, D.C.: National Academies Press.

Pal, M., and Dahn Prakash. 1998. "Chenopodium: Seed protein, fractionation and amino acid composition." International Journal of Food Sciences and Nutrition 49, no. 4: 271-275.

Parson, Elsie Klews. 1939. Pueblo Indian Religion, 2 vols. Chicago: University of Chicago Press.

Pataky, J.K., and K.M. Snetselaar. 2006. "Common smut of corn." The Plant Health Instructor. DOI:10.1094/PHI-I-2006-0927-01.

Phillips Jr, D.A., 2009. "Adoption and intensification of agriculture in the North American Southwest: Notes toward a quantitative approach." American Antiquity 74, no. 4 (October): 691-707.

Pianka, Eric R. 2011. Evolutionary Ecology, $7^{\text {th }}$ Ed. E-book.

Piperno, Delores R. 2006. "The origins of plant cultivation and domestication in the Neotropics: a behavioral ecological perspective." In Behavioral ecology and the transition to agriculture, edited by D. J. Kennett and B. Winterhalder, 137-166. Berkeley: University of California Press.

Piperno, Dolores R. 2011. "The origins of plant cultivation and domestication in the New World tropics: patterns, process, and new developments." Current Anthropology 52, no. S4: S453S470.

Pope, Kevin O., Mary E.D. Pohl, John G. Jones, David L. Lentz, Christopher Von Nagy, Francisco J. Vega, and Irvy R. Quitmyer. 2001. "Origin and environmental setting of ancient agriculture in the lowlands of Mesoamerica." Science 292, no. 5520: 1370-1373.

Powers, Margaret A. 1984. The Salvage of Archaeological Data from Turkey Pen Ruin, Grand Gulch Primitive Area, San Juan County, Utah. Contributions to Anthropology Series, No. 808. Farmington, New Mexico: Division of Conservation Archaeology, San Juan County Archaeological Research Center and Library.

Pryor, F.L., 1986. "The adoption of agriculture: Some theoretical and empirical evidence." American Anthropologist, 88, no. 4 (December): 879-894. 
Pyke, H.G., H. R. Pulliam, and E. L. Chamov. 1977. "Optimal Foraging Theory: A Selective Review of Theory and Tests." Quarterly Review of Biology 52:137-154.

Radomski, Elizabeth. 1999. "Continuing Analysis of Bulk Midden Samples from Turkey Pen Ruin, Cedar Mesa, Utah." Report on file, Laboratory of Archaeology, University of British Columbia, Vancouver.

Reed, Erik K. 1954. "Transition to history in the Pueblo southwest." American Anthropologist 56, no. 4: 592-597.

Reed, Erik K. 1974. "The Greater Southwest." In Prehistoric Man in the New World, 6th ed., edited by Jesse Jennings and E. Norbeck, 175-192. Chicago: University of Chicago Press.

Reid, J. Jefferson 2006. "A Grasshopper Pueblo Perspective on the Mogollon of the Arizona Mountains." In Dynamics of Southwest Prehistory, edited by Linda Cordell and George Gumerman, 65-98. Tuscaloosa: The University of Alabama Press.

Reinhard, Karl J. 1988. "Diet, Parasitism, and Anemia in the Prehistoric Southwest.” PhD diss., Texas A\&M University.

Reinhard, Karl J. 1992. "Parasitology as an Interpretive Tool in Archaeology." American Antiquity 57, no.2: 231-245.

Reinhard, Karl J. 1993. "The utility of pollen concentration in coprolite analysis: expanding upon Dean's comments." Journal of Ethnobiology 9, no. 3: 114-128.

Reinhard, Karl J., and Vaughn M. Bryant. 1992. "Coprolite analysis: a biological perspective on archaeology." Archaeological Method and Theory 4 (January): 245-288.

Reinhard, Karl J., D. L. Hamilton, and Richard H. Hevly. 1991. "Use of pollen concentration in paleopharmacology: coprolite evidence of medicinal plants." Journal of Ethnobiology 11, no. 1: $117-132$.

Reinhard, Karl J., Richard H. Hevly, and Glenn A. Anderson. 1987. "Helminth Remains from Prehistoric Indian Coprolites on the Colorado Plateau." The Journal of Parasitology 73, no.3: 630-639.

Reinhard, Karl J. and John G. Jones. 1987. "Dietary and Parasitological Analysis of Turkey Pen Cave: A Basketmaker II Village in the Grand Gulch, Utah." Document on file, Texas A \& M University, College Station.

Riley, Tim. 2012. "Assessing diet and seasonality in the Lower Pecos canyonlands: an evaluation of coprolite specimens as records of individual dietary decisions." Journal of Archaeological Science 39: 145-162. 
Rindos, David. 1980. "Symbiosis, instability, and the origins and spread of agriculture: a new model." Current Anthropology 21: 751-772.

Rindos, David. 1984. The Origins of Agriculture: An Evolutionary Perspective. London: Academic Press.

Robbins, W.W., J.P. Harrington, Barbara Freire-Marreco. 1916. Ethnobotany of the Tewa Indians. Bureau of American Ethnology, Bulletin 55, Washington D.C.

Roberts, N. 1989. The Holocene: An Environmental History. Oxford: Basil Blackwell.

Rohland, Nadin, and Michael Hofreiter. 2007. "Ancient DNA extraction from bones and teeth." Nature protocols 2, no. 7: 1756-1762.

Roos, Christopher I., Michael Aiuvalasit, Jenna Battillo, Chris Kiahtipes, and Thomas Swetnam. 2015. "Multi-Millennial Fire Histories from Sedimentary Archives: Human and Climate Impacts." Paper presented at the Society for American Archaeology meetings, San Francisco, April 15-19.

Roth, Barbara J. 2017. Agricultural Beginnings in the American Southwest. Lanham: Rowman and Littlefield.

Rouston, Cody C., Connie A. Woodhouse, and Jonathan T. Overpeck. 2011. "Second century megadrought in the Rio Grande headwaters, Colorado: How unusual was medieval drought?" Geophysical Research Letters Vol. 38: L22703.

Sahlins, Marshall D. 1972. Stone age economics. Aldine: Chicago.

Sampietro, Maria Lourdes, O. Lao, David Caramelli, Martina Lari, R. Pou, M. Marti, Jaume Bertranpetit, and Carles Lalueza-Fox. 2007. "Palaeogenetic evidence supports a dual model of Neolithic spreading into Europe." Proceedings of the Royal Society of London B: Biological Sciences 274, no. 1622: 2161-2167.

Schmitt, Dave N., David B. Madsen, and Karen D. Lupo. 2004. "The Worst of Times, the Best of Times: Jackrabbit Hunting by Middle Holocene Human Foragers in the Bonneville Basin of Western North America." In Colonisation, Migration, and Marginal Areas, edited by M. Mondoni, S. Muñoz, and S. Wickler, 86-95. Oxford: Oxbow Books.

Sesler, L. M., and T.D. Hovezak. 2011. "Farming at the Edge of Paradise: Basketmaker II Emergence in New Mexico’s San Juan Basin.”Southwestern Lore 77, no. 2: 9-20.

Simms, Steven R. 1985. "Acquisition Costs and Nutritional Data on Great Basin Resources." Journal of California and Great Basin Anthropology 7, no. 1: 117-125.

Simms, Steven R. 1987. Behavioral ecology and hunter-gatherer foraging: an example from the Great Basin. Oxford: British Archaeological Reports, International Series 381. 
Simopoulos, Artemis P. 2004. "Omega-3 Fatty Acids and Antioxidants in Edible Wild Plants." Biological Research Vol. 37: 263-277.

Simpson, Stephen J., Richard M. Sibly, Kwang Pum Lee, Spencer T. Behmer, and David Raubenheimer. 2004. "Optimal foraging when regulating intake of multiple nutrients." Animal Behaviour 68, no. 6: 1299-1311.

Skibo, J. M., and Eric Blinman. 1999. "Exploring the origins of pottery on the Colorado Plateau." In Pottery and People: A Dynamic Interaction, edited by James M. Skibo and Gary M. Feinman, 171-183. Salt Lake City: University of Utah Press.

Smiley, F.E. 1985. "The Chronometrics of Early Agricultural Sites in Northeastern Arizona: Approaches to the Interpretation of Radiocarbon Dates." PhD diss., University of Michigan.

Smiley, F.E. 1994. "The Agricultural Transition in the Northern Southwest: Patterns in the Current Chronometric Data." Kiva 60, no. 2: 165-189.

Smiley, F.E. 1998. "Applying radiocarbon models: Lolomai Phase chronometry on Black Mesa." In Archaeological Chronometry: Radiocarbon and Tree-ring Models and Applications on Black Mesa, Arizona, edited by F.E. Smiley and R.V. Ahlstrom, 99-134. Carbondale: Southern Illinois University, Center for Archaeological Investigations Occasional Paper 16.

Smiley, F.E. 2002. "The First Black Mesa Farmers: The White Dog and Lolomai Phases” In Prehistoric Culture Change on the Colorado Plateau: Ten Thousand Years on Black Mesa, edited by Shirley Powell and Francis E. Smiley, 37-65. Tucson: University of Arizona Press.

Smiley, F.E., W. Parry, and G. Gumerman. 1986. "Early Agriculture in the Black Mesa/March Pass Region of Arizona: New Chronometric Data and Recent Excavations at Three Fir Shelter." Paper given at the annual Society for American Archaeology meetings, New Orleans.

Smith, Bruce D. 2001. "Documenting plant domestication: the consilience of biological and archaeological approaches.” PNAS 98: 1324-1326.

Smith, Eric A., 1983. "Evolutionary ecology and the analysis of human social behavior." In Rethinking Human Adaptation, edited by R. Dyson-Hudson \& M.A. Little. Boulder: Westview Press.

Smith, Eric A. 1991. Inujjuamiunt Foraging Strategies: Evolutionary Ecology of an Arctic Hunting Economy. Livingston: Transaction Publishers.

Smith, Vernon L. 1975. "The primitive hunter culture, Pleistocene extinction, and the rise of agriculture." Journal of Political Economy 83, no.4 (August): 727-755. 
Speller, Camilla F, Brian M. Kemp, Scott Wyatt, Cara Monroe, William D. Lipe, U.M. Arndt, Dongya Yang. 2010. "Ancient mitochondrial DNA analysis reveals complexity of indigenous North American turkey domestication.” PNAS USA 107: 2807-2812.

Spielmann, K.A., and E.A. Angstadt-Leto. 1996. "Hunting, gathering, and health in the Prehistoric Southwest." In Evolving Complexity and Environmental Risk in Prehistoric Southwest. Studies of Scientific Complexity, vol. 24, edited by J. Tainter and B.B. Tainter, 79106. Reading, Massachusetts: Addison-Wesley.

Stephens, D. W., and J. R. Krebs. 1986. Foraging theory. Princeton, NJ: Princeton University Press.

Sterck, Elisabeth H.M., David P. Watts, and Carel P. van Schaik. 1997. "The evolution of female social relationships in nonhuman primates." Behavioral Ecology and Sociobiology 41, no. 5 (November): 291-309.

Stešková, Andrea, Monkia Morochovičová, and Emília Lešková. 2006. "Vitamin C degradation during storage of fortified foods." Journal of Food and Nutrition Research 45, no. 2: 55-61.

Stevenson, Matilda Cox. 1909. Ethnobotany of the Zuni Indians. Bureau of American Ethnology, Annual Report, Vol. 30, pp. 31-102. Washington, D.C.

Stiger, Mark A. 1979. "Mesa Verde subsistence patterns from Basketmaker to Pueblo III." Kiva 44, no. 2: 133-144.

Stiner, Mary C., Natalie D. Munro, and Todd A. Surovell. 2000. "The Tortoise and the Hare: Small-Game Use, the Broad-Spectrum Revolution, and Paleolithic Demography." Current Anthropology 41, no. 1 (February): 39-79.

Sullivan, Alan P. 2015. "The Archaeology of Ruderal Agriculture." In Traditional Arid Lands Agriculture:Understanding the Past for the Future, edited by Scott E. Ingram and Robert C. Hunt, 273-305. Tucson: University of Arizona Press.

Szuter, Christine R. 1984. "Faunal Exploitation and the Reliance on Small Animals among the Hohokam." In Hohokam Archaeology along the Salt-Gila Aqueduct Project, Volume VII: Environment and Subsistence, edited by L. Teague and P. Crown. Archaeological Series, 150 (tDAR id: 376387); doi:10.6067/XCV8M0468H.

Szuter, Christine R. 1989. "Hunting by prehistoric horticulturalists in the American Southwest." PhD diss., University of Arizona.

Tausch, R.J., C.L. Nowak, and S.A. Mensing. 2004. "Climate change and associated vegetation dynamics during the Holocene: the paleoecological record." In Great Basin Riparian Ecosystems: Ecology, Management and Restoration, edited by Jeanne C. Chambers and Jerry R. Miller, 24-48. Washington, D.C.: Island Press. 
Thomas, R.G., and S.E. Gebhardt. 2006. "Nuts and seeds as sources of alpha and gamma tocopherols." Paper presented at the ICR/WCRF International Research Conference, Washington, D.C., July 13-14.

Tirmenstein, D. 1999. “Achnatherum hymenoides.” In: Fire Effects Information System. U.S. Department of Agriculture, Forest Service, Rocky Mountain Research Station, Fire Sciences Laboratory. http://www.fs.fed.us/database/feis.

Torroni, Antonio, Theodore G. Schurr, Margaret F. Cabell, Michael D. Brown, James V. Neel, Merethe Larsen, David G. Smith, Carlos M. Vullo, and Douglas C. Wallace. 1993. "Asian affinities and continental radiation of the four founding Native American mtDNAs." American Journal of Human Genetics 53, no. 3: 563-590.

Traverse, A. 1988. Paleopalynology. Boston: Unwin Hyman.

U.S. Department of Agriculture (USDA), Agricultural Research Service. 2012. USDA National Nutrient Database for Standard Reference, Release 25. Nutrient Data Laboratory Home Page, http://www.ars.usda.gov/ba/bhnrc/ndl.

Ugan, Andrew. 2005. "Does Size Matter? Body Size, Mass Collecting, and Their Implications for Understanding Prehistoric Foraging Behavior." American Antiquity 70, no. 1 (January): 75-89.

Underhill, Ruth. 1991. Life in the Pueblos. Santa Fe: Ancient City Press.

Valverde, María Elena, Talía Hernández-Pérez, and Octavio Paredes-López. 2015. “Edible mushrooms: improving human health and promoting quality life." International Journal of Microbiology, Article ID 376387: 1-14. http://dx.doi.org/10.1155/2015/376387.

Valverde, María Elena, Octavio Paredes-López, Jerald K. Pataky, Fidel Guevara-Lara, and T. S. Pineda. 1995. "Huitlacoche (Ustilago maydis) as a food source - biology, composition, and production." Critical Reviews in Food Science \& Nutrition 35, no. 3: 191-229.

Vierra, Bradley. 2008. Early Agriculture on the Southwestern Periphery of the Colorado Plateau: Diversity in Tactics. In Archaeology without Borders: Contact, Commerce, and Change in the U.S. Southwest and Northwestern Mexico, edited by Laurie D. Webster and Maxine E. McBrinn, 71-88. Boulder: University Press of Colorado.

Weisdorf, Jacob L. 2004. "From stagnation to growth: Revisiting three historical regimes." Journal of Population Economics 17, no. 3 (August): 455-472.

Weisdorf, Jacob L. 2005. "From Foraging To Farming: Explaining the Neolithic Revolution," Journal of Economic Surveys 19, no. 4: 561-586. 
Weninger, Bernhard, and Olaf Jöris. 2008. "A 14 C age calibration curve for the last $60 \mathrm{ka}$ : the Greenland-Hulu U/Th timescale and its impact on understanding the Middle to Upper Paleolithic transition in Western Eurasia." Journal of Human Evolution 55, no. 5: 772-781.

West, Gerald J. 1978. "Recent Palynology of the Cedar Mesa Area, Utah.” PhD diss., University of California, Davis.

West, Stuart A., and Maxwell N. Burton-Chellew. 2013. "Human behavioral ecology." Behavioral Ecology 24, no. 5: 1043-1045.

West-Eberhard, Mary Jane. 2003. "Developmental plasticity and evolution.” Oxford: Oxford University Press.

White, Leslie A. 1949. The Science of Culture. New York: Farrar, Strauss.

White, Leslie A. 1959. The Evolution of Culture. New York: McGraw-Hill.

Whiting, Alfred F. 1939. Ethnobotany of the Hopi. Museum of Northern Arizona, Bulletin No. 15, Northern Arizona Society of Science and Art, Flagstaff.

Williams-Dean, Glenna. 1978. "Ethnobotany and Cultural Ecology of Prehistoric Man in Southwest Texas.” Ph.D. diss., Texas A \& M University.

Wills, W.H. 1988. "Early Agriculture and Sedentism in the American Southwest: Evidence and Interpretations." Journal of World Prehistory 2, no. 4: 445-488.

Winterhalder, B. 1981. "Optimal foraging strategies and hunter-gatherer research in anthropology: theory and models." In Hunter-gatherer foraging strategies: Ethnographic and archaeological analyses, edited by B. Winterhalder and E.A. Smith, 13-35. Chicago: University of Chicago Press.

Winterhalder, B., and C. Goland. 1997. "An evolutionary ecology perspective on diet choice, risk, and plant domestication." In People, plants, and landscapes: studies in paleoethnobotany, edited by K. J. Gremillion, 123-160. Tuscaloosa: University of Alabama Press.

Winterhalder, B., and D. J. Kennett. 2006. "Behavioral ecology and the transition from hunting and gathering to agriculture." In Behavioral Ecology and the Transition to Agriculture, edited by D. J. Kennett and B. Winterhalder, 1-21. Berkeley: University of California Press.

Winterhalder, Bruce, and Eric A. Smith. 2000. "Analyzing adaptive strategies: human behavioral ecology at twenty-five," Evolutionary Anthropology 9, no. 2: 51-72.

Woodbury, Richard B., and Ezra B.W. Zubrow. 1979. "Agricultural Beginnings, 2000 B.C.-A.D. 500.” In Handbook of North American Indians, Southwest, vol. 9. Alfonso Ortiz, ed. Washington, D.C.: Smithsonian Institution Press. 
Wormington, Hannah Marie. 1961. Prehistoric Indians of the Southwest. Denver: Denver Museum of Natural History, Popular Series 7.

Wright Jr, H.E., 1960. "Climate and prehistoric man in the eastern Mediterranean.” In Prehistoric Investigations in Iraqi Kurdistan, edited by R.J. Braidwood and B. Howe, 71-95. Chicago: University of Chicago Press.

Wyatt, Scott, Brian M. Kemp, Cara Monroe, and William D. Lipe. 2009. "Domestic Turkeys in the American Southwest: Imported Birds or an Independent Domestication." Poster presented at the annual Society for American Archaeology meeting, Atlanta, Georgia, April $22-26$.

Zeder, Melinda. 2006. "Central questions in the domestication of plants and animals." Evolutionary Anthropology 15, no. 3:105-117.

Zeder, Melinda A. 2012. "The broad spectrum revolution at 40: resource diversity, intensification, and an alternative to optimal foraging explanations." Journal of Anthropological Archaeology 31, no. 3: 241-264.

Zeder, Melinda A., Eve Emshwiller, Bruce D. Smith, and Daniel G. Bradley. 2006. "Documenting domestication: the intersection of genetics and archaeology." TRENDS in Genetics 22, no. 3 (March): 139-155. 